University of Zurich

Department of Economics

Working Paper Series

ISSN 1664-7041 (print)

ISSN 1664-705X (online)

Working Paper No. 124

\title{
Systematic Consumption Risk in Currency Returns
}

Mathias Hoffmann and Rahel Suter

June 2013 


\title{
Systematic Consumption Risk in Currency Returns*
}

\author{
Mathias Hoffmann $\quad$ Rahel Suter ${ }^{\dagger}$
}

June 2013

\begin{abstract}
We sort currencies into portfolios by countries' consumption growth over the past year. The excess return of the highest-consumption-growth currency portfolio over the portfolio of lowest-consumption-growth currencies is positive on average, compensating investors for large negative returns during world-wide downturns. This return-our consumption carry factor-prices the cross-section of portfolio-sorted and of bilateral currency returns. Our results rest on minimal theoretical restrictions but can be interpreted in a habit formation model: sorting currencies on past consumption growth approximates sorting countries based on risk aversion and low (high) risk-aversion currencies depreciate (appreciate) in times of global turmoil.
\end{abstract}

JEL Classification Numbers: E44, F31, F44, G12, G15

Keywords: foreign exchange,uncovered interest parity, carry trade returns, consumption risk, asset pricing, habit model

\footnotetext{
${ }^{*}$ We would like to thank Adrien Verdelhan and Angelo Ranaldo for very helpful discussions and comments. We are also grateful to seminar participants at the University of Zurich and at the CESifo Money Macro and Finance conference 2013 in Munich.

${ }^{\dagger}$ Both authors are at the University of Zurich., Department of Economics, International Trade and Finance Group. Mail address: Zuerichbergstrasse 14, CH-8032 Zurich, SWITZERLAND. Hoffmann is also affiliated with CESifo Munich. E-mail: mathias.hoffmann@econ.uzh.ch and rahel.suter@econ.uzh.ch Web: http://www.econ.uzh.ch/itf
} 


\section{Introduction}

In this paper, we provide evidence that currency returns reflect cross-country differences in consumption risk. We do so by sorting currencies into portfolios based on countries' consumption growth over the last four quarters. High-past-consumption-growth currency portfolios pay consistently higher excess returns than low-past-consumption-growth currency portfolios. A consumption carry factor that reflects the return of going short on currencies of low-pastconsumption-growth countries and long on currencies of high-past-consumption growth countries explains the cross-section of currency returns in a sample of 33 countries over the period 1990 - 2010. We call this factor the consumption carry factor and denote it by $H M L_{\Delta c}$.

In recent years, the idea that movements in currency prices can be explained by the trade-off between risk and return has gained renewed attention and considerable empirical support. At a general level, a couple of conditions need to be fulfilled for currency returns to reflect a compensation for some form of macroeconomic or financial risk. First, currencies that pay high returns on average must perform relatively badly in bad times, whereas currencies that pay low returns on average must perform well in bad times. Second, currency returns must reflect cross-country differences in the exposure to common (global) risk, because only global risk will be priced in integrated world capital markets. Lustig, Roussanov and Verdelhan (2011) show that currency returns are well explained by a two-factor model in which the first factor is the average return on the dollar vis-à-vis all other currencies, and the second factor is the spread in returns between a portfolio of high-interest-rate currencies and a portfolio of low- interestrate currencies. As the latter factor, which is a carry trade factor and denoted $H M L_{F X}$, pays off badly in crises, differences in the exposure of high- and low-interest-rate currencies to this factor can explain a substantial fraction of the variation in the cross section of interest-ratesorted currency portfolios. Verdelhan (2011) extends this framework to the pricing of bilateral exchange rates and argues that differences in the exposure to a (level) dollar factor are also a key element of the systematic variation in exchange rates. Ranaldo and Soderlind (2010) find that so-called 'safe haven' currencies pay relatively high returns precisely when foreign exchange market volatility increases, whereas the returns from 'investment currencies' are low in times of high foreign exchange market turbulences. Menkhoff et al. (2012a) add to these findings by showing that a foreign exchange volatility innovation factor rationalizes the spread in returns 
of interest-rate-sorted currency portfolios. Together, all these results suggest that the returns obtained from holding particular currencies or currency portfolios compensate an investor for global market risk.

While these studies provide compelling evidence for a risk-return trade-off in foreign exchange markets, they propose financial factors as an explanation for currency returns. Hence, they do not fully answer the question whether these risk factors truly reflect macroeconomic and, in particular, consumption risk. Another strand of the literature has recently begun to address this issue. For example, Lustig and Verdelhan (2007) argue that an extended version of the consumption-based capital asset pricing model (C-CAPM) with Epstein-Zin preferences and a durable consumption good can explain the cross section of interest-rate-sorted currency portfolios. Colacito and Croce (2011) show that a version of the long-run risk model by Bansal and Yaron (2004) explains currency movements quite well, and Verdelhan (2010) shows that consumption habits can explain the cross section of currency returns.

The analysis in this paper positions itself between these two strands of the literature. We follow the first strand and construct a simple pricing factor that is based on sorting currencies into portfolios according to ex ante observable characteristics. This approach allows us to discuss the determinants of currency returns under as few theoretical assumptions as possible — in particular, we do not have to specify strong restrictions on preferences. We follow the second strand of the literature, however, by focusing on consumption fluctuations as a driver of variation in currency returns. Linking these two approaches allows us to determine the structure of consumption risk priced into currencies directly from the data without having to confront the particular moment restrictions that specific versions of the consumption-based asset pricing model may impose on the data. Still, in a last step, we relate our results back to the consumption-based literature by interpreting them in the context of a consumption-based model with habit formation.

We sort currencies into portfolios based on countries' past consumption growth. Currencies of countries with higher past consumption growth consistently pay higher returns than currencies of countries with low consumption growth, and the spread in these returns is well explained by the consumption carry factor $H M L_{\Delta c}$, which equals the difference in returns of the high and the low-consumption-growth currency portfolios. 
Our consumption carry factor $H M L_{\Delta c}$ is constructed in analogy to the $H M L_{F X}$ factor proposed by Lustig, Roussanov and Verdelhan (2011), and it has a number of interesting properties. For example, even though our $H M L_{\Delta c}$ factor is correlated with the Lustig, Roussanov and Verdelhan (2011) $H M L_{F X}$ factor, the two are clearly not the same variable. In particular, the consumption-based carry strategy did a lot better than the interest-rate-based carry strategy during the recent financial crisis. In fact, returns from the consumption factor $H M L_{\Delta c}$ are much less skewed than returns from the interest carry factor $H M L_{F X}$. In a direct comparison of its ability to price exchange rates, the consumption carry factor $H M L_{\Delta c}$ compares favorably with $H M L_{F X}$ and other financial risk factors that have recently been proposed in the literature. In particular, it is also successful in pricing the interest-rate-sorted currency portfolios used elsewhere in the literature. In addition, we show that $H M L_{\Delta c}$ also prices individual currency pairs in a framework in which individual currency betas vary as a function of past consumption growth.

While we emphasize that our empirical results are obtained without recourse to a particular consumption-based asset pricing model, we conclude by linking them back to economic theory. Specifically, we suggest that they be interpreted within the framework of a consumptionbased model with habit formation in the mold of Campbell and Cochrane (1999) and Verdelhan (2010).

In a model with habit formation, sorting currencies on past consumption growth is very similar to sorting countries by their surplus consumption ratio and, therefore, by their degree of risk aversion. Countries that recently have experienced a series of high (low) consumption growth rates have high (low) surplus consumption ratios and therefore a low (high) degree of risk aversion. In complete financial markets, changes in the real exchange rate are determined by differences in countries' marginal utility growth rates. Because, in the habit model, marginal utility in high-risk-aversion countries is more sensitive to global consumption shocks than in low-risk-aversion countries, optimal risk sharing requires that currencies of countries with high (low) risk aversion appreciate (depreciate) in times of global downturns, transferring purchasing power to the more risk averse country. This implies that the high average returns paid by currencies with high past consumption growth compensate investors for the risk of a large depreciation during global downturns. When interpreted in the context of the habit model, our 
$H M L_{\Delta c}$ factor therefore reflects the spread between the return of low- and high-risk-aversion currencies. We show that a realistically calibrated version of the habit model with a global consumption growth shock can broadly replicate the empirical findings that we present in the main part of the paper.

The paper is organized as follows. The next section further connects our empirical approach and the previous literature. Section 3 defines currency returns and discusses the formation of portfolios based on past consumption growth. Section 4 describes the data set used in the empirical analysis, and Section 5 presents the empirical results. In Section 6, we interpret our empirical results in the context of a version of the Campbell and Cochrane (1999) habit model. Section 7 presents an overview of some robustness checks, and Section 8 concludes.

\section{Related literature}

Starting with Fama (1984), a large literature has documented the resounding rejection of uncovered interest parity (UIP) in the data. In fact, there is considerable structure in this rejection: currencies of countries with high interest rates do not depreciate as much as would be implied by UIP. This UIP puzzle, along with the finding by Meese and Rogoff (1983) that exchange rates are hard to predict out-of-sample, gave rise to a large empirical literature on exchange rate modeling. It is probably fair to say that much of this early literature was rather skeptical with respect to risk-based explanations of currency returns. Engel (1996) and Lewis (1995) provide useful surveys. During the last decade, the notion that currency returns, just like those of other assets, could be determined by risk premia has gained renewed attention and - probably because of the availability of more, better and larger data sets and theoretical advances in asset pricing theory - is continuing to gather empirical support.

A valid explanation of the UIP puzzle in terms of risk premia would require that investment in currencies with high interest rates - which promise high returns on average - would deliver especially low returns in bad times for investors. If this was the case, carry trade profits would just compensate an investor for risk that he exposes himself to when holding particular currencies. Empirically, however, it is challenging to identify risk factors, and especially 
macroeconomic risk factors, that would drive currency risk premia 1 In this respect, an important contribution is the study by Lustig and Verdelhan (2007). As interest rates seem to predict currency returns, Lustig and Verdelhan sorted a wide cross section of currencies into portfolios according to their interest rate differentials with the US. Portfolios are rebalanced every period such that the first portfolio always contains the lowest-interest-rate currencies and the last portfolio always contains the highest-interest-rate currencies. Sorting currencies into portfolios eliminates diversifiable, currency-specific components of returns such that sharp estimates of the risk-return tradeoff of currency investments are obtained. Eventually, Lustig and Verdelhan (2007) show within the framework of consumption-based capital asset pricing models that the growth rate of durable and nondurable consumption expenditures, as well as the mean return of the US stock market, are helpful in explaining currency portfolio returns.

In a subsequent study, using a data-driven approach in the spirit of Fama and French (1993), Hanno N. Lustig, Nikolai L. Roussanov and Adrien Verdelhan (2011) find that the currency portfolios themselves contain information to explain the cross section of portfolio returns. Lustig, Roussanov and Verdelhan (2011) identify two factors that together account for most of the variability in the cross section of currency portfolio returns. The first factor, which they coin the 'dollar risk factor', is the average return that an investor gains by borrowing in US dollars and investing in equal weights in all currencies available. This dollar-specific factor acts as a level factor for portfolio returns. The second factor equals the return that a global investor gains by going short in the low-interest-rate currency portfolio and long in the high-interestrate currency portfolio. Lustig, Roussanov and Verdelhan (2011) denote this carry trade factor $H M L_{F X}$. While profitable for most of the time, such a carry trade strategy yields low returns during times of global turmoil, which implies a negative $H M L_{F X}$ factor. As expected returns increase monotonically from low to high interest rate currency portfolios, and because the covariation of portfolio returns and $H M L_{F X}$ is higher, the higher the interest rates of a particular currency portfolio are, $H M L_{F X}$ qualifies as a slope factor for currency portfolio returns. Closely related to these results, the study by Menkhoff et al. (2012a) concludes that a factor that measures news in global foreign exchange market volatility decisively explains the returns to carry trades. High expected carry trade returns can be rationalized within standard asset pricing

\footnotetext{
${ }_{1}$ Craig Burnside, Martin Eichenbaum, Isaac Kleshchelski and Sergio Rebelo (2011) find that traditional risk factors do not explain currency returns, instead attributing the forward premium to peso problems.
} 
models, because these returns turn especially low during times of high foreign exchange market volatility surprises when investors particularly fear losses. Brunnermeier, Nagel and Pedersen (2008) uncover another link between the performance of carry trades and market volatility. According to their reasoning, a sudden increase in stock market volatility (as measured by the CBOE's VIX) could cause a decrease in risk appetite and funding liquidity, which then makes investors unwind their carry trades. An orchestrated sellout of investment currencies depreciates their prices all the more such that unexpectedly low returns to carry trades are realized. In accordance with this interpretation, Ranaldo and Soderlind (2010) find that currency market volatility has a nonlinear effect on currency returns. In particular, Ranaldo and Soderlind show that it takes a high currency market volatility to affect, for example, the CHF/USD exchange rate, but exchange rate reactions are then particularly strong. Charlotte Christiansen, Angel Ranaldo and Paul Soederlind (2001) demonstrate that the exposure of currency returns to the US stock and bond markets varies as a function of foreign exchange market volatility. Mancini, Ranaldo and Wrampelmeyer (2013) show that liquidity is a priced factor in currency returns.

Our paper is related to a number of recent studies that have started to link the carry trade to observable macroeconomic fundamentals. Jorda and Taylor (2009) show that the profitability of currency carry strategies can be improved by using macroeconomic conditioning information such as deviations from purchasing power parity. Their fundamental carry strategy leads to a higher Sharpe ratio and less negative skewness of returns relative to the conventional carry strategy. Nozaki (2010) reports similar results for a fundamental strategy in which the investor goes long in currencies that are undervalued relative to some simple model of the equilibrium exchange rate and short in overvalued currencies. Such an investment strategy leads to a much lower Sharpe ratio than the typical carry trade strategy, but it outperforms carry trades in times of high market turmoil. Habib and Stracca (2011) examine what country characteristics determine the safe haven status of a currency. In a large cross section of developed and emerging economies, they find that the only variable that robustly predicts whether a particular currency is a 'safe haven' against global volatility risk is a country's net foreign asset position.

Our analysis is also closely related to Menkhoff et al. (2012b) who sort currencies into portfolios based on a range of macroeconomic fundamentals, such as past GDP growth, past money growth or the deviation from a Taylor rule. They find that past macroeconomic fundamentals 
have significant predictive power for currency returns. Our approach is similar in that we sort on a particular macroeconomic characteristic - past consumption growth. However, different from Menkhoff et al, we use spreads between high consumption- and low consumption growth portfolios as a pricing factor.

Hence, while a number of studies document a role for macroeconomic fundamentals in explaining momentum or predictability in currency returns, none of them has moved on to examine the pricing power of such fundamentals-based risk factors. Also, to our knowledge, none of these papers have used business cycle frequency movements in consumption as conditioning information in constructing such a carry factor, as we do here. As our results are obtained without particular restrictions on preferences (as is usually the case in consumptionbased asset pricing models) they provide independent evidence that the heterogeneity in past consumption movements is priced into currencies.

In the next section, we present a foreign exchange investment strategy that is directly based on the cross-sectional distribution of consumption growth rates. This allows us to unveil a direct link between patterns of international consumption comovement and returns to investment in the foreign exchange market.

\section{Forming currency portfolios based on past consumption growth}

This section first introduces notation concerning currency returns. Then, we discuss how to form currency portfolios based on cross-country differences in past consumption growth rates. Eventually, we introduce the consumption-based carry trade factor $H M L_{\Delta c}$ and discuss its statistical properties.

\subsection{Currency returns}

From the perspective of a US investor, the gross excess return of investing into the currency of a foreign country $k$ is given by

$$
R X_{t+1}^{k}=\frac{\left(1+i_{t}^{k}\right)}{\left(1+i_{t}^{U S}\right)} \frac{S_{t}^{k}}{S_{t+1}^{k}}
$$


where $S_{t}^{k}$ denotes the current spot price of one US dollar measured in units of currency $k$ and $i_{t}^{k}$ denotes the one-period risk-free rate of interest in currency $k$ at time $t$. An increase in $S_{t}^{k}$ indicates a depreciation of currency $k$ against the US dollar. Except in times of high market turmoil and at very high frequencies (see for example Baba, Sakurai and Packer (2012)), covered interest rate parity holds such that the interest rate differential between two currencies equals the forward premium.

$$
F_{t, t+1}^{k}\left(1+i_{t}^{U S}\right)=S_{t}^{k}\left(1+i_{t}^{k}\right)
$$

$F_{t, t+1}^{k}$ denotes the forward price of one US dollar to be delivered in period $t+1$ measured in units of currency $k$. Taking logs and substituting equation (2) into equation (1) yields the following approximate equation for currency returns $s^{2}$

$$
\begin{aligned}
r x_{t+1}^{k} & =i_{t}^{k}-i_{t}^{U S}-\Delta s_{t+1}^{k} \\
& =f_{t, t+1}^{k}-s_{t+1}^{k}
\end{aligned}
$$

where, henceforth, $r x_{t+1}^{k}=R X_{t+1}^{k}-1$ denotes the (net) excess return on investment. This is the return that a US investor obtains from buying currency $k$ in the spot market today and selling it forward. Under uncovered interest parity, $r x_{t+1}^{k}$ should be equal to zero in expectation. However, the failure of the uncovered interest rate parity relationship has been documented widely in the literature: currencies that trade at a forward discount, i.e. currencies that pay higher interest rates than a given base currency, typically do not depreciate as much as would be implied by uncovered interest rate parity. Hence, borrowing in low-interest-rate currencies and investing in high-interest-rate currencies generates positive expected excess returns. Conversely, currencies that trade at a forward premium tend to generate negative expected returns. The observation that expected returns from currency investment are not zero forms the point of departure for the analysis in this paper. We argue that positive expected currency returns compensate investors for systematic cross-country differences in consumption risk.

\footnotetext{
${ }^{2}$ Using forward prices instead of interest rate differentials to calculate currency excess returns has a number of advantages. In particular, problems concerning the correct matching of maturities for interest differentials are avoided. Also, the forward returns are implementable at rather low trading costs, and investors hardly expose themselves to counterparty risk (King, Osler and Rime (2011)).
} 


\subsection{Consumption-growth-sorted currency portfolios}

Portfolios formed with respect to past consumption growth rates reveal a stable pattern in currency excess returns: currencies of countries with higher past consumption growth promise higher excess returns than currencies of low-consumption-growth countries, and, while relatively high on average, carry trades that borrow in low-consumption-growth currencies and lend in high-consumption-growth currencies perform especially poorly during times of global turmoil when investors might particularly fear losses.

At the beginning of each new quarter, we sort currencies into $n$ portfolios based on the associated countries' consumption growth rate over the preceding four quarters, such that the first portfolio always contains currencies of countries with the lowest $n$-tile of past consumption growth rates, and the last portfolio always contains currencies with the highest $n$-tile of past consumption growth rates.

Table (1) shows descriptive statistics for $n=6$ portfolios formed out of a sample of OECD countries over the period from 1990 to 2010. A detailed description of the data follows in the next section, and details on the composition of the portfolios are given in the Appendix. Average returns increase with average past consumption growth. The table shows that investment in the portfolio of the highest-consumption-growth countries yields average annual returns of about 4.2 percent, whereas the portfolio of currencies of the lowest-consumption-growth countries only yields an annual return of 0.6 percent. High-consumption-growth portfolios also have higher Sharpe ratios than low-consumption-growth portfolios. These results suggest that cross-country differences in past consumption growth are an indicator of the differences in the risk exposures of currencies.

The key element of asset pricing is that there are states of the world in which investors particularly fear losses. We argue that a factor that indicates that such bad states have occurred is given by the difference between the return of the high-consumption-growth portfolio and that of the low-consumption-growth portfolio. Hence, this factor - which we refer to as $H M L_{\Delta c}$ or as the 'consumption-carry factor' - is the cross-country average return that a global investor obtains when she borrows in the currencies of countries with the world's lowest consumption growth and invests in the currencies of countries with the world's highest consumption growth. 
The last column of Table (1) shows that this carry trade returns 3.6 percent a year, with a Sharpe ratio of 0.27 . The empirical analysis of the next section will reveal that this $H M L_{\Delta c}$ factor explains the cross-sectional difference in expected portfolio returns to a considerable extent and that it is globally priced.

The second last column of Table (1) shows descriptive statistics for $\overline{r x}$, which is the average return that an investor achieves by borrowing at the beginning of each quarter in US dollars and investing in equal weights into all currencies available in the sample over a holding period of one quarter. Lustig, Roussanov and Verdelhan (2011) call this factor the 'dollar risk factor', because it captures the idiosyncratic (country-specific) component of an investment strategy that funds itself in dollars and goes long in the cross section of all other currencies. At each point in time, the dollar risk factor therefore essentially captures the average rate of depreciation of the dollar against all other currencies. As this dollar factor is important for the level of all dollar-denominated returns, it is important to include it in all our pricing exercises below. However, because of its country-specific nature, we do not expect that this US dollar factor can explain the cross-sectional difference in the returns of different currency portfolios. As argued by Lustig, Roussanov and Verdelhan (2011), it should therefore not be globally priced. This means that there should be no differences across currency portfolios in the exposure to this factor.

Conversely, we will show in the next sections that the $H M L_{\Delta c}$ factor is globally priced - that is, we will show that it prices the cross section of currencies exactly because currency portfolios have different degrees of exposure to it.

A couple of remarks on the procedure for sorting currencies into portfolios based on past consumption growth rates are in order. First, it is important to recognize that, over time, currencies change portfolios, reflecting countries' changing position in the cross-country distribution of consumption growth rates. This is the essence of forming portfolios: the fact that individual currencies may change portfolios reflects the fact that they may not have a fixed exposure to the risk that we wish to price. This may imply that individual currencies do not have a constant beta with respect to the risk factor $H M L_{\Delta c}$. However, as we will show, and as has also been emphasized by Lustig and Verdelhan (2007) and Lustig, Roussanov and Verdelhan (2011), 
portfolios of currencies do have a constant beta with respect to the risk factor $H M L_{\Delta c} \stackrel{3}{3}^{3}$

Second, we focus on consumption growth over the past four quarters to build currency portfolios, instead of consumption growth rates at the highest available (i.e. quarterly) frequency. This reflects the recent focus of the literature on the role of low- to medium-frequency components in consumption for asset pricing. For example, quarterly consumption data might be a very noisy measure of true consumption, so that averaging consumption growth over several periods could provide a better approximation of the ultimate consumption risk that investors care about ${ }^{4}$ Alternatively, investors might have a preference for an early resolution of uncertainty, so that small but potentially very persistent movements in long-term consumption growth carry a much higher risk price than short-term fluctuations in consumption ${ }^{5}$ Furthermore, forming portfolios over annual consumption growth rates is likely to make the formation of consumption-based portfolios more easily implementable as a tradable strategy: consumption data at a quarterly frequency may not be observable in real time because of publication lags and frequent data revisions. Consumption growth at an annual frequency is plausibly much less affected by this problem. Finally, building growth rates over one year implicitly also deal with seasonal effects present in some of the consumption growth series.

\subsection{The consumption carry factor $H M L_{\Delta c}$}

This section discusses the consumption carry factor $H M L_{\Delta c}$ in more detail and sets it in relation to other pricing factors that have been proposed in the literature. Table (4) presents key statistics for $H M L_{\Delta c}$, as well as for other factors: the mean return of the consumption-carry strategy is 3.6 percent per year, and the Sharpe ratio is around 0.27. These figures are both smaller

\footnotetext{
${ }^{3}$ Note that the approach of building portfolios is also robust to missing data: for some countries, available consumption series do not span the whole sampling period, for other countries, forward exchange rates became available only in the late 1990s, and euro countries are excluded from the sample after they introduced the common European currency.

${ }^{4}$ Within the framework of the basic consumption-based capital asset pricing model (C-CAPM), Jagannathan and Wang (2007) show that the fourth quarter to fourth quarter consumption growth rate is a powerful pricing factor, and Parker and Julliard (2005) find that the covariance of returns and consumption growth across the 25 Fama and French (1989) portfolios explains the difference in expected returns observed in the US stock market extremely well, if consumption growth is measured over the quarter of the return and many following quarters. Lettau and Ludvigson (2001) reason that consumption should react predominantly to permanent shocks in wealth, such that the consumption-to-wealth ratio (cay) is unaffected. Fluctuations in cay therefore signal transitory variation in wealth (i.e. future returns), which implies that cay is a powerful pricing factor for asset returns.

${ }^{5}$ In the long-run risk models introduced by Bansal and Yaron (2004), consumption growth follows an ARMA(1,1) process with a slow-moving permanent component, such that shocks will affect consumption at a very long horizon. As agents dislike such long-run risk, a highly volatile consumption-based discount factor results, which has the power to explain observed asset returns.
} 
than the respective values for Lustig et al.'s (2011) forward-discount-based carry trade strategy $H M L_{F X}$ which, calculated using quarterly data, pays an average annual return of around 6.1 percent with a Sharpe ratio of 0.30. Figure (2) plots $H M L_{\Delta c}$ against $H M L_{F X}$. The correlation of the two factors is highly significant, but at 0.36 far from perfect. Figure (2) suggests that $H M L_{\Delta c}$ and $H M L_{F X}$ are particularly highly correlated during some periods of global turmoil such as the Euro crisis of 1992, the Mexican Peso crisis of 1994, September 112001 and the Bear Stearns bankruptcy in August 2007. The returns also often comove during more tranquil periods. Interestingly, the two factors do not strongly move together during the Lehman shock in 2008, whereby the consumption-based carry trade strategy provided distinctly less volatile returns than the forward-discount-based carry trade strategy. In fact, the returns from the consumption- based carry trade strategy are substantially less skewed than $H M L_{F X}$ (with a standardized third moment of 0.08 for $H M L_{\Delta c}$ as opposed to -0.84 for $\left.H M L_{F X}\right)$. With regard to its relation to traditional pricing factors motivated by the (C-)CAPM, consumption carry trade returns are basically uncorrelated with world average consumption growth and with the global stock market return as measured by the MSCI world index. However, $H M L_{\Delta c}$ is significantly negatively correlated with the cross-country variance of consumption growth rates. Section (5) will reveal that the consumption- based carry trade factor $H M L_{\Delta c}$ indeed mirrors risk that is priced in currency markets.

\section{The data}

The main data set used in this analysis includes time series of quarterly consumption growth rates, as well as daily midpoint quotes of spot and forward exchange rates for a cross section of 33 OECD countries, which are Australia, Austria, Belgium, Canada, Chile, the Czech Republic, Denmark, Estonia, Finland, France, Germany, Greece, Hungary, Ireland, Iceland, Israel, Italy, Japan, South Korea, Mexico, Netherlands, New Zealand, Norway, Poland, Portugal, the Slovak Republic, Slovenia, Spain, Sweden, Switzerland, the United Kingdom, the United States and the euro area. Quarterly spot and forward exchange rate series are the quoted price of the last trading day of each quarter. Consumption growth rates are measured in real per capita terms, and quarterly population estimates are obtained by linearly interpolating annual population figures. The main analysis uses a data set that spans the period from the first quarter of 1990 
to the fourth quarter of 2010; in the Appendix, we also present results obtained from using a longer data set that starts in the first quarter of 1986. The data are sourced from various providers accessed via Datastream and from OECD.Stat ${ }^{6}$, and consumption price index series are sourced from the IFS. Details on the source and time span of the data for each country are listed in Table A.1 in the Appendix.

\section{Empirical results}

\subsection{Pricing currency returns}

The price of an asset equals its expected discounted payoff. This price reflects the nondiversifiable component of risk associated with a particular asset, which is determined by its exposure to a set of common risk factors. As carry trades are a zero-net-investment strategy, if the law of one price holds, the return on each portfolio $j$, denoted by $r x_{t+1}^{j}$, must satisfy

$$
0=E\left(M_{t, t+1} r x_{t, t+1}^{j}\right)
$$

where $M_{t+1}$ denotes the stochastic discount factor that prices the payoffs denominated in US dollars. We assume that the stochastic discount factor $M$ is linear in the pricing factors

$$
M_{t+1}=1-\boldsymbol{b}^{\prime} \boldsymbol{f}_{t+1}^{\prime}
$$

where $f_{t+1}$ denotes a matrix of risk factors containing the different factors in its columns, and $\boldsymbol{b}$ is the column vector of factor loadings. Equation (4) and (5) imply that

$$
\begin{aligned}
E\left(r x_{t+1}^{j}\right) & =-\left(\operatorname{cov}\left(M_{t+1}, r x_{t+1}^{j}\right) \operatorname{var}\left(M_{t+1}\right)^{-1}\right)\left(\operatorname{var}\left(M_{t+1}\right) E\left(M_{t+1}\right)^{-1}\right) \\
& =\beta^{j \prime} \lambda
\end{aligned}
$$

where the column vectors $\beta^{j}$ contain regression coefficients that are obtained by running time series regressions of portfolio returns $r x^{j}$ on the factors of the stochastic discount factor. The market price of risk $\lambda$ mirrored by each factor can be estimated by running a cross-sectional

${ }^{6}$ OECD (2012), OECD.Stat, (database). http:/ / stats.oecd.org/Index.aspx (Accessed on 02 August 2012) 
regression of expected portfolio returns on $\beta^{j}$. Substituting the expression for the stochastic discount factor (5) into the Euler equation (4) yields the following alternative expression for the expected returns of currency portfolio $j$

$$
\boldsymbol{E}\left(r x_{t+1}^{j}\right)=\operatorname{cov}\left(f_{t+1}, r x_{t+1}^{j}\right)^{\prime} \boldsymbol{b}
$$

where $\operatorname{cov}($.$) denotes the column vector of covariances of the individual elements of f$ with $r x$. Hence, the market price of risk $\lambda$ and the factor loadings $\boldsymbol{b}$ are related by $\lambda=\operatorname{var}\left(f_{t+1}\right) \boldsymbol{b}$ where $\operatorname{var}($.$) denotes the covariance matrix of f$. The factor loadings $\boldsymbol{b}$ are estimated by a cross-sectional regression of expected excess returns on the covariance between returns and factors.

Our specification for the stochastic discount factor includes two factors

$$
M_{t+1}=1-b_{\overline{r x}} \cdot \overline{r x}_{t+1}-b_{H M L \_\Delta c} \cdot H M L_{-} \Delta c_{t+1}
$$

where our main interest is on the consumption carry trade factor $H M L_{\Delta c}$. As we will argue, $H M L_{\Delta c}$ acts as a global slope factor that determines return differences in the cross section of currency excess returns. As a second factor, we include the return to a US investor who owns an equal-weighted portfolio of the cross section of all currencies. As shown by Lustig, Roussanov and Verdelhan (2011), this factor, referred to as $\overline{r x}$, captures base-currency-specific (here: dollarspecific) influences on the cross section of currency returns. It is therefore an idiosyncratic factor and acts as a level shifter for all dollar-denominated returns.

\section{Time series regression}

A factor mirrors global risk if differences in expected returns across portfolios can be explained by differences in the extent to which portfolios load on this factor. We obtain the loadings or $\beta$ s on the risk factors $\overline{r x}$ and $H M L_{\Delta c}$ by running the following time series regression separately for each currency portfolio $j$.

$$
r x_{t, t+1}^{j}=a^{j}+\beta_{\overline{r x}}^{j} \cdot \overline{r x}_{t, t+1}+\beta_{H M L \_\Delta c}^{j} \cdot H M L \_\Delta c_{t, t+1}+\varepsilon_{t, t+1}^{j}
$$


Figure 3 plots the estimate of $\beta_{H M L \_\Delta c}^{j}$ for each currency portfolio $j$ against its mean excess return. The low-consumption-growth portfolio pays the lowest returns on average, and its correlation with $H M L_{\Delta c}$ is relatively low: in bad times, when $H M L_{\Delta c}$ declines, this portfolio still performs relatively well and thus shields an investor's income stream against low returns. In contrast, the return of the high-consumption-growth portfolio covaries more strongly with $H M L_{\Delta c}$. Indeed, the estimates of $\beta_{H M L_{-} \Delta c}^{j}$ increase almost monotonically from low- to highgrowth portfolios, which implies that currencies of countries with higher past consumption growth are more exposed to risk mirrored by $H M L_{\Delta c}$.

Table (2) presents the results from estimating equation (8). The first and the last portfolio load significantly on $H M L_{\Delta c}$, but the consumption carry factor also has explanatory power for the currency portfolios with intermediate levels of past consumption growth. The observation that portfolios of currencies of countries with relatively high past consumption growth pay relatively high returns on average, together with the finding that high-consumption-growth currency portfolios covary more strongly with the consumption carry trade factor, implies that $H M L_{\Delta c}$ explains the cross-sectional difference in expected portfolio returns: high-growthcurrency portfolios pay higher expected returns because they perform badly exactly when $H M L_{\Delta c}$ is low, which is in bad economic times when investors are especially concerned that their portfolios do not perform badly. The dollar risk factor $\overline{r x}$ on the contrary does not account for the difference in returns across portfolios, because all portfolios load on it with a roughly equal estimated coefficient $\beta_{\bar{r} x}^{j}$ of about one. This suggests that $\overline{r x}$ is indeed a local factor that accounts for shifts in the average level of US-dollar denominated returns that the investor obtains from investing in foreign currencies during any given quarter.

\section{Cross-sectional regression}

While $\boldsymbol{\beta}^{j}=\left[\begin{array}{ll}\beta_{\overline{r x}}^{j} & \beta_{H M L \_}^{j}{ }_{c}\end{array}\right]^{\prime}$ measures the exposure of each currency portfolio $j$ to the proposed risk factors, $\lambda=\left[\begin{array}{ll}\lambda_{\overline{r x}} & \lambda_{H M L \_\Delta c}\end{array}\right]^{\prime}$ is commonly interpreted as the price of risk. In equation (6), $\lambda$ corresponds to the ratio of the variation of the stochastic discount factor and its expected value; that is, it captures the price of the factors brought forward at the risk-free rate. We follow Cochrane (2005) (Chapter 13) and estimate equations (6) using GMM 7 Inference is

\footnotetext{
${ }^{7}$ Using GMM to estimate the price of the risk factors $\lambda=\left(\lambda_{\overline{r x}}, \lambda_{H M L_{-} \Delta c}\right)^{\prime}$ implies that two sets of moment conditions are evaluated at the same time: those that generate the regressors $\beta$ and those that generate the cross-sectional
} 
based on a Newey and West (1987) covariance matrix estimator with a bandwidth of five lags. As expected, Table (3) reveals that the dollar risk factor $\overline{r x}$ is not priced. The price of the consumption carry trade factor $H M L_{\Delta c}$ on the contrary is significantly positive, and it amounts to 372 basis points per annum. This implies that an asset with a $\beta$ of one earns a risk premium of 3.72 percent per annum 8 , and equation (6) indicates that currency portfolios with a higher $\beta_{H M L \_\Delta c}$ pay higher expected returns.

To test whether the consumption carry trade factor $H M L_{\Delta c}$ helps to price the currency portfolios given the presence of the other risk factor $\overline{r x}$, we focus on the asset pricing model in discount factor form given by equation $\left[7\right.$. We estimate the vector $\boldsymbol{b}=\left[\begin{array}{ll}b_{\overline{r x}} & \left.b_{H M L \_} \Delta\right]^{\prime}\end{array}\right]^{\text {to- }}$ gether with the covariance of factors and portfolio returns using GMM. We find that the estimate $b_{H M L} \Delta c$ is positive and significantly different from zero at the five percent confidence level, whereas $b_{\overline{r x}}$ has no significant impact on the discount factor of US investors. This result confirms the conjecture that the consumption carry factor $H M L_{\Delta c}$ mirrors global risk, whereas the dollar risk factor $\overline{r x}$ does not. It is consistent with the prediction of models in which the investor's utility is increasing and concave in consumption, which produces a high intertemporal marginal rate of substitution when consumption is low: in bad times for investors, the consumption carry trade factor $H M L_{\Delta c}$ is low, which together with a positive $b_{H M L} \Delta c$ implies a high discount factor $M$ - see equation (5).

Regarding the fit of the model, Figure (4) plots the average returns of the consumption-growth sorted currency portfolios against the returns predicted by the model. The model explains the returns of the six currency portfolios well: the $p$-value of the pricing error test amounts to $72 \%$, which implies that we cannot reject the null that the pricing errors from the cross-sectional regression of mean currency portfolio returns on the $\beta$ s equal zero.

These results suggest that $H M L_{\Delta c}$ captures global risk in the world cross section of currencies. In the next section, we examine whether $H M L_{\Delta c}$ prices a cross section of test portfolios that have been sorted by forward discounts (as in Lustig, Roussanov and Verdelhan (2011)) and

regression coefficients $\lambda$. In contrast to a two-pass estimation procedure, where an estimate of $\lambda$ is obtained by running a cross-sectional regression of expected asset returns on the $\beta$ s that were obtained previously by running time series regressions as specified in equation (8), using GMM has the advantage that the covariance matrix between the two sets of moment conditions takes into account that the $\beta$ s are estimated coefficients as well. This leads to larger standard errors for the $\lambda$ coefficient estimates.

${ }^{8} \mathrm{As}$ the risk factor $H M L_{\Delta c}$ is a linear combination of the returns of two test assets, it has a time series regression $\beta$ of one on itself. Hence, the price of risk $\lambda$ should equal the mean of $H M L_{\Delta c}$, which holds true in our estimation exercise. 
compare the pricing power of the consumption carry factor to that of two other extant factors, the Lustig, Roussanov and Verdelhan (2011) $H M L_{F X}$ factor and the Menkhoff et al. (2012a) foreign exchange volatility innovation factor, which have both been constructed from purely financial information.

\subsection{Forward--discount-sorted currency portfolios and further risk factors}

If the consumption carry trade factor $H M L_{\Delta c}$ mirrors global, nondiversifiable risk, this factor should explain the difference in expected returns of any assets. Initiated by Lustig and Verdelhan (2007), the most commonly used test assets in the current literature on currency pricing are forward-discount-sorted currency portfolios. The results presented in Table (5) suggest that the consumption carry trade factor prices this cross section of test assets as well, and that it compares favorably to other risk factors proposed by the literature.

In Table (5), the test assets are six currency portfolios that have been constructed for each quarter by sorting the currencies of the OECD data sample on their forward discount toward the US observed at the end of the preceding quarter. Descriptive statistics for these forward-discountsorted currency portfolios are provided in Table (5.2) in the Appendix. Using this set of test assets, we estimate the price of the consumption carry trade factor $H M L_{\Delta c}$ to be 908 basis points a year, and it is significantly different from zero at the five percent confidence level.

The second and third columns of Table (5) show estimates of risk prices and factor loadings for two further risk factors; namely, for the Lustig, Roussanov and Verdelhan (2011) $H M L_{F X}$ factor and the Menkhoff et al. (2012a) foreign exchange volatility innovation $V O L$ factor. We have constructed both risk factors as described in the respective papers using the quarterly data of the OECD sample specified in Section (4). Both risk factors, $H M L_{F X}$ and $V O L$, are able to price the quarterly forward-discount-sorted currency portfolios.

\subsection{Horse race between pricing factors}

In this section, we run a horse race between the three foreign exchange risk factors $H M L_{\Delta c}$, $H M L_{F X}$ and VOL. The test assets are six forward-discount-sorted currency portfolios (see Table 
A.3 in the Appendix) plus six previous year consumption-growth-sorted currency portfolios (see Table 1 ).

In Table (6), the panel on the left shows the estimated price of risk $\lambda$ for the three foreign exchange risk factors when included jointly in the stochastic discount factor together with the dollar risk factor $\overline{r x}$. Testing for $\lambda^{i}=0$ in the beta representation of the asset pricing model $E\left(r x^{j}\right)=\boldsymbol{\beta}^{j \prime} \lambda$ amounts to testing whether the factor $f^{i}$ is correlated with the true discount factor (see Cochrane (2005)). The table reveals that both carry trade factors, the consumption carry trade factor $H M L_{\Delta c}$ as well as the forward-discount-based carry trade factor $H M L_{F X}$, are significantly priced and thus determine the stochastic discount factor that prices the consumptiongrowth-sorted and the forward-discount-sorted currency portfolios.

The relationship between the risk price $\lambda$ and the factor loadings on the discount factor, $\boldsymbol{b}$ is given by $\lambda=\operatorname{var}(\boldsymbol{f}) \boldsymbol{b}$. As the foreign exchange risk factors $f=\left(\overline{r x} H M L_{\Delta c} H M L_{F X} V O L\right)^{\prime}$ are correlated (see Table 4), testing for $\lambda=0$ does not answer the same question as testing for the joint hypothesis $\boldsymbol{b}=\mathbf{0}$. The parameters $\boldsymbol{b}$ of the stochastic discount factor $M_{t+1}=1-\boldsymbol{b}^{\prime} \boldsymbol{f}_{t+1}$ capture whether a factor is marginally useful in pricing assets, given the presence of the other factors. In Table (6), the panel on the right reveals that our consumption carry trade factor is a highly significant pricing factor given the dollar factor $\overline{r x}$, but it turns insignificant if the forward-discount-based carry trade factor $H M L_{F X}$ is additionally included into the analysis. Clearly, because $H M L_{F X}$ and $H M L_{\Delta c}$ are correlated, it becomes difficult that the two risk factors survive next to each other. The same applies to the foreign exchange volatility factor $V O L$, which is significantly correlated with all the other pricing factors. This explains why the individual factor loadings generally turn insignificant as soon as this volatility factor is included in the analysis. Note that when all three factors are included in the pricing exercise, our factor $H M L_{\Delta c}$ is the only one to remain marginally significant.

The analysis of this section has revealed that all of the three factors, $H M L_{\Delta c}, H M L_{F X}$ and $V O L$, qualify as global risk factors, which persist next to each other in some settings, but not in other settings. This suggests that, at least to some extent, these factors mirror the same kind of global risk. Indeed, a principal components analysis of the three candidate risk factors reveals that the first principal component accounts for about $60 \%$ of the variability present in the factors and that it is significantly priced. The results from the principal components analysis 
are summarized in Table (A.9) and Table (A.10). The observation that there exists a dominant principal component of the risk factors that is priced robustly confirms the conjecture that the three risk factors effectively measure the same thing.

To summarize, the results in this section show that $H M L_{\Delta c}$ successfully prices the cross section of both consumption-growth-sorted and forward-discount-sorted currency portfolios. We have also shown that $H M L_{\Delta c}$ compares well with other pricing factors that have previously been suggested in the literature. While we are not attempting to claim that we 'beat' other factors, we emphasize that our factor differs from these previous factors in that it is constructed based on past macroeconomic fundamentals - specifically consumption growth rates. This suggests that international differences in medium-term consumption growth are informative with respect to the risk exposure of a country's currency to global shocks.

\subsection{Explaining bilateral currency returns}

Our results so far show that there are systematic differences in the exposure to the consumption carry factor across currency portfolios sorted on different criteria - interest rates and past consumption growth - and that these differences are priced. By contrast, individual currencies will not generally have a fixed, time-invariant exposure to the global factor: because currencies change portfolios over time, their exposure to the consumption carry risk factor $H M L_{\Delta c}$ will in general be time-varying as well. However, because we observe that the expected returns of high-past-consumption-growth currency portfolios covary more strongly with $H M L_{\Delta c}$ than expected returns of low-consumption-growth currency portfolios, a country's past consumption growth rate should pin down its exposure to $H M L_{\Delta c}$. This reasoning allows us to price individual currency pairs using a $\beta$-representation in which the $\beta$ is a time-varying function of the consumption growth differential between the country of which the US investor holds currency and the US. This motivates the panel regression

$$
r x_{t, t+1}^{k}=a+\gamma_{1}\left(\widetilde{c}_{t-4, t}^{k}\right)+\gamma_{2}\left(\widetilde{c}_{t-4, t}^{k}\right) \cdot\left(H M L_{-} \Delta c_{t, t+1}\right)+\gamma_{3} H M L_{-} \Delta c_{t, t+1}+\gamma_{4} \overline{r x}_{t, t+1}+\epsilon_{t, t+1}^{k}(9)
$$


where $k$ indexes an individual country, and where $\widetilde{c}_{t-4, t}^{k}=\Delta c_{t-4, t}^{k}-\Delta c_{t-4, t}^{U S}$ is the difference between the US consumption growth rate and the consumption growth rate of country $k$ over the quarters from $t-4$ to $t$. In this specification, country $k^{\prime}$ s exposure to $H M L_{\Delta c}$ is given by

$$
\beta^{k}(t)=\gamma_{2}\left(\widetilde{c}_{t-4, t}^{k}\right)+\gamma_{3}
$$

and therefore varies over time as a function of a country's past consumption growth. Conversely, in this regression, the term $\gamma_{3} H M L_{\Delta c, t+1}+\gamma_{4} \overline{r x}_{t+1}$ captures effects that are common to the cross section of returns.

The currencies for which complete time series for consumption growth, and forward exchange and spot exchange rates are available over the period from 1990(1) to 2010(4) are the Australian dollar, the Canadian dollar, the Danish krone, the Japanese yen, the New Zealand dollar, the Norwegian krone, the Swedish krona, the Swiss franc and the British pound. Table (7) shows the results from the bilateral pricing regression 9 based on these nine currencies.

Note first that the interaction of $H M L_{\Delta c}$ with past country-level consumption growth - the coefficient $\gamma_{2}-$ is positive and significant, whereas $\gamma_{3}$ is not significant. This underpins the interpretation of $H M L_{\Delta c}$ as a global slope factor that explains differences in returns between currencies provided that these countries have different consumption growth rates. As countries change their position in the cross-sectional distribution of past consumption growth rates, their exposure to $H M L_{\Delta c}$ will change as well. Conversely, $H M L_{\Delta c}$ does not significantly impact the average dollar-denominated return on foreign currency. This role of a level factor is, again, mainly played by $\overline{r x}$, which loads with a coefficient of virtually one on the cross section of currency returns.

To illustrate further that differences in the exposure to $H M L_{\Delta c}$ explain the cross section of currency returns and that $\overline{r x}$ fully captures level shifts in dollar-denominated returns, we also estimate a version of the panel regression in which we control for time- and country-fixed effects

$$
r x_{t, t+1}^{k}=\gamma_{1}\left(\widetilde{c}_{t-4, t}^{k}\right)+\gamma_{2}\left(\widetilde{c}_{t-4, t}^{k}\right) \cdot\left(H M L_{-} \Delta c_{t, t+1}\right)+\tau_{t}+\delta^{k}+\epsilon_{t, t+1}^{k}
$$

where the terms $\delta^{k}$ and $\tau_{t}$ denote country- and time-fixed effects. This panel regression displays 
a very similar level of fit to the pricing regression above, and the coefficients $\gamma_{1}$ and $\gamma_{2}$ are also very similar and significant; see Table (7). This illustrates that potentially unobserved country characteristics do not affect the results regarding the sensitivity of individual currencies with respect to the common risk factor $H M L_{\Delta c}$. It is also interesting to note that the estimate of the time-fixed effect $\tau_{t}$ in equation (10) is closely linked to the dollar risk factor $\overline{r x}_{t}$ : the correlation of the two series is about 0.96 . This confirms that the dollar risk factor - the average return an investor gains by borrowing in US dollars and investing in all currencies available in the market - provides a level factor for the cross section of dollar returns.

Regressions (9) and (10) suggest that excess returns from currency investment are related to past consumption growth even at the level of individual currencies: because both $\gamma_{1}$ and $\gamma_{2}$ are positive, and because $H M L_{\Delta c}$ is positive on average, currencies of countries with higher than US consumption growth pay positive expected returns, whereas currencies of countries with relatively low consumption growth pay negative expected returns. However, excess returns on high-consumption-growth currencies may turn negative, and expected returns on low-growth currency portfolios may turn positive, when there is a large negative shock to $H M L_{\Delta c}$, which will be the case in bad times when global stock market returns decline and consumption dispersion increases (see Table 4 ).

To emphasize that it is truly exchange rate risk that drives currency returns, and not forward discounts that are known ex ante, the middle panel of Table (7) reports results from estimating regressions (9) and (10) again, but now with nominal exchange rate changes, $-\Delta s_{t, t+1}^{k}$, instead of currency returns as the left-hand variable 9 The observation that the estimates for $\gamma_{1}$ and $\gamma_{2}$ remain virtually unchanged corroborates our conclusion that nonzero expected currency excess returns merely compensate an investor for the exchange rate risk to which he exposes himself when holding currencies of countries with high past consumption growth that promise positive expected returns. Finally, the bottom panel of Table (7) shows the results that are obtained when replacing the left-hand variable in equations (9) and (10) with the real exchange rate change $-\Delta q_{t, t+1}^{k}=-\left(\Delta s_{t, t+1}^{k}+\Delta p_{t, t+1}^{k}-\Delta p_{t, t+1}^{U S}\right)$. Again, the estimates remain largely unaffected vis-à-vis the earlier specifications. ${ }^{10}$

\footnotetext{
${ }^{9}$ As currency excess returns are given by $r x_{t, t+1}^{k}=f_{t, t+1}^{k}-s_{t+1}^{k}-\Delta s_{t, t+1}^{k}$, for the sake of comparability, we use the negative of the nominal exchange rate change $-\Delta s_{t, t+1}^{k}$ as the left-hand variable. Recall that $-\Delta s_{t, t+1}^{k}>0$ indicates an appreciation of currency $k$ against the US dollar between $t$ and $t+1$.

${ }^{10}$ The regressions in Table 7 may appear reminiscent of the regressions often used in the literature on the
} 


\section{Interpreting the stylized facts: a consumption habit model}

We have shown that currencies of countries that recently experienced consumption booms appreciate on average, whereas currencies of low-past-consumption-growth countries tend to depreciate. This pattern reflects a compensation for global risk: consumption boom currencies depreciate strongly in times of global distress. In this section, we interpret these stylized facts using a version of the consumption habit model proposed by Campbell and Cochrane (1999), based on Verdelhan (2010). As we show, in this model, sorting currencies on their consumption growth over the last several quarters approximates sorting them on their risk aversion. Intuitively, a sequence of high consumption growth rates leads to high surplus consumption relative to habit and, therefore, to low risk aversion. Conversely, a country that experiences low consumption growth over several quarters will have a low surplus consumption ratio and, therefore, high levels of risk aversion.

It has previously been shown by Verdelhan (2010) that the habit model can reproduce the uncovered interest rate parity puzzle and that the resulting nonzero expected carry trade returns compensate investors for consumption growth risk. Unlike Verdelhan (2010), however, our version of the model explicitly allows for a global component in all countries' consumption growth rates. This is important for the interpretation of our results: while country-specific consumption growth shocks disappear at the portfolio level, the average country in any large portfolio will still be affected by global consumption growth risk. Thereby, marginal utility in high-growth, low-risk-aversion countries reacts less sensitively to consumption shocks than marginal utility in low-growth, high-risk-aversion countries. Therefore, the return spread between a portfolio of consumption boom countries and a portfolio of consumption bust countries - our $H M L_{\Delta c}$ factor — reflects international differences in the exposure of marginal utility growth to global consumption growth risk. Hence, the habit formation model suggests that the $H M L_{\Delta c}$ factor captures differences in risk aversion between countries.

consumption-real-exchange-rate puzzle that was initiated by Backus and Smith (1993) and Kollmann (1995): in standard macroeconomic models with constant relative risk aversion and complete financial markets, consumption growth differences between countries should be offset by real exchange rate movements such that countries with low consumption growth should experience an appreciation. This implies a high contemporaneous correlation between real exchange rate changes and relative consumption growth rates. It is well known that this correlation is not present in the data. The results presented in this section, instead, suggest that there is a significant but timevarying link between real exchange rates and past consumption growth. In the next section, we interpret this pattern in the context of a consumption based model with habit formation. 
We now proceed to present the model and then use simulated data to illustrate that the model can replicate some of the major empirical regularities that we discovered in the OECD data sample.

\subsection{The model}

Our setup closely follows Campbell and Cochrane (1999) and Verdelhan (2010). There are $k=1 \ldots K$ endowment economies in each of which a representative agent is characterized by external habit preferences

$$
E \sum_{t=0}^{\infty} \beta^{t} \frac{\left(C_{t}^{k}-H_{t}^{k}\right)^{1-\gamma}-1}{1-\gamma}
$$

where $C_{t}$ denotes the level of consumption of the single good, and $H_{t}$ is the external consumption habit level. The relation between consumption and habits is captured by the surplus consumption ratio $S_{t}^{k} \equiv\left(C_{t}^{k}-H_{t}^{k}\right) / C_{t}^{k}$, which depends on past consumption through the following process for the log surplus consumption ratio $s_{t}$ :

$$
\mathrm{s}_{t}^{k}=(1-\phi) \overline{\mathbf{s}}+\phi \mathbf{s}_{t}^{k}+\lambda\left(\mathrm{s}_{t}^{k}\right)\left(\Delta c_{t+1}^{k}-g\right)
$$

where $0<\phi<1$ and where $g$ and $\bar{s}$ are the unconditional means of consumption growth and the $\log$ consumption surplus ratio ${ }^{11}$ The function $\lambda\left(\mathrm{s}_{\mathrm{t}}\right)$ governs how sensitively the surplus consumption ratio reacts to the current realization of consumption growth. It is given by

$$
\lambda\left(\mathrm{s}_{t}\right)=\frac{1}{\overline{\mathrm{s}}} \sqrt{1-2\left(\mathrm{~s}_{t}-\overline{\mathrm{s}}\right)}-1, \text { when } \mathrm{s} \leq \mathrm{s}_{\max }, 0 \text { elsewhere }
$$

where $\overline{\mathrm{S}}=\sigma \sqrt{\frac{\gamma}{1-\phi-B / \gamma}}, \mathrm{s}_{\max }=\overline{\mathrm{s}}+\left(1-\overline{\mathrm{S}}^{2}\right) / 2$, and $B=\gamma(1-\phi)-\left(\gamma^{2} \sigma^{2}\right) /\left(\overline{\mathrm{S}}^{2}\right)$, and $\sigma$ denotes the standard deviation of consumption growth.

In this model, the coefficient of relative risk aversion of country $k$ is given by $-C_{t}^{k} U_{c c}(t) / U_{c}(t)=$ $\gamma / S_{t}^{k}$. Hence, if country $k^{\prime}$ s consumption is close to the habit level, the surplus consumption

\footnotetext{
11 We use sans serif letters ( $\mathrm{S}$ and $\mathrm{s}$ ) to denote the surplus consumption ratio and its logarithm, respectively. The spot nominal exchange rate and its logarithm continue to be denoted by the standard typeface $S$ and $s$. Using different typefaces in this way allows us to stay in keeping with both the international finance literature and the literature on habit formation, which both use the letter ' $\mathrm{S}$ '.
} 
ratio of country $k$ is low, which implies that the representative agent of country $k$ is highly risk averse. In this model, the stochastic discount factor is given by

$$
M_{t+1}^{k}=\beta\left(\frac{\mathrm{S}_{t+1} C_{t+1}}{\mathrm{~S}_{t} C_{t}}\right)^{-\gamma}=\beta \exp \left\{-\gamma\left[g+(\phi-1)\left(\mathrm{s}_{t}^{k}-\overline{\mathrm{s}}\right)+\left(1+\lambda\left(\mathrm{s}_{t}^{k}\right)\right)\left(\Delta c_{t+1}^{k}-g\right)\right]\right\}
$$

where $g$ is the mean growth rate of consumption. The risk-free interest rate is $r_{t}^{k}=\bar{r}-B\left(\mathrm{~s}_{t}^{k}-\overline{\mathrm{s}}\right)$ with $\bar{r}=-\ln (\beta)+\gamma g-\left(\gamma^{2} \sigma^{2}\right) /\left(2 \bar{S}^{2}\right) 12$ We follow Verdelhan (2010) and impose $B<0$. This implies that risk-free interest rates are procyclical; that is, higher in countries with higher surplus consumption ratios.

We assume that consumption growth of country $k$ follows an i.i.d. normal process.

$$
\begin{aligned}
\Delta c_{t+1}^{k}=g+\xi_{t+1}+u_{t+1}^{k} \quad & \xi_{t+1} \sim \text { i.i.d. } N\left(0, \sigma_{g l o b}^{2}\right), u_{t+1}^{k} \sim \text { i.i.d. } N\left(0, \sigma_{\text {idio }}^{2}\right) \\
& \operatorname{cov}\left(\xi_{t+1}, u_{t+1}^{k}\right)=0
\end{aligned}
$$

At each point in time, the average growth rate $g$ and the global shock to consumption growth $\xi_{t+1}$ are common to all countries, whereas $u_{t+1}^{k}$ denotes country-specific shocks to consumption growth. Concerning the variance of the global and the country-specific shocks, we assume that $\sigma_{g l o b}=\sigma_{\text {idio }}=\sigma / \sqrt{2}$. As we will discuss shortly, the presence of a global component in consumption growth is important in explaining our results.

We assume that financial markets are complete, which implies that the change in the real exchange rate between two countries equals the ratio of the two countries' marginal utility growth rates or stochastic discount factors

$$
\frac{Q_{t+1}^{k}}{Q_{t}^{k}}=\frac{M_{t+1}}{M_{t+1}^{k}}
$$

where $Q_{t}^{k}$ is the real exchange rate measured in units of country $k$ goods per one unit of the home country good, so that an increase in $Q^{k}$ implies a depreciation of country $k^{\prime}$ s currency visà-vis the home country. Taking logarithms and substituting in from above for the logarithmic pricing kernel, we obtain the rate of change of the real exchange rates

\footnotetext{
${ }^{12}$ For details about the derivation of equation 11 , the reader is referred to Campbell and Cochrane (1999) and Verdelhan (2010).
} 


$$
\Delta q_{t+1}^{k}=\kappa_{t}+\gamma\left(1+\lambda\left(\mathrm{s}_{t}^{k}\right)\right)\left(\Delta c_{t+1}^{k}-g\right)-\gamma\left(1+\lambda\left(\mathrm{s}_{t}\right)\right)\left(\Delta c_{t+1}-g\right)
$$

where $\kappa_{t}$ summarizes all variables known at time $t$.

It is instructive to compare this condition for optimal risk sharing with the one obtained from a model with constant relative risk aversion preferences without habit formation (see, e.g., Backus and Smith (1993) and Kollmann (1995)), which is given by the following.

$$
\Delta q_{t+1}^{k}=\kappa_{t}+\gamma\left(\Delta c_{t+1}^{k}-\Delta c_{t+1}\right)
$$

The model without habit formation predicts that exchange rates move in lockstep with consumption growth differences between countries. It is well known that this condition is grossly violated in the data. By contrast, in the habit model, whether the real exchange rate appreciates or depreciates will not only depend on current differences in consumption growth between countries. Rather, past differences will matter as well, because they are reflected in differences in the surplus consumption ratio between the two countries. Specifically, if countries differ in their consumption histories, the real exchange rate will change even if both countries experience the same consumption shock $\Delta c_{t+1}^{k}=\Delta c_{t+1} \neq 0$ : because the sensitivity function $\lambda(\mathrm{s})$ is low when surplus consumption is high, the country with the higher surplus and, therefore, the higher average consumption over the recent past will experience an appreciation if the common consumption shock is positive, or a depreciation if the shock is negative. The reason for this is that risk aversion in the high-surplus (low- $\lambda$ ) country is low and that marginal utility growth is less exposed to the common consumption shock. Optimal risk sharing entails that purchasing power is redistributed to the high-risk-aversion country in periods when both countries are hit by the same negative consumption growth shock.

Hence, in the habit model, countries differ in their exposure of marginal utility growth to the same common shock. These differences in exposure to common shocks are also the source of 
the currency risk premium in this model, which is given by the following

$$
E\left(r x_{t+1}^{k}\right)=r_{t}^{k}-r_{t}-E_{t}\left(\Delta q_{t+1}^{k}\right)=\frac{\gamma^{2} \sigma^{2}}{\overline{\mathrm{s}}^{2}}\left(\mathrm{~s}_{t}^{k}-\mathrm{s}_{t}\right)
$$

Equation (12) shows that currencies of consumption boom countries generate positive expected excess returns. This risk premium compensates for a likely depreciation of the currency in times of low aggregate consumption growth. As we show in our simulations, sorting currencies on past consumption growth is very similar to sorting them on their surplus consumption ratio.

To allow this intuition to extend to portfolios - as our empirical results suggest it does consumption growth must therefore have a common (global) component that does not wash out in sufficiently large portfolios of currencies. To see this, average equation (11) over a subset of $I \subset\{1 \ldots . . K\}$ of our $K$ currencies. If the number of elements in $I$, denoted here by $\# I$, is sufficiently large, we get the following.

$$
\frac{1}{\# I} \sum_{k \in I} \Delta q_{t+1}^{k}=\tilde{\kappa_{t}}+\gamma\left(\frac{1}{\# I} \sum_{k \in I}\left(1+\lambda\left(\mathrm{s}_{t}^{k}\right)\right)\right) \xi_{t+1}-\gamma\left(1+\lambda\left(\mathrm{s}_{t}\right)\right)\left(\Delta c_{t+1}\right)
$$

Specifically, forming portfolios by sorting currencies on their past consumption growth and assuming that there are many currencies in each of the consumption-growth-sorted portfolios, the stochastic component of the returns described by our consumption carry factor $H M L_{\Delta c}$ is determined by changes in the average rate of change in the real exchange rate between highand low-consumption-growth currencies, given by

$$
\Delta q_{t+1}^{h l}=\hat{k}_{t}+\gamma\left[\lambda_{t}^{h}-\lambda_{t}^{l}\right] \xi_{t+1}
$$

where $\lambda_{t}^{h}$ and $\lambda_{t}^{l}$ are the average values of the sensitivity function of high $h$ and low $l$ surplus consumption ratio country portfolios. Exchange rate changes between large portfolios of currencies are therefore solely driven by differences in the exposure to global consumption risk: portfolios of currencies from countries with high surplus consumption ratios - which recently have experienced a series of high consumption growth rates - appreciate if positive global consumption growth shocks occur, and depreciate if the global shock turns out to be nega-

\footnotetext{
${ }^{13}$ for further details, see Campbell and Cochrane (1999) and Verdelhan 2010)
} 
tive. The reason is that marginal utility in countries with high surplus consumption (low risk aversion) has lower exposure to global consumption risk than countries with high risk aversion. Optimal risk sharing therefore entails that wealth is redistributed to high-risk-aversion countries when there are negative global shocks.

\subsection{Calibration and results}

We assume that all countries share the same set of parameters. The risk-aversion parameter $\gamma$ is set equal to 2, which corresponds to the value chosen by Campbell and Cochrane (1999) and Verdelhan (2010). We estimate the average consumption growth rate $g$ and its standard error $\sigma$ from the OECD data sample used in the main analysis of this study. Taking sample means over all 33 countries, we find that the quarterly consumption growth rate corresponds to $g=$ $0.52 \%$, and its standard deviation is $\sigma=1.1 \%$. This implies a standard deviation of the global shock and the country-specific shock of $\sigma_{\text {glob }}=\sigma_{\text {idio }}=\sigma / \sqrt{2}=0.81$. The country-specific endowment shocks $u_{t+1}^{k}$, which all have variance $\sigma_{\text {idio }}$, are uncorrelated across countries, but there is a common consumption growth shock in all countries' consumption growth rate $\xi_{t+1}$ with variance $\sigma_{g l o b}$. The quarterly real risk-free interest rate is set equal to $\bar{r}=0.24 \%$, which corresponds to the average real US T-bill rate measured over the period from the first quarter of 1990 to the fourth quarter of 2010. T-bill rates and consumer price inflation are obtained from the IFS data tap $\mathrm{e}^{14}$. As in Verdelhan (2010), we set $B=-0.01$. The persistence parameter $\phi$ is chosen such that the mean value of the consumption carry factor $H M L_{\Delta c}$ approximately corresponds to its sample counterpart; using real returns to calculate the consumption carry factor from our OECD data sample, we find that $H M L_{\Delta c, t+1}^{\text {real }}=3.6 \%$ per year. For $\phi=0.985$, the simulated consumption carry factor pays an average return of about this size. These parameter values imply that $\beta=0.99, \overline{\mathrm{S}}=0.11$ and $\overline{\mathrm{S}}_{\max }=0.18$. All parameter values are thus close to the values chosen by Campbell and Cochrane (1999) and Verdelhan (2010), Table (8) presents an overview of the chosen parameter values.

With these parameters and 10000 endowment shocks, we generate data and build currency portfolio returns, the dollar risk factor $\overline{r x}$ as well as the consumption carry factor $H M L_{\Delta c}$. In analogy to the empirical analysis in this study, we generate data for 33 countries and then sort

\footnotetext{
${ }^{14}$ US T-bill rates correspond to line $11160 \mathrm{C} . . . \mathrm{ZF}$, and consumer price inflation is calculated from $11164 \ldots . \mathrm{ZF} . .$. .
} 
countries into six portfolios according to their consumption growth rates over the previous four quarters. Table (9) presents the moments for the currency portfolios that this simulation delivers.

Simulated portfolios of countries that have recently experienced higher consumption growth pay an investor who borrows in his home currency and invests in these portfolios higher returns on average. Furthermore, consumption boom countries have high surplus consumption ratios, which translate into low risk aversion, and thus relatively smooth intertemporal marginal rates of substitution in consumption. The more risk averse the investor is compared with the average country in a particular currency portfolio - that is, the lower his surplus consumption ratio is relative to the average portfolio surplus consumption ratio - the more exposed his marginal utility will be to consumption growth shocks. Currencies of countries with high exposure to global consumption growth shocks will therefore appreciate when a negative global consumption shock occurs. This reflects optimal risk sharing: the exchange rate appreciation redistributes purchasing power to the high-risk-aversion, high-marginal- utility country in recessions.

As carry trade returns are procyclical and thus risky, the investor demands a higher risk premium for investment into portfolios with higher surplus consumption ratios. Against the background of this model, we can therefore interpret our sorting of countries into portfolios according to their recent consumption growth rates as sorting countries on their surplus consumption ratios or risk aversion, and portfolios with higher past consumption growth rates expose the investor to more home and global consumption growth risk. This explains why consumption boom currencies pay higher expected returns.

Equation (14) suggests that within the framework of the consumption habit model outlined above, our consumption carry factor $H M L_{\Delta c}$ should mirror global risk only, and it should be high if consumption growth is globally high and low otherwise. In the simulation with 33 countries and 10000 global and country-specific endowment shocks, the correlation between the global consumption growth shock $\xi_{t+1}$ and $H M L_{\Delta c}$ equals about 0.4. This correlation is not perfect because with 33 countries, portfolios are not sufficiently large such that not all idiosyncratic endowment shocks $u_{t+1}^{k}$ average out. Increasing the number of countries in the simulation increases this correlation, and for $K=66$ countries, it equals about 0.7 . 
The simulated consumption carry factor $H M L_{\Delta c}$ is a globally priced risk factor, whereas the mean currency return factor $\overline{r x}$ is not. Table 10 presents results from estimating the asset pricing model of Section (5) again, but instead of using the data from our sample of 33 OECD countries, test assets and pricing factors are constructed from simulated data. The habit model with the parameter values specified above generates the stylized facts that we described for the OECD data sample: country portfolio returns covary more strongly with the global recession factor $H M L_{\Delta c}$ the higher their consumption growth rate has been recently, and the risk factor $H M L_{\Delta c}$ is globally priced whereas the level factor $\overline{r x}$ is not.

\section{Robustness checks}

The Appendix presents several robustness checks that confirm our results. First, similar to Lustig, Roussanov and Verdelhan (2011) and Mancini, Ranaldo and Wrampelmeyer (2013), in Table A.4, we regress portfolio foreign exchange rate changes, $-\Delta s_{t, t+1}^{j}$, rather than portfolio carry trade returns, $r x_{t, t+1}^{j}$, on the dollar return factor and on $H M L_{\Delta c}$. All $H M L_{\Delta c}$ betas in Table (A.4) are basically the same as those in Table (2) which were based on carry trade returns. Also, risk prices and factor loadings remain largely unchanged when exchange rate changes are used (see Table(A.5)). This implies that low past consumption growth currency portfolios offer insurance against $H M L_{\Delta c}$ risk because they appreciate when the consumption carry factor $H M L_{\Delta c}$ drops, not because the forward discounts on these currencies decline. On the other hand, high past consumption growth currency portfolios expose carry traders to $H M L_{\Delta c}$ risk because they depreciate when $H M L_{\Delta c}$ declines and not because forward discounts increase.

Second, we sort currencies into portfolios according to their $\beta$ with respect to the consumption carry trade factor $H M L_{\Delta c}$. To do so, we estimate the following regression for each currency $k$ separately over rolling windows of 20 quarters.

$$
r x_{t, t+1}^{k}=a^{k}+\beta_{1}^{k} \cdot \overline{r x}_{t, t+1}+\beta_{2}^{k} \cdot H M L_{-} \Delta c_{t, t+1}+\varepsilon_{t, t+1}^{k}
$$

Hence, to obtain estimates $\beta_{2, t}^{k}$, we run regression (15) using time series that span the preceding 20 quarters; i.e. the quarters from $t-19$ to $t$. Because of this rolling window estimation procedure, the first five years of observations are lost, such that the analysis covers the pe- 
riod from 1995(1) to 2010(4). Table A.6 reveals that portfolios of currencies with a high $\beta_{2}^{k}$, i.e. currencies that at a given point in time load heavily on the risk factor $H M L_{\Delta c}$, pay higher returns on average and have experienced higher consumption growth rates over the preceding year. This confirms our result that high-consumption-growth currency portfolios are more exposed to global risk than low-consumption-growth portfolios. Third, in the same spirit as Mancini, Ranaldo and Wrampelmeyer (2013), we add average portfolio forward discounts, $f_{t, t+1}^{j}-s_{t+1}^{j}$, as an explanatory variable when regressing portfolio average currency excess returns, $r x_{t, t+1}^{j}$, on the dollar risk factor and on the consumption carry factor. Table A.7 reveals that all $H M L_{\Delta c}$ betas remain nearly unchanged. Fourth, we calculate real currency excess returns, $r x_{t, t+1}^{k, r e a l}=f_{t, t+1}^{k}-s_{t+1}^{k}-\Delta p_{t, t+1}^{U S}$, to obtain portfolio average returns and the pricing factors. Subtracting inflation from currency returns reduces these returns such that the low past consumption growth currency portfolios offer negative real returns on average. But all the asset pricing results remain virtually unchanged, see tables A.11, A.12, A.13. We also use different data samples to build currency portfolios and to run our asset pricing exercise. Tables A.14-A.19 show that our results are robust to the omission of the recent global financial crisis, and that they hold in a longer data sample that starts in 1986 already. Further, we estimate the model with alternative base currencies. Using the Swiss franc, the Canadian dollar, the British Pound, the Norwegian krone or the Australian dollar as base currencies, we obtain very similar results to those using the US dollar. By way of example, results for the Swiss franc are presented in Tables A.23, A.24, A.25). Finally, we only use the most traded currencies to build consumption growth portfolios. The most traded currencies are the Australian dollar, Canadian dollar, Swiss franc, Euro, British pound, Hong-Kong dollar, Japanese yen, Mexican peso, Norwegian krone, New Zealand dollar, Swedish krone, and the US dollar (USD). We sort these currencies into 3 portfolios. Again, as shown in Tables A.20, A.21, A.22 average currency portfolio returns increase monotonically from the low past consumption growth portfolio to the high past consumption growth portfolio, high consumption growth currencies load more positively on the consumption carry factor $H M L_{\Delta c}$, and $H M L_{\Delta c}$ carries a significantly positive risk price, whereas the dollar risk factor, $\overline{r x}$, is not priced. 


\section{Summary and conclusion}

In this paper, we have suggested a new, consumption-based factor for pricing currency returns. Our factor, which we refer to as the consumption carry factor or $H M L_{\Delta c}$, is based on sorting currencies into portfolios based on past consumption growth and reflects the excess return of borrowing in countries with the lowest consumption growth in the world over the past year and investing in the currencies of countries that have experienced relative consumption booms over the last year. $H M L_{\Delta c}$ is a global risk factor in the sense that it successfully explains the world cross section of currencies - for portfolios sorted on either past consumption growth or on forward discounts as well as for individual currency pairs. In fact, we show that currencies with high past consumption growth trade at high forward discounts, so that countries with consumption booms appreciate much more than uncovered interest parity (UIP) would imply, whereas countries with low past consumption growth appreciate by less than is implied by UIP. These excess returns on consumption boom currencies are a compensation for the higher exposure of these currencies with respect to our global factor: high-consumption-growth currencies depreciate more during times of aggregate distress, exposing investors to global risk. The consumption carry factor $H M L_{\Delta c}$ is as effective as other, purely financial factors that have been proposed in the recent literature.

Our results are built on minimal theoretical restrictions and, in particular, are free of any specific assumptions about preferences. They therefore provide strong independent evidence that risk associated with longer- to medium-term movements in consumption are a key driver of the cross section of currency returns. While our results impose minimal restrictions on preferences, we showed that they can be interpreted in the context of a consumption-based habit formation model. In the habit model, sorting currencies on past consumption growth is akin to sorting countries according to their risk aversion: countries with high (low) past consumption growth have high (low) surplus consumption ratios and low (high) risk aversion. Global consumption shocks therefore load more (less) strongly on marginal utility in low (high) consumption growth countries, and optimal risk sharing requires that these currencies should appreciate (depreciate) in worldwide downturns - as we find in the data. 


\section{References}

Baba, Naohiko, Yuji Sakurai, and Frank Packer. 2012. “Foreign Exchange Futures, Forwards, and Swaps." Handbook of Exchange Rates, , ed. I. W. Marsh J. James and L. Sarno, 623-645. in James, Jessica, Marsh, Ian W. \& Sarno, Lucio, eds. Handbook of Exchange Rates, John Wiley \& Sons, Inc.

Backus, David K., and Gregor W. Smith. 1993. "Consumption and real exchange rates in dynamic economies with non-traded goods." Journal of International Economics, 35(3-4): 297 316.

Bansal, Ravi, and Amir Yaron. 2004. "Risks for the Long Run: A Potential Resolution of Asset Pricing Puzzles." The Journal of Finance, 59(4): 1481-1509.

Brunnermeier, Markus K., Stefan Nagel, and Lasse H. Pedersen. 2008. "Carry Trades and Currency Crashes." National Bureau of Economic Research Working Paper.

Burnside, Craig, Martin Eichenbaum, Isaac Kleshchelski, and Sergio Rebelo. 2011. “Do Peso Problems Explain the Returns to the Carry Trade?" Review of Financial Studies, 24(3): 853-891.

Campbell, John Y., and John Cochrane. 1999. "Force of Habit: A Consumption-Based Explanation of Aggregate Stock Market Behavior." Journal of Political Economy, 107(2): 205-251.

Christiansen, Charlotte, Angel Ranaldo, and Paul Soederlind. 2001. “The Time Varying Systematic Risk of Carry Trade Strategies." Journal of Financial and Quantitative Analysis, 46: 11071125.

Cochrane, John H. 2005. Asset Pricing. Princeton University Press, Princeton and Oxford.

Colacito, Riccardo, and Mariano M. Croce. 2011. “Risks for the Long Run and the Real Exchange Rate." Journal of Political Economy, 119(1): 153 - 181.

Engel, Charles. 1996. "The forward discount anomaly and the risk premium: A survey of recent evidence." Journal of Empirical Finance, 3(2): 123 - 192.

Fama, Eugene F. 1984. "Forward and spot exchange rates." Journal of Monetary Economics, 14(3): $319-338$. 
Fama, Eugene F., and Kenneth R. French. 1989. “Business conditions and expected returns on stocks and bonds." Journal of Financial Economics, 25(1): 23 - 49.

Fama, Eugene F., and Kenneth R. French. 1993. "Common risk factors in the returns on stocks and bonds." Journal of Financial Economics, 33(1): 3-56.

Habib, Maurizio Michael, and Livio Stracca. 2011. “Getting beyond carry trade: what makes a safe haven currency?" European Central Bank Working Paper.

Jagannathan, Ravi, and Yong Wang. 2007. "Lazy Investors, Discretionary Consumption, and the Cross-Section of Stock Returns." Journal of Finance, 62(4): 1623-1661.

Jorda, Oscar, and Alan M. Taylor. 2009. “The Carry Trade and Fundamentals: Nothing to Fear But FEER Itself." National Bureau of Economic Research Working Paper.

King, Michael R., Carol Osler, and Dagfinn Rime. 2011. “Foreign exchange market structure, players and evolution." Norges Bank Working Paper.

Kollmann, Robert. 1995. “Consumption, real exchange rates and the structure of international asset markets." Journal of International Money and Finance, 14(2): 191 - 211.

Lettau, Martin, and Sydney Ludvigson. 2001. "Resurrecting the (C)CAPM: A Cross-Sectional Test When Risk Premia Are Time-Varying." Journal of Political Economy, 109(6): 1238-1287.

Lewis, Karen K. 1995. "Puzzles in international financial markets.” 1913-1917. in Grossmann, Gene M. \& Rogoff, Kenneth, eds. Handbook of International Economics. Elsevier, North Holland, Amsterdam, New York and Oxford.

Lustig, Hanno N., and Adrien Verdelhan. 2007. “The Cross Section of Foreign Currency Risk Premia and Consumption Growth Risk." American Economic Review, 97(1): 89 - 117.

Lustig, Hanno N., Nikolai L. Roussanov, and Adrien Verdelhan. 2011. “Common Risk Factors in Currency Markets." The Review of Financial Studies, 24(11): 3731-3777.

Mancini, Loriano, Angelo Ranaldo, and Jan Wrampelmeyer. 2013. "Liquidity in the Foreign Exchange Market: Measurement, Commonality, and Risk Premiums." forthcoming in Journal of Finance. 
Meese, Richard A., and Kenneth Rogoff. 1983. "Empirical exchange rate models of the seventies: Do they fit out of sample?" Journal of International Economics, 14(1-2): $3-24$.

Menkhoff, Lukas, Lucio Sarno, Maik Schmeling, and Andreas Schrimpf. 2012a. "Carry Trades and Global Foreign Exchange Volatility." Journal of Finance, 67(2): 681 - 718.

Menkhoff, Lukas, Lucio Sarno, Maik Schmeling, and Andreas Schrimpf. 2012b. “Currency Risk Premia and Macro Fundamentals." Manuscript, September 17.

Newey, Whitney K, and Kenneth D West. 1987. "A Simple, Positive Semi-definite, Heteroskedasticity and Autocorrelation Consistent Covariance Matrix." Econometrica, 55(3): 70308.

Nozaki, Masahiro. 2010. “Do Currency Fundamentals Matter for Currency Speculators?” International Monetary Fund (IMF) Working Paper.

Parker, Jonathan A., and Christian Julliard. 2005. "Consumption Risk and the Cross Section of Expected Returns." Journal of Political Economy, 113(1): pp. 185-222.

Ranaldo, Angelo, and Paul Soderlind. 2010. "Safe Haven Currencies." Review of Finance, 14(3): 385-407.

Verdelhan, Adrien. 2010. "A Habit-Based Explanation of the Exchange Rate Risk Premium." The Journal of Finance, 65(1): 123-146.

Verdelhan, Adrien. 2011. "The Share of Systematic Risk in Bilateral Exchange Rates." available at SSRN: http:/ / ssrn.com/abstract=1930516 Working Paper. 
Figure 1: $H M L_{\Delta c}$ and consumption growth
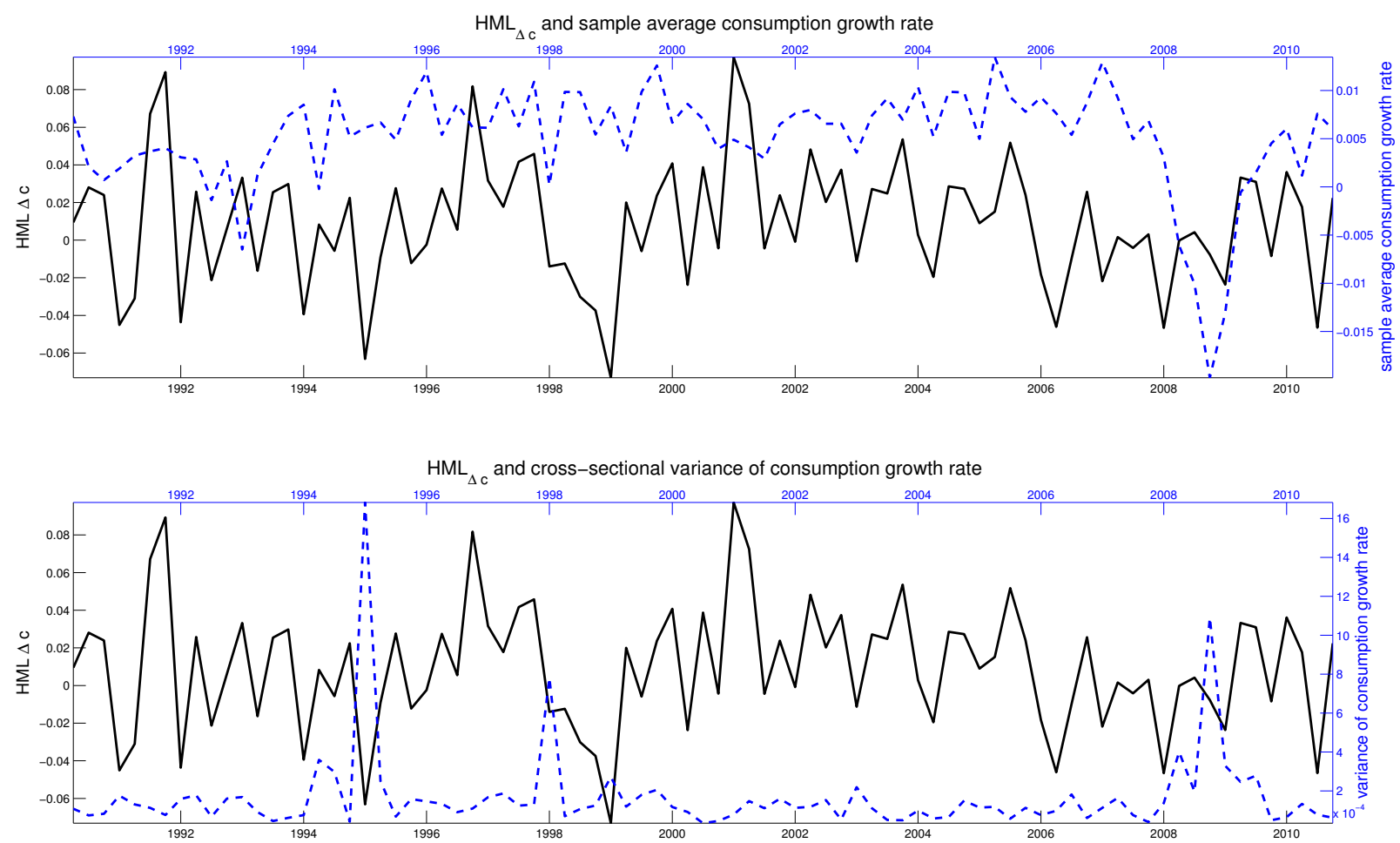

The black solid line plots the consumption carry trade return $H M L_{\Delta c}$, and the blue, dotted line shows the sample average consumption grotwh rate in the upper figure, and the cross-sectional variance of consumption growth in the lower figure. The $H M L_{\Delta c}$ factor is the cross-country average return a global investor obtains when she borrows in the currencies of countries which experienced low consumption growth over the last year and invests in currencies of countries with high past consumption growth. The data is at quarterly frequency and encompasses the OECD sample specified in the main text. 
Figure 2: $H M L_{F X}$ against $H M L_{\Delta c}$

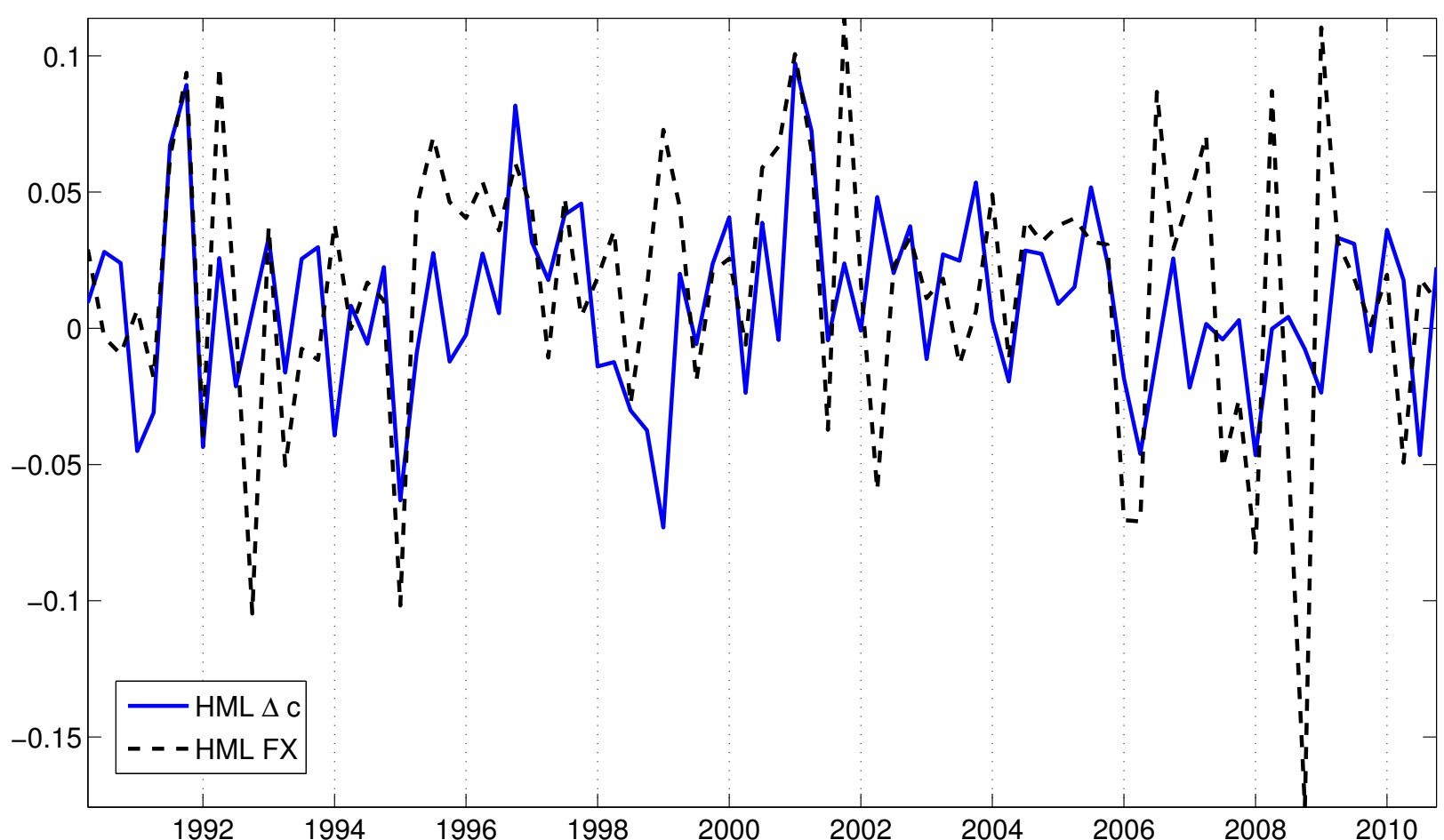

The blue solid line plots the consumption carry trade factor $H M L_{\Delta c}$, and the black, dotted line shows the Lustig et al. (2011) carry trade factor $H M L_{F X}$. The $H M L_{\Delta c}$ factor is the cross-country average return a global investor obtains when she borrows in the currencies of countries which experienced low consumption growth over the last year and invests in currencies of countries with high past consumption growth. The $H M L_{F X}$ factor corresponds to the return obtained from borrowing in low interest rate currencies and lending in high interest rate currencies. Both factors have been constructed from quarterly data which encompass the OECD sample specified in the main text. 
Figure 3: time series estimates of $\beta_{H M L \_\Delta c}^{j}$ against mean currency portfolio returns

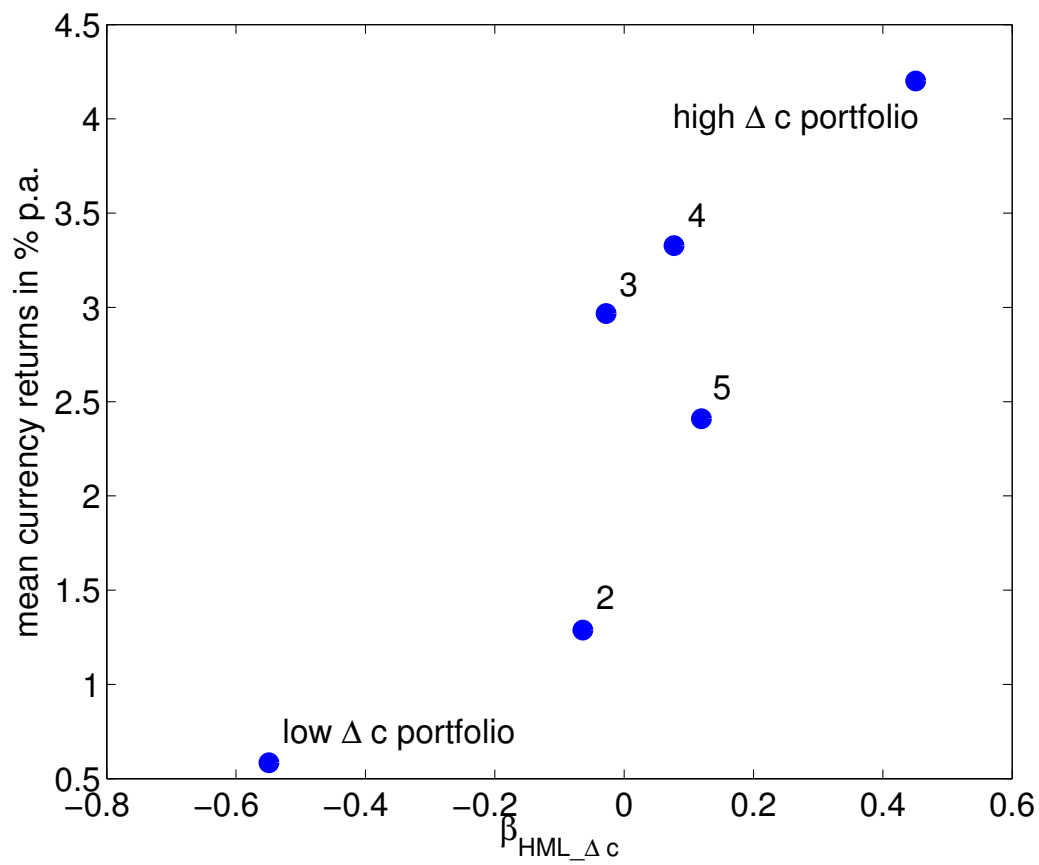

Running the following time series regression for each currency portfolio $j$ separately,

$$
r x_{t+1}^{j}=\alpha^{j}+\beta_{\overline{r x}}^{j} \cdot \overline{r x}_{t+1}+\beta_{H M L \_\Delta c}^{j} \cdot H M L_{-} \Delta c_{t+1}+\varepsilon_{t+1}^{j}
$$

this figure plots the estimate of $\beta_{2}^{j}$ on the horizontal axis against mean portfolio returns $(1 / T) \sum_{t=1}^{T} r x_{t}^{j}$ on the vertical axis. 
Figure 4: actual vs fitted mean consumption growth sorted currency portfolio returns

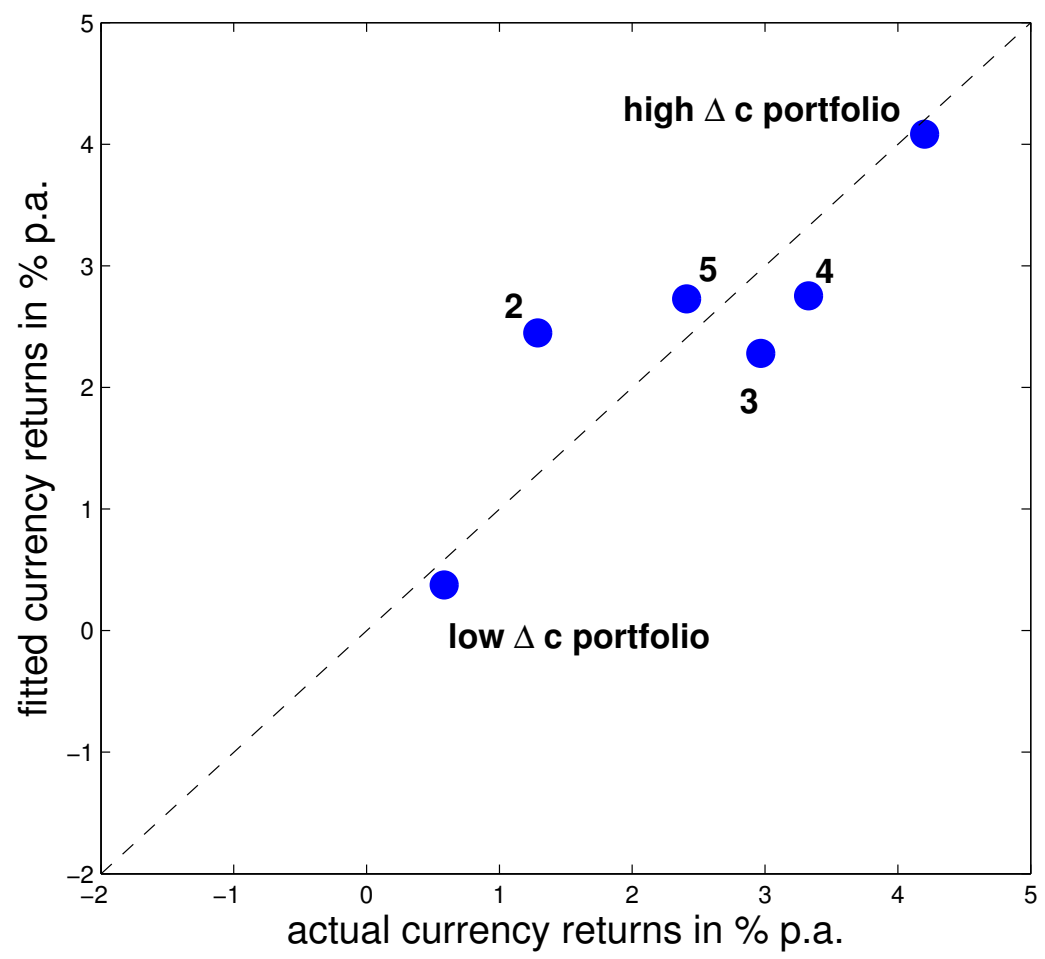

On the horizontal axis, this figure shows actual mean consumption growth sorted currency portfolio returns, on the vertical axis, the returns predicted by the model are shown. As described in section (5.1), the model is given by $\boldsymbol{E}\left(M_{t+1} r x_{t+1}^{j}\right)=0$ and $M_{t}=1-\boldsymbol{b}^{\prime}\left(f_{t}-\boldsymbol{E}(\boldsymbol{f})\right)$. Factors $f$ included in the analysis are $\overline{r x}$ and $H M L_{\Delta c}$ as described in the text. 

Table 1: currency portfolios sorted on previous year consumption growth

\begin{tabular}{|c|c|c|c|c|c|c|c|c|}
\hline portfolio $j$ & low & 2 & 3 & 4 & 5 & high & $\overline{r x}$ & $H M L_{\Delta c}$ \\
\hline & \multicolumn{8}{|c|}{ excess return: $r x^{j}$} \\
\hline mean & 0.5843 & 1.2882 & 2.9673 & 3.3275 & 2.4090 & 4.2012 & 2.4521 & 3.6169 \\
\hline std & 19.3868 & 21.3215 & 19.7383 & 20.9398 & 18.7540 & 19.8020 & 18.0767 & 13.3143 \\
\hline \multirow[t]{2}{*}{ Sharpe ratio } & 0.0301 & 0.0604 & 0.1503 & 0.1589 & 0.1285 & 0.2122 & 0.1356 & 0.2717 \\
\hline & \multicolumn{8}{|c|}{ spot change: $\Delta s^{j}$} \\
\hline mean & 0.9662 & 0.0817 & -1.4008 & -1.3396 & -0.8545 & -1.6124 & & \\
\hline \multirow[t]{2}{*}{ std } & 19.5364 & 21.1760 & 19.9418 & 20.9312 & 18.4037 & 19.8600 & & \\
\hline & \multicolumn{8}{|c|}{ consumption growth: $\Delta c_{t-4, t}^{j}$} \\
\hline mean & -1.2237 & 0.6728 & 1.5040 & 2.2225 & 3.0734 & 5.1521 & & \\
\hline \multirow[t]{2}{*}{ std } & 3.2260 & 1.5270 & 1.3992 & 1.3506 & 1.3734 & 1.8136 & & \\
\hline & \multicolumn{8}{|c|}{ forward discount: $f^{j}-s^{j}$} \\
\hline mean & 0.0039 & 0.0034 & 0.0039 & 0.0050 & 0.0039 & 0.0065 & & \\
\hline std & 0.0075 & 0.0058 & 0.0059 & 0.0065 & 0.0058 & 0.0058 & & \\
\hline
\end{tabular}

This table presents descriptive statistics for the returns a US investor obtains from investing in different currency portfolios. At the beginning of each quarter, currencies are sorted into six portfolios based on the associated countries' consumption growth rates over the preceding four quarters. The first portfolio always contains currencies of countries with the lowest sixtile of consumption growth rates, and the sixth portfolio always contains currencies of countries with the highest sixtile of consumption growth rates. The second last column presents the average return a US investor obtains when borrowing in US dollars and investing in equal weights into all currencies, this return is labelled $\overline{r x}_{t, t+1}$. The last column shows descriptive statistics for the consumption-based carry trade portfolio $H M L_{\Delta c}$ which is given by a short position in all currencies of the low consumption growth portfolio and a long position in the currencies of the high consumption growth portfolio. Portfolio excess returns are calculated as $r x_{t, t+1}^{j}=f_{t, t+1}^{j}-s_{t}^{j}-\Delta s_{t+1}^{j}$, where $r x_{t, t+1}^{j}$ is the average quarterly return from borrowing in US dollars and investing in equal weights in all currencies of portfolio $j . f_{t, t+1}^{j}$ is the average of the log $3 \mathrm{M}$ forward exchange rate of the currencies in portfolio $j$ against the US dollar, and $\Delta s_{t, t+1}^{j}$ is the portfolio average of the log difference of the spot exchange rate between dates $t$ and $t+1 . f_{t}^{j}-s_{t}^{j}$ is the average forward discount of the currencies in portfolio $j$ against the US dollar. Exchange rates are in direct quotation, i.e. an increase in $s^{j}$ implies a depreciation of the currencies in portfolio $j$ against the US dollar. Except for the forward discounts, all statistics are presented in percentages per annum. The data sample encompasses the OECD country set specified in the main text and in the appendix, and it spans the period from 1990(1) to 2010(4). The data is at quarterly frequency. 
Table 2: factor betas

\begin{tabular}{lllcr}
\hline \multirow{2}{*}{ low } & $a^{j}$ & $\beta_{\overline{r x}}^{j}$ & $\beta_{H M L \_c}^{j}$ & $\bar{R}^{2}$ \\
\cline { 2 - 5 } 2 & 0.0015 & $0.9895^{* * *}$ & $-0.5490^{* * *}$ & \\
& $(0.0012)$ & $(0.0349)$ & $(0.0506)$ & 0.94 \\
& $0.0032^{*}$ & $1.1018^{* * *}$ & -0.0638 & 0.87 \\
3 & $(0.0020)$ & $(0.0491)$ & $(0.0633)$ & \\
& $0.0074^{* * *}$ & $0.9782^{* * *}$ & -0.0278 & 0.80 \\
4 & $(0.0026)$ & $(0.0728)$ & $(0.0737)$ & 0.77 \\
& $0.0083^{* * *}$ & $1.0123^{* * *}$ & 0.0773 & \\
5 & $(0.0029)$ & $(0.0660)$ & $(0.0939)$ & 0.83 \\
& $0.0060^{* * *}$ & $0.9378^{* * *}$ & $0.1195^{* *}$ & \\
\multirow{2}{*}{ high } & $(0.0017)$ & $(0.0428)$ & $(0.0648)$ & 0.95 \\
\hline
\end{tabular}

This table shows estimates and standard errors obtained from running the following time series regression for each currency portfolio $j$ separately:

$$
r x_{t, t+1}^{j}=a^{j}+\beta_{\overline{r x}}^{j} \cdot \overline{r x}_{t, t+1}+\beta_{H M L_{-} \Delta c}^{j} \cdot H M L_{-} \Delta c_{t, t+1}+\varepsilon_{t, t+1}^{j}
$$

Standard errors are corrected for serial correlation using the Newey and West (1987) estimator for the covariance matrix of the error terms $\varepsilon_{t, t+1}^{j}$. 
Table 3: risk price and factor loadings

\begin{tabular}{lllll}
\hline & $\lambda_{\overline{r x}}$ & $\lambda_{H M L \_\Delta c}$ & $b_{\overline{r x}}$ & $b_{H M L \_c}$ \\
\hline OLS estimate & 0.0061 & $0.0093^{* * *}$ & 2.5914 & $8.2184^{* * *}$ \\
standard error & $(0.0050)$ & $(0.0041)$ & $(2.6509)$ & $(3.9283)$ \\
\cline { 2 - 5 } $\begin{array}{l}\text { pricing error test } \\
R^{2}\end{array}$ & & 0.7319 & & 0.7060 \\
\hline GLS estimate & 0.0061 & $0.0092^{* * *}$ & 2.7358 & 0.74 \\
standard error & $(0.0052)$ & $(0.0039)$ & $(2.4047)$ & $8.6663^{* * *}$ \\
pricing error test & & 0.72 & & $(3.7474)$ \\
\hline
\end{tabular}

This first two columns of this table report results from estimating the following cross-sectional regression:

$$
\boldsymbol{E}\left(r x^{j}\right)=\beta_{\overline{r x}}^{j} \cdot \lambda_{\overline{r x}}+\beta_{H M L_{-} \Delta c}^{j} \cdot \lambda_{H M L_{-} \Delta c}+\alpha^{j}
$$

$\beta_{\overline{T x}}^{j}$ and $\beta_{H M L \triangle \Delta c}^{j}$ correspond to the estimates obtained from running time series regressions of portfolio returns on the risk factors as reported in Table (2). Here, the factor $\beta$ s and the prices of risk $\lambda_{\overline{r x}}$ and $\lambda_{H M L} \triangle \Delta c$ have been estimated jointly using GMM. This approach yields standard errors which correct for the fact that the $\beta$ s are estimates. The third and the fourth column of this table report results from estimating the following cross-sectional regression:

$$
\boldsymbol{E}\left(r x^{j}\right)=\operatorname{cov}\left(\overline{r x}, r x^{j}\right) \cdot b_{\overline{r x}}+\operatorname{cov}\left(H M L_{-} \Delta c, r x^{j}\right) \cdot b_{H M L \_\Delta c}+\alpha^{j}
$$

where again, covariances and factor loadings $b$ have been estimated jointly using GMM. Let $\mu^{j}=\frac{1}{T} \sum_{t=1}^{T} r x_{t}^{j}$ denote the (time-) average return on portfolio $j$ and $\mu=\left[\begin{array}{llll}\mu^{1}, & \mu^{2}, & \ldots & \mu^{J}\end{array}\right]^{\prime}$ the $J \times 1$ vector stacking these average returns. Furthermore, let $\bar{\mu}=\frac{1}{T} \sum_{j=1}^{J} \mu^{j}=\mu^{\prime} \mathbf{1} / J$ where $\mathbf{1}$ is a $J \times 1$ vector of ones. Then $R^{2}$ measures are obtained using $R^{2}=1-\frac{\hat{\alpha}^{\prime} \hat{\alpha}}{(\mu-\bar{\mu})^{\prime}(\mu-\bar{\mu} \mathbf{1})}$ where $\hat{\alpha}=\left[\begin{array}{llll}\alpha^{1}, & \alpha^{2}, \quad \ldots \quad \alpha\end{array}\right]^{\prime}$ is the vector of average portfolio $j$ pricing errors $\alpha^{j}$ given by $\alpha^{j}=\overline{r x}^{j}-\operatorname{cov}\left(\hat{f}, r x^{j}\right)^{\prime} \hat{\boldsymbol{b}}=\overline{r x}^{j}-\widehat{\boldsymbol{\beta}}^{j} \hat{\lambda}$ where $\beta^{j}=\left[\begin{array}{ll}\beta_{\overline{r x}}^{j} & \beta_{H M L \_\Delta c}^{j}\end{array}\right]^{\prime}$ and $\lambda^{j}=\left[\begin{array}{ll}\lambda_{\overline{r x}}^{j} & \lambda_{H M L \_\Delta c}^{j}\end{array}\right]^{\prime}$. Hats denote estimates. The pricing error test reports the $\mathrm{p}$-value for the null that the pricing errors are jointly zero. 
Table 4: descriptive statistics of candidate pricing factors

\begin{tabular}{|c|c|c|c|c|c|c|c|}
\hline & $H M L_{\Delta c}$ & $H M L_{F X}$ & $\overline{r x}$ & $V O L$ & MSCI world & $\operatorname{mean}\left(\Delta c_{t}\right)$ & $\operatorname{var}\left(\Delta c_{t}\right)$ \\
\hline mean & 3.6169 & 6.1482 & 2.4521 & 0.0002 & 4.8330 & 2.1380 & 26.7759 \\
\hline $\begin{array}{l}\text { standard } \\
\text { deviation }\end{array}$ & 13.3143 & 20.3838 & 18.0767 & 0.0012 & 34.7695 & 1.2203 & 35.7181 \\
\hline sharpe ratio & 0.2717 & 0.3016 & 0.1194 & - & 0.1390 & - & - \\
\hline \multirow[t]{3}{*}{ skewness } & 0.0789 & -0.8422 & 0.1356 & - & -0.7236 & -2.0409 & - \\
\hline & \multicolumn{7}{|c|}{ correlation matrix of pricing factors } \\
\hline & $H M L_{\Delta c}$ & $H M L_{F X}$ & $\overline{r x}$ & $V O L$ & MSCI world & $\operatorname{mean}(\Delta c)$ & $\operatorname{var}(\Delta c)$ \\
\hline \multirow[t]{2}{*}{$H M L_{\Delta c}$} & 1 & $0.3611^{* * *}$ & 0.0706 & -0.2232 & -0.1246 & 0.0522 & $-0.2974^{* * *}$ \\
\hline & & $(0.0007)$ & $(0.5257)$ & $(0.0426)$ & $(0.2617)$ & $(0.6395)$ & $(0.0063)$ \\
\hline \multirow[t]{2}{*}{$H M L_{F X}$} & & 1 & 0.1227 & $-0.5583^{* * *}$ & 0.0423 & 0.2081 & $-0.3333^{* * *}$ \\
\hline & & & $(0.2690)$ & $(0.0000)$ & $(0.7044)$ & $(0.0591)$ & $(0.0021)$ \\
\hline \multirow[t]{2}{*}{$\overline{r x}$} & & & 1 & -0.2709 & 0.0550 & $0.2401^{* * *}$ & -0.0460 \\
\hline & & & & $(0.0132)$ & $(0.6215)$ & $(0.0288)$ & $(0.6794)$ \\
\hline \multirow[t]{2}{*}{$V O L$} & & & & 1 & -0.1000 & $-0.2550^{* * *}$ & $0.3389^{* * *}$ \\
\hline & & & & & $(0.3682)$ & $(0.0200)$ & $(0.0017)$ \\
\hline \multirow[t]{2}{*}{ MSCI world } & & & & & 1 & 0.1588 & -0.0270 \\
\hline & & & & & & $(0.1515)$ & $(0.8086)$ \\
\hline \multirow[t]{2}{*}{$\operatorname{mean}(\Delta c)$} & & & & & & 1 & $-0.3695^{* * *}$ \\
\hline & & & & & & & $(0.0006)$ \\
\hline $\operatorname{var}(\Delta c)$ & & & & & & & 1 \\
\hline
\end{tabular}

This table presents descriptive statistics as well as the cross-correlation matrix of different pricing factors used in asset pricing models. All factors (except the return of the MSCI world index) have been constructed using the quarterly OECD data set over the period from 1990(1) to 2010(4). The factors $H M L_{\Delta c}$ and $H M L_{F X}$ are the difference in the returns of high and low consumption growth and forward discount sorted currency portfolios. The foreign exchange volatiliy innovation factor $V O L$ is constructed as described in Menkhoff et al. 2012a]. The factors mean $(\Delta c)_{t}$ and $\operatorname{var}(\Delta c)_{t}$ are the cross-sectional mean and variance of quarterly consumption growth rates measured over the quarter from $t$ to $t+1$. The variable MSCI world corresponds to the growth rate (log difference) of the MSCI world index, of which end of quarter values have been downloaded from http://www.msci.com/products/indices/performance.html on January 21, 2013. All moments are reported in percentages per annum, only for the volatiliy factor $V O L$, the mean and the standard deviation are quarterly values. In the lower panel, the numbers reported in parentheses are p-values for the null that the correlation between two risk factors is zero. If the $\mathrm{p}$-value is small, say less than 0.05 , then a particular correlation is significantly different from zero. 
Table 5: forward discount sorted currency portfolios and alternative risk factors

\begin{tabular}{|c|c|c|c|c|c|c|}
\hline & \multicolumn{4}{|c|}{ Factor Prices $\lambda$} & \multirow[b]{2}{*}{$\mathrm{p}$-value } & \multirow[b]{2}{*}{$R^{2}$} \\
\hline & $\overline{r x}$ & $H M L_{\Delta c}$ & $H M L_{F X}$ & $V O L$ & & \\
\hline Estimate & 0.0061 & $0.0227^{* * *}$ & & & & \\
\hline standard error & $(0.0050)$ & $(0.0112)$ & & & 0.4229 & 0.78 \\
\hline Estimate & 0.0060 & & $0.0154^{* * *}$ & & & \\
\hline standard error & $(0.0050)$ & & $(0.0053)$ & & 0.7489 & 0.87 \\
\hline Estimate & 0.0058 & & & $-0.0006^{* * *}$ & & \\
\hline standard error & $(0.0051)$ & & & $(0.0003)$ & 0.5133 & 0.80 \\
\hline
\end{tabular}

This table reports the results obtained from estimating the following asset pricing model using three different sets of pricing factors

$$
\boldsymbol{E}\left(r x^{j}\right)=\boldsymbol{\beta}^{j \prime} \lambda
$$

Pricing factors are the mean dollar currency return $\overline{r x}$ plus either the consumption-based carry trade factor $H M L_{\Delta c}$, or the forwarddiscount based carry trade factor $H M L_{F X}$, which has been suggested by Lustig, Roussanov and Verdelhan (2011), or the FX volatiliy innovation factor $V O L$, which has been proposed by Menkhoff et al. (2012a). $V O L$ is the innovation to global FX volatiliy and is constructed as described in their paper (p. 692). As in Lustig, Roussanov and Verdelhan (2011) and Menkhoff et al. (2012a), test assets are six forward discount sorted currency portfolios. The data encompasses the OECD countries specified in the main text, and it spans the period from 1990(1) to 2010(4). For each model, the pricing error test reports the p-value for the null that the pricing errors are jointly zero. The $R^{2}$ measure is obtained as described in the notes of table 3 . 


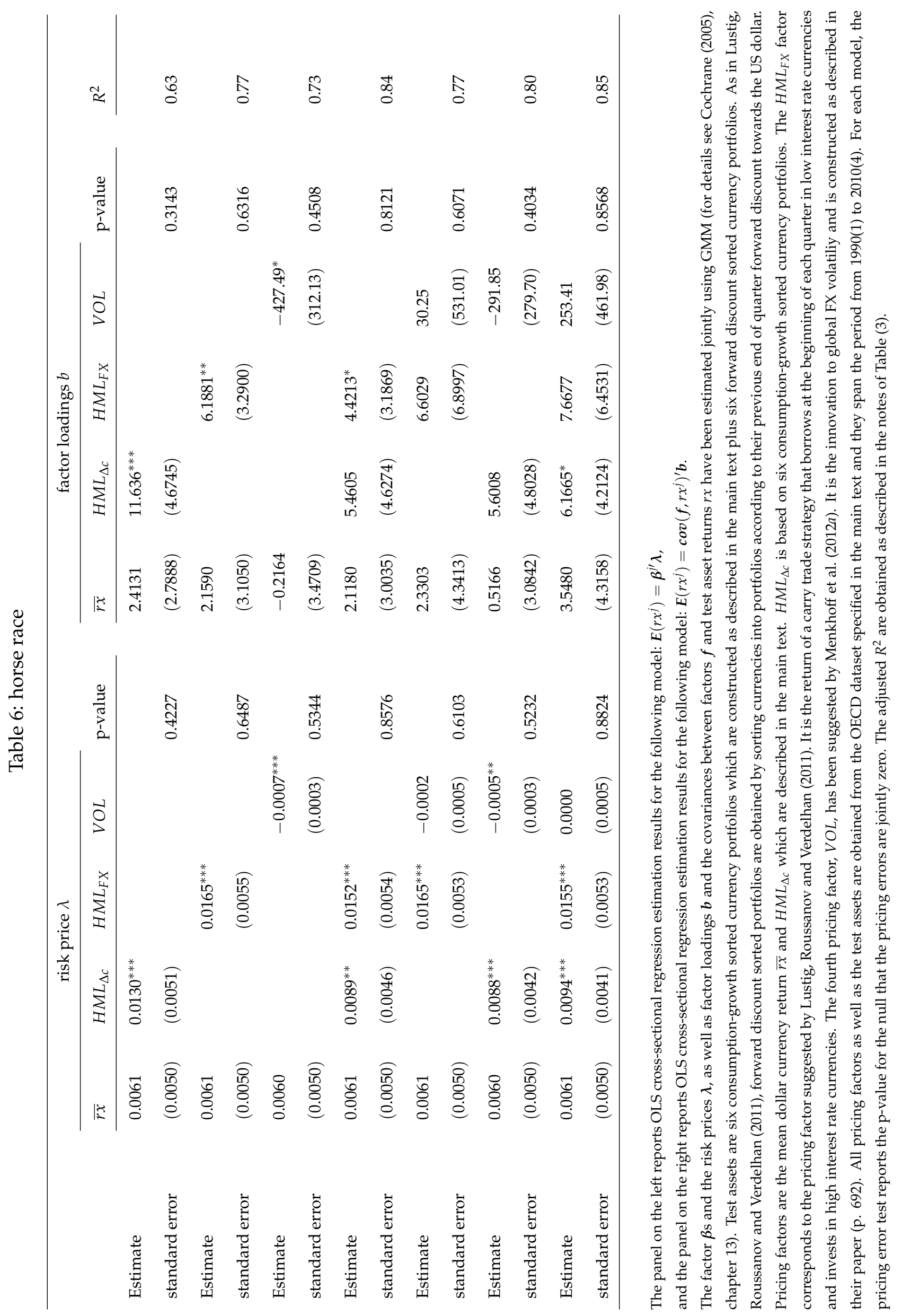


Table 7: pricing the cross-section of individual currencies: panel estimation

\begin{tabular}{|c|c|c|c|c|c|c|c|}
\hline & $\gamma_{1}$ & $\gamma_{2}$ & $\gamma_{3}$ & $\gamma_{4}$ & $\tau_{t}$ & $\delta^{k}$ & $R^{2}$ \\
\hline & \multicolumn{7}{|c|}{$r x_{t, t+1}^{k}=a+\gamma_{1}\left(\Delta c_{t-4, t}^{k}-\Delta c_{t-4, t}^{U S}\right)+\gamma_{2}\left(\Delta c_{t-4, t}^{k}-\Delta c_{t-4, t}^{U S}\right) \cdot\left(H M L_{\Delta c}\right)_{t, t+1}+\gamma_{3}\left(H M L_{\Delta c}\right)_{t, t+1}+\gamma_{4} \overline{r x}_{t, t+1}+\epsilon_{t, t+1}$} \\
\hline estimate & $0.1664^{* * *}$ & $8.2512^{* * *}$ & -0.0401 & $0.8 \mathrm{~s}$ & & & \\
\hline \multirow[t]{2}{*}{ se } & $(0.0652)$ & $(2.3891)$ & $(0.0541)$ & $(0.0$ & & & 0.53 \\
\hline & \multicolumn{7}{|c|}{$r x_{t, t+1}^{k}=\gamma_{1}\left(\Delta c_{t-4, t}^{k}-\Delta c_{t-4, t}^{U S}\right)+\gamma_{2}\left(\Delta c_{t-4, t}^{k}-\Delta c_{t-4, t}^{U S}\right) \cdot\left(H M L_{\Delta c}\right)_{t, t+1}+\tau_{t . t+1}+\delta^{k}+\epsilon_{t, t+1}$} \\
\hline estimate & $0.1257^{*}$ & $13.3064^{* * *}$ & & & yes & yes & \\
\hline \multirow[t]{2}{*}{ se } & $(0.0802)$ & $(3.0713)$ & & & & & 0.51 \\
\hline & \multicolumn{7}{|c|}{$-\Delta s_{t, t+1}^{k}=a+\gamma_{1}\left(\Delta c_{t-4, t}^{k}-\Delta c_{t-4, t}^{U S}\right)+\gamma_{2}\left(\Delta c_{t-4, t}^{k}-\Delta c_{t-4, t}^{U S}\right) \cdot\left(H M L_{\Delta c}\right)_{t, t+1}+\gamma_{3}\left(H M L_{\Delta c}\right)_{t, t+1}+\gamma_{4} \overline{r x}_{t, t+1}+\epsilon_{t, t+1}$} \\
\hline estimate & $0.1299^{* *}$ & $8.5076^{* * *}$ & -0.0400 & $0.8 \mathrm{~s}$ & & & \\
\hline \multirow[t]{2}{*}{ se } & 0.0692 & 2.4113 & 0.0544 & 0.05 & & & 0.52 \\
\hline & \multicolumn{7}{|c|}{$-\Delta s_{t, t+1}^{k}=\gamma_{1}\left(\Delta c_{t-4, t}^{k}-\Delta c_{t-4, t}^{U S}\right)+\gamma_{2}\left(\Delta c_{t-4, t}^{k}-\Delta c_{t-4, t}^{U S}\right) \cdot\left(H M L_{\Delta c}\right)_{t, t+1}+\tau_{t . t+1}+\delta^{k}+\epsilon_{t, t+1}$} \\
\hline estimate & $0.1336^{* *}$ & $13.0077^{* * *}$ & & & yes & yes & \\
\hline \multirow[t]{2}{*}{ se } & $(0.0790)$ & $(3.0872)$ & & & & & 0.50 \\
\hline & \multicolumn{7}{|c|}{$-\Delta q_{t, t+1}^{k}=a+\gamma_{1}\left(\Delta c_{t-4, t}^{k}-\Delta c_{t-4, t}^{U S}\right)+\gamma_{2}\left(\Delta c_{t-4, t}^{k}-\Delta c_{t-4, t}^{U S}\right) \cdot\left(H M L_{\Delta c}\right)_{t, t+1}+\gamma_{3}\left(H M L_{\Delta c}\right)_{t, t+1}+\gamma_{4} \overline{r x}_{t, t+1}+\epsilon_{t, t+1}$} \\
\hline estimate & $0.1299^{* *}$ & $8.5076^{* * *}$ & -0.0400 & $0.8 \mathrm{~s}$ & & & \\
\hline \multirow[t]{2}{*}{ se } & 0.0692 & 2.4113 & 0.0544 & 0.05 & & & 0.52 \\
\hline & \multicolumn{7}{|c|}{$-\Delta q_{t, t+1}^{k}=\gamma_{1}\left(\Delta c_{t-4, t}^{k}-\Delta c_{t-4, t}^{U S}\right)+\gamma_{2}\left(\Delta c_{t-4, t}^{k}-\Delta c_{t-4, t}^{U S}\right) \cdot\left(H M L_{\Delta c}\right)_{t, t+1}+\tau_{t . t+1}+\delta^{k}+\epsilon_{t, t+1}$} \\
\hline estimate & $0.1637^{* * *}$ & $12.8704^{* * *}$ & & & yes & yes & \\
\hline se & $(0.0796)$ & $(3.0811)$ & & & & & 0.50 \\
\hline
\end{tabular}

The table reports results from the panel regressions presented at the top of each sub-panel. Here a description of the variables: $r x_{t, t+1}^{k}=$ $i_{t}^{k}-i_{t}^{U S}-\Delta s_{t+1}^{k}$ is the return an investor obtains by borrowing in US dollars and investing into the currency of country $k$ over the holding period form $t$ to $t+1$, which corresponds to one quarter. $\Delta c_{t-4, t}^{k}-\Delta c_{t-4, t}^{U S}$ is the four quarter consumption growth differential between country $k$ and the US, $H M L_{\Delta c}$ is the consumption based carry trade factor as described in the text, and $\delta^{k}$ and $\tau_{t}$ are countryand time fixed effects. Eventually, $\Delta s_{t, t+1}^{k}$ is the quarterly change (log difference) of the bilateral exchange rate between the currency of country $k$ and the US dollar. An increase in $s^{k}$ indicates a depreciation of the currency of country $k$ towards the US dollar. $\Delta q_{t, t+1}^{k}$ is the change of the real bilateral exchange rate respectively. The data spans the period 1990(1) - 2010(4) and includes nine single currencies for which complete time series of spot and forward exchange rates as well as consumption growth rates are available. These currencies are the Australian dollar, the Canadian dollar, the Danish krone, the Japanese yen, the New Zealand dollar, the Norwegian krone, the Swedish krone, the Swiss fanc and the UK pound. Standard errors are autocorrelation and heteroscedasticity consistent Newey and West (1987)). 
Table 8: habit model, parameter values

$\begin{array}{ll}\text { this paper } & \text { Campbell and } \\ \text { Cochrane (1999) } & \text { Verdelhan (2010) }\end{array}$

\section{calibrated parameters}

\begin{tabular}{llll}
$g(\%)$ & 0.52 & 0.74 & 0.53 \\
$\sigma(\%)$ & 1.1 & 0.75 & 0.51 \\
$\sigma_{\text {idio }}(\%)$ & 0.81 & - & - \\
$\sigma_{g l o b}(\%)$ & 0.81 & - & - \\
$\bar{r}(\%)$ & 0.24 & 0.23 & 0.34 \\
$\gamma$ & 2.00 & 2.00 & 2.00 \\
$\phi$ & 0.99 & 0.97 & 0.99 \\
$B$ & -0.01 & - & -0.01 \\
$\rho$ & & - & 0.15 \\
& & & \\
$\beta$ & implied parameters & & 1.00 \\
$\bar{S}$ & 0.99 & 0.97 & 0.07 \\
$S_{\text {max }}$ & 0.11 & 0.06 & 0.12 \\
\hline
\end{tabular}

This table presents the parameters of the habit formation model outlined in section (6) and their chosen values in this paper, in Campbell and Cochrane (1999) and in Verdelhan (2010). The data is at quarterly frequency. For this paper, the reference period is 1990(1)-2010(4) (1947-1995 in Campbell and Cochrane (1999), and 1947(2)-2004(4) in Verdelhan (2010)). The average consumption growth rate $g$ and its standard error $\sigma$ are estimated from the OECD data sample used in the main analysis of this study. The standard error of consumption growth $\sigma$ is decomposed into a global and an idiosyncratic component such that $\sigma_{\text {glob }}=\sigma_{\text {idio }}=\sigma / \sqrt{2}$, whereby we assume that countryspecific and global consumption growth shocks are uncorrelated. The quarterly real risk-free rate corresponds to the average real U.S. T-bill rate over the reference period, it is sourced from the IFS data tape (US T-bill rates corresponds to line 11160C..ZF, and consumer price inflation is calculated from 11164...ZF...). The persistence parameter $\phi$ is chosen such that the mean value of the consumption carry factor $H M L_{\Delta c}$ approximately corresponds to its sample counterpart; using real returns to calculate the consumption carry factor from our OECD data sample, we find $H M L_{\Delta c, t+1}^{\text {real }}=3.6 \%$ per year. In Verdelhan 2010), $\rho$ corresponds to the correlation of each simulated countries consumption growth shocks. 
Table 9: habit model, simulation results: currency portfolios

\begin{tabular}{|c|c|c|c|c|c|c|c|c|}
\hline portfolio $j$ & low & 2 & 3 & 4 & 5 & high & $\overline{r x}$ & $H M L_{\Delta c}$ \\
\hline & \multicolumn{8}{|c|}{ excess return: $r x^{j}$} \\
\hline mean & -2.0304 & -0.6261 & 0.0961 & 0.3569 & 0.7291 & 2.7386 & 0.2197 & 4.7690 \\
\hline std & 70.2673 & 71.0148 & 69.7664 & 69.2951 & 69.9644 & 68.3367 & 65.3018 & 39.4324 \\
\hline \multirow[t]{2}{*}{ Sharpe ratio } & -0.0289 & -0.0088 & 0.0014 & 0.0052 & 0.0104 & 0.0401 & 0.0034 & 0.1209 \\
\hline & \multicolumn{8}{|c|}{ spot change: $\Delta q^{j}$} \\
\hline mean & 1.6841 & 0.6532 & 0.1197 & 0.0082 & -0.1825 & -1.8997 & & \\
\hline \multirow[t]{2}{*}{ std } & 70.0772 & 70.8630 & 69.6082 & 69.1211 & 69.7800 & 68.1630 & & \\
\hline & \multicolumn{8}{|c|}{ consumption growth: $\Delta c_{t-4, t}^{j}$} \\
\hline mean & -0.0739 & 1.1155 & 1.7842 & 2.3969 & 3.0654 & 4.2479 & & \\
\hline \multirow[t]{2}{*}{ std } & 1.6059 & 1.5753 & 1.5680 & 1.5695 & 1.5766 & 1.6069 & & \\
\hline & \multicolumn{8}{|c|}{ surplus consumption ratio: $s_{t}$} \\
\hline mean & 0.1080 & 0.1160 & 0.1204 & 0.1240 & 0.1284 & 0.1359 & & \\
\hline \multirow[t]{2}{*}{ std } & 0.0345 & 0.0347 & 0.0347 & 0.0344 & 0.0337 & 0.0321 & & \\
\hline & \multicolumn{8}{|c|}{ interest rate differential: $r^{j}-r$} \\
\hline mean & -3.60 & 0.04 & 0.20 & 0.36 & 0.56 & 0.84 & & \\
\hline std & 1.96 & 2.00 & 2.00 & 2.00 & 1.96 & 2.04 & & \\
\hline
\end{tabular}

This table presents descriptive statistics for six currency portfolios obtained from simulated data. With the parameters presented in Table 8 and 10'000 endowment shocks, we use the habit model outlined in section (6) to generate data for 33 hypothetical countries which then are sorted into portfolios according to their consumption growth rate over the previous four periods. This procedure is analogous to the approach taken in the empirical asset pricing analysis of this paper. The first portfolio always contains countries with the lowest sixtile of consumption growth rates, and the sixth portfolio always contains countries with the highest sixtile of consumption growth rates. Currency excess returns $r x_{t, t+1}^{j}$, which an investor obtains when borrowing at home and investing into particular currency portfolios, average interest rate differentials between portfolio $j$ and the home country $r_{t, t+1}^{j}-r_{t, t+1}$, consumption growth rates $\Delta c_{t-4, t}^{j}$ and real exchange rate changes $\Delta q_{t, t+1}^{j}$ are expressed in percentage per annum. The real exchange rate is measured in units of foreign goods per home good, such that $\Delta q^{j}<0$ implies an appreciation of the foreign good. The portfolio average surplus consumption ratios $s_{t}$ refer to quarterly values. The second last column presents descriptive statistics for the simulated return the home investor gains when borrowing at home and investing each period in all the other countries of the sample, and the last column presents the returns the average (global) investor obtains when borrowing in low growth countries and investing in high growth countries: as in the main analysis of this paper, $H M L_{\Delta c}$ is given by the difference in returns of the high and the low growth portfolio. 
Table 10: habit model, asset pricing results using simulated data

\begin{tabular}{|c|c|c|c|c|}
\hline \multicolumn{5}{|c|}{ Panel A: risk prices and factor loadings } \\
\hline & $\lambda_{\overline{r x}}$ & $\lambda_{H M L_{-} \Delta c}$ & $b_{\overline{r x}}$ & $b_{H M L \_\Delta c}$ \\
\hline OLS estimate & 0.0005 & $0.0115^{* * *}$ & 0.0235 & $1.1865^{* * *}$ \\
\hline standard error & $(0.0016)$ & $(0.0010)$ & $(0.0605)$ & $(0.1025)$ \\
\hline pricing error test & \multicolumn{3}{|c|}{0.00} & 0.00 \\
\hline$R^{2}$ & \multicolumn{3}{|c|}{0.89} & 0.89 \\
\hline \multicolumn{5}{|c|}{ Panel B: time series regression } \\
\hline \multirow{3}{*}{ low } & $a^{j}$ & $\beta_{\overline{r x}}^{j}$ & $\beta_{H M L \_\Delta c}^{j}$ & $R^{2}$ \\
\hline & $-0.0051^{* * *}$ & $0.9949^{* * *}$ & $-0.5722^{* * *}$ & \\
\hline & $(0.0003)$ & $(0.0026)$ & $(0.0044)$ & 0.96 \\
\hline \multirow[t]{2}{*}{2} & $-0.0016^{* * *}$ & $1.0104^{* * *}$ & $0.0116^{*}$ & \\
\hline & $(0.0006)$ & $(0.0053)$ & $(0.0082)$ & 0.86 \\
\hline \multirow[t]{2}{*}{3} & 0.0002 & $0.9996^{* * *}$ & $0.0311^{* * *}$ & \\
\hline & $(0.0006)$ & $(0.0049)$ & $(0.0077)$ & 0.88 \\
\hline \multirow[t]{2}{*}{4} & $0.0009^{*}$ & $0.9951^{* * *}$ & $0.0514^{* * *}$ & \\
\hline & $(0.0006)$ & $(0.0052)$ & $(0.0080)$ & 0.88 \\
\hline \multirow[t]{2}{*}{5} & $0.0018^{* * *}$ & $1.0073^{* * *}$ & $0.0792^{* * *}$ & \\
\hline & $(0.0006)$ & $(0.0050)$ & $(0.0073)$ & 0.89 \\
\hline \multirow[t]{2}{*}{ high } & $0.0068^{* * *}$ & $0.9949^{* * *}$ & $0.4278^{* * *}$ & \\
\hline & $(0.0003)$ & $(0.0026)$ & $(0.0044)$ & 0.96 \\
\hline
\end{tabular}

This table shows estimates and standard errors obtained from running the same asset pricing exercise as in the empirical analysis of this paper, but instead of the OECD data set, simulated data are used. From the habit model outlined in section (6) and 10000 endowment shocks, data for 33 hypothetical countries have been constructed, and at each point in time, countries have been sorted into six portfolios according to their consumption growth rates realized over the preceding four periods. Test asset returns are the returns a home investor obtains each period by borrowing at home and investing in the different portfolios.

In panel $\mathbf{A}$, the first two columns report results from estimating the following cross-sectional regression using GMM:

$$
\boldsymbol{E}\left(r x^{j}\right)=\beta_{\overline{r x}}^{j} \cdot \lambda_{\overline{r x}}+\beta_{H M L \_\Delta c}^{j} \cdot \lambda_{H M L \_\Delta c}+\alpha^{j}
$$

The third and the fourth columns show results from estimating the following cross-sectional regression:

$$
E\left(r x^{j}\right)=\operatorname{cov}\left(\overline{r x}, r x^{j}\right) \cdot b_{\overline{r x}}+\operatorname{cov}\left(H M L_{-} \Delta c, r x^{j}\right) \cdot b_{H M L \_\Delta c}+\alpha^{j}
$$

where covariances and factor loadings $b$ have been estimated jointly using GMM. $R^{2}$ measures are obtained as described in the notes below Table 3 . The pricing error test reports the $p$-value for the null that the pricing errors jointly are zero.

Panel B shows estimates and standard errors obtained from running the following time series regression for each currency portfolio $j$ separately:

$$
r x_{t, t+1}^{j}=a^{j}+\beta_{\overline{r x}}^{j} \cdot \overline{r x}_{t, t+1}+\beta_{H M L \_\Delta c}^{j} \cdot H M L_{-} \Delta c_{t, t+1}+\varepsilon_{t, t+1}^{j}
$$




\section{Appendix: for publication as additional web material only.}

Table A.1: data

\begin{tabular}{|c|c|c|c|c|}
\hline Austria & consumption growth: & & population: & \\
\hline \multirow[t]{6}{*}{1985 Q1 - 1998 Q4 } & 1970 Q1 - 1998 Q4 & (OECD) & $1970-2010$ & (OECD) \\
\hline & & & CPI: & \\
\hline & & & 1980 Q1 - 2012 Q4 & (12264..XZF...) \\
\hline & spot exchange rate: & & forward exchange rate: & \\
\hline & 1984 M4 - 1993 M12 & (AUSTSCH) & 1980 M1- 1998 M12 & (AUSTS3F) \\
\hline & 1994 M1 - 2012 M10 & (AUSTSC\$) & 1997 M1- 2012 M10 & (USATS3F) \\
\hline Australia & consumption growth: & & & \\
\hline \multirow[t]{5}{*}{1985 Q1- 2010 Q4 } & 1970 Q1- 2010 Q4 & (OECD) & & (OECD) \\
\hline & & & CPI: & \\
\hline & & & 1980 Q1 - 2012 Q4 & (19364..XZF...) \\
\hline & spot exchange rate: & & forward exchange rate: & \\
\hline & 1980 M1 - 1998 M12 & (AUUSBOE) & 1984 M12- 1998 M12 & (BBAUD3F) \\
\hline Belgium & consumption growth: & & population: & \\
\hline \multirow[t]{6}{*}{1985 Q1- 1998 Q4 } & $\begin{array}{l}1970 \text { Q1- } 1998 \text { Q4 } \\
\text { (outlier: 1995 Q1) }\end{array}$ & (BGCNPER.D) & 1970 - 2010 (break: 2011) & (OECD) \\
\hline & & & CPI: & \\
\hline & & & 1980 Q1 - 2012 Q4 & (19364..XZF...) \\
\hline & spot exchange rate: & & forward exchange rate: & \\
\hline & 1984 M4 - 1993 M12 & (BELGLUX) & 1980 M1- 1998 M12 & (BELXF3F) \\
\hline & 1994 M1 - 1998 M12 & (BELGLU\$) & 1997 M1- 1998 M12 & (USBEF3F) \\
\hline Canada & consumption growth: & & population: & \\
\hline \multirow[t]{6}{*}{1985 Q1- 2010 Q4 } & 1970 Q1- 2010 Q4 & (OECD) & 1970 - 2010 (break: 2011) & (OECD) \\
\hline & & & CPI: & \\
\hline & & & 1980 Q1 - 2012 Q4 & $(12464 . . X Z F \ldots)$ \\
\hline & spot exchange rate: & & forward exchange rate: & \\
\hline & 1980 M1 - 2012 M10 & (CNUSBOE) & 1980 M1- 1996 M12 & (CNDOL3F) \\
\hline & & & 1997 M1- 2012 M10 & (USCAD3F) \\
\hline \multirow[t]{6}{*}{ Chile } & consumption growth: & & population: & \\
\hline & 1995 Q1 - 2012Q3 & (OECD) & $1970-2010$ & (OECD) \\
\hline & & & CPI: & \\
\hline & & & 1980 Q1 - 2012 Q4 & $(22864 . . X Z F \ldots)$ \\
\hline & spot exchange rate: & & forward exchange rate: & \\
\hline & 1993 M12 -2012 M10 & (CHILPE\$) & 2004 M3 - 2012 M10 & (USCLP3F) \\
\hline Czech Republic & consumption growth: & & population: & \\
\hline \multirow[t]{6}{*}{1995 Q2 - 2010 Q4 } & 1995 Q2- 2010 Q4 & (OECD) & 1970 - 2010 (break: 2011) & (OECD) \\
\hline & & & CPI: & \\
\hline & & & 1980 Q1 - 2012 Q4 & $(93564 . . X Z F \ldots)$ \\
\hline & spot exchange rate: & & forward exchange rate: & \\
\hline & 1989 M11- 1994 M12 & (CZECHCM) & 1996 M12- 2012 M10 & (USCZK3F) \\
\hline & 1995 M1 - 12012 M10 & (CZECHC\$) & & \\
\hline
\end{tabular}




\begin{tabular}{|c|c|c|c|c|}
\hline Denmark & consumption growth: & & population: & \\
\hline \multirow[t]{6}{*}{1985 Q1- 2010 Q4 } & 1970 Q1- 2010 Q4 & (OECD) & 1970 - 2010 (break: 2011) & (OECD) \\
\hline & & & CPI: & \\
\hline & & & 1980 Q1 - 2012 Q4 & (12864..XZF...) \\
\hline & spot exchange rate: & & forward exchange rate: & \\
\hline & 1980 M1 - 1993 M12 & (DANISHK) & 1980 M1- 1996 M12 & (DANIS3F) \\
\hline & 1994 M1 - 2012 M10 & (DANISH\$) & 1997 M1- 2012 M10 & (USDKK3F) \\
\hline Estonia & consumption growth: & & population: & \\
\hline \multirow[t]{6}{*}{2004 Q1-2010 Q4 } & 1995 Q2-2010 Q4 & (OECD) & $1970-2010$ & (OECD) \\
\hline & & & CPI: & \\
\hline & & & 1993 Q1 - 2012 Q4 & (93964..XZF...) \\
\hline & spot exchange rate: & & forward exchange rate: & \\
\hline & 1992 M10- 1997 M5 & (ESTOKRN) & 2004 M3 - 2010 M12 & (USEEK3F) \\
\hline & 1997 M6- 2010 M12 & (ESTOKR\$) & & \\
\hline Euro Area & consumption growth: & & population: & \\
\hline \multirow[t]{5}{*}{1999 Q1-2010 Q4 } & 1995 Q2-2010 Q4 & (OECD) & 1999 - 2010 (break: 2011) & evolving membership \\
\hline & & & CPI: & \\
\hline & & & 1998 Q1 - 2012 Q4 & (16364..XZF...) \\
\hline & spot exchange rate: & & forward exchange rate: & \\
\hline & 1999 M1 - 2012 M10 & (MSEREUR) & 1998 M12 - 2012 M10 & (EUDOL3F) \\
\hline Finland & consumption growth: & & population: & \\
\hline \multirow[t]{6}{*}{ 1996 Q4- 1998 Q4 } & 1970 Q1- 1998 Q4 & (FNCNPER.D) & $1970-2010$ & (OECD) \\
\hline & & & CPI: & \\
\hline & & & 1980 Q1 - 2012 Q4 & (17264..XZF...) \\
\hline & spot exchange rate: & & forward exchange rate: & \\
\hline & 1980 M1 - 1993 M12 & (FINMARK) & 1996 M12- 1998 M12 & (USFIM3F) \\
\hline & 1994 M1 - 1998 M12 & (FINMAR\$) & & \\
\hline France & consumption growth: & & population: & \\
\hline \multirow[t]{6}{*}{1985 Q1-1998 Q4 } & 1970 Q1-1998 Q4 & (OECD) & $1970-2010$ & (OECD) \\
\hline & & & CPI: & \\
\hline & & & 1980 Q1 - 2012 Q4 & (13264..XZF...) \\
\hline & spot exchange rate: & & forward exchange rate: & \\
\hline & 1980 M1 - 1993 M12 & (FRENFRA) & 1980 M1- 1996 M12 & (FRENF3F) \\
\hline & 1994 M1 - 1998 M12 & (FRENFR\$) & 1997 M1- 1998 M12 & (USFRF3F) \\
\hline Germany & consumption growth: & & population: & \\
\hline \multirow[t]{6}{*}{1985 Q1- 1998 Q4 } & 1970 Q1 - 1998 Q4 & (OECD) & 1970 - 2010 (break: 2011) & (OECD) \\
\hline & & & CPI: & \\
\hline & & & 1992 Q1 - 2012 Q4 & (13464..XZF...) \\
\hline & spot exchange rate: & & forward exchange rate: & \\
\hline & 1980 M1 - 1993 M12D & (MARKER) & 1980 M1- 1996 M12 & (DMARK3F) \\
\hline & 1994 M1 - 1998 M12 & (DMARKE\$) & 1997 M1- 1998 M12 & (USDEM3F) \\
\hline Grece & consumption growth: & & population: & \\
\hline \multirow[t]{6}{*}{1996 Q4 - 2000 Q4 } & 1970 Q1 - 2010 Q4 & (OECD) & 1970 - 2010 (break: 2011) & (OECD) \\
\hline & & & CPI: & \\
\hline & & & 1980 Q1 - 2012 Q4 & $(17464 . . X Z F \ldots)$ \\
\hline & spot exchange rate: & & forward exchange rate: & \\
\hline & 1980 M1 - 1993 M12 & GREDRAC & 1996 M12 - 2000 M12 & USGRD3F \\
\hline & 1994 M1 - 2000 M12 & GREDRA\$ & & \\
\hline
\end{tabular}




\begin{tabular}{|c|c|c|c|c|}
\hline Hungary & consumption growth: & & population: & \\
\hline \multirow[t]{6}{*}{1997 Q4- 2010 Q4 } & 1995 Q2- 2010 Q4 & (OECD) & $1970-2010$ & (OECD) \\
\hline & & & CPI: & \\
\hline & & & 1980 Q1 - 2012 Q4 & (94464..XZF...) \\
\hline & spot exchange rate: & & forward exchange rate: & \\
\hline & 1989 M7 - 1993 M12 & (HUNFORT) & 1997 M10 - 2012 M10 & (USHUF3F) \\
\hline & 1994 M1 - 2012 M10 & (HUNFOR\$) & & \\
\hline Iceland & consumption growth: & & population: & \\
\hline \multirow[t]{6}{*}{2004 Q1- 2010 Q4 } & 1997 Q2- 2010 Q4 & (OECD) & $1970-2010$ & (OECD) \\
\hline & & & CPI: & \\
\hline & & & 1984 Q1 - 2012 Q4 & (17664..XZF...) \\
\hline & spot exchange rate: & & forward exchange rate: & \\
\hline & 1983 M1 - 1997 M6I & (CEKRON) & 2004 M3 - 2012 M10 & (USISK3F) \\
\hline & 1997 M6 - 2012 M10 & (ICEKRO\$) & & \\
\hline Ireland & consumption growth: & & population: & \\
\hline \multirow[t]{6}{*}{1985 Q1 - 2010 Q4 } & 1970 Q1 - 2010 Q4 & (OECD) & 1970 - 2010 (break: 2011) & (OECD) \\
\hline & & & CPI: & \\
\hline & & & 1980 Q1 - 2012 Q4 & (17864..XZF...) \\
\hline & spot exchange rate: & & forward exchange rate: & \\
\hline & 1980 M1 - 1993 M12 & IPUNTER & 1980 M1 - 1996 M12 & IPUNT3F \\
\hline & 1994 M1 - 1998 M12 & IPUNTEI & 1997 M1 - 1998 M12 & UKIEP3F \\
\hline Israel & consumption growth: & & population: & \\
\hline \multirow[t]{6}{*}{2004 Q1- 2010 Q4 } & 1995 Q2- 2010 Q4 & (OECD) & $1970-2010$ & (ISI99Z..O) \\
\hline & & & CPI: & \\
\hline & & & 1980 Q1 - 2012 Q4 & (43664..XZF...) \\
\hline & spot exchange rate: & & forward exchange rate: & \\
\hline & 1980 M1 - 1993 M12 & (ISRSHEK) & 2004 M3 - 2012 M10 & (USILS3F) \\
\hline & 1994 M1 - 2012 M10 & (ISRSHE\$) & & \\
\hline Italy & consumption growth: & & population: & \\
\hline \multirow[t]{6}{*}{1985 Q1-1998 Q4 } & 1970 Q1-1998 Q4 & (OECD) & 1970 - 2010 (break: 2011) & (OECD) \\
\hline & & & CPI: & \\
\hline & & & 1980 Q1 - 2012 Q4 & (13664..XZF...) \\
\hline & spot exchange rate: & & forward exchange rate: & \\
\hline & 1980 M1 - 1993 M12 & (ITALIRE) & 1980 M1- 1996 M12 & (ITALY3F) \\
\hline & 1994 M1 - 1998 M12 & (ITALIR\$) & 1997 M1- 1998 M12 & (USITL3F) \\
\hline Japan & consumption growth: & & population: & \\
\hline \multirow[t]{6}{*}{1985 Q1-2010 Q4 } & 1970 Q1-2010 Q4 & (OECD) & $1970-2010$ & (OECD) \\
\hline & & & CPI: & \\
\hline & & & 1980 Q1 - 2012 Q4 & (15864..XZF...) \\
\hline & spot exchange rate: & & forward exchange rate: & \\
\hline & 1980 M1 - 1993 M12 & (JAPAYEN) & 1980 M1- 1996 M12 & (JAPYN3F) \\
\hline & 1994 M1 - 2012 M10 & (JAPAYE\$) & 1997 M1- 2012 M10 & (USJPY3F) \\
\hline
\end{tabular}




\begin{tabular}{|c|c|c|c|c|}
\hline Mexico & consumption growth: & & population: & \\
\hline \multirow[t]{4}{*}{ 1996 Q4- 2010 Q4 } & 1970 Q1- 2010 Q4 & (OECD) & $1970-2010$ & (OECD) \\
\hline & & & CPI: & \\
\hline & spot exchange rate: & & forward exchange rate: & \\
\hline & 1994 M1 - 2012 M10 & (MEXPES\$) & 1996 M12- 2012 M10 & (USMXN3F) \\
\hline Netherlands & consumption growth: & & population: & \\
\hline \multirow[t]{6}{*}{1985 Q1-1998 Q4 } & 1970 Q1-1998 Q4 & (OECD) & 1970 - 2010 (break: 2011) & (OECD) \\
\hline & & & CPI: & \\
\hline & & & 1980 Q1 - 2012 Q4 & $(13864 . . X Z F \ldots)$ \\
\hline & spot exchange rate: & & forward exchange rate: & \\
\hline & 1980 M1 - 1993 M12 & (GUILDER) & 1980 M1- 1998 M12 & (GUILD3F) \\
\hline & 1994 M1 - 1998 M12 & (GUILDE\$) & & \\
\hline New Zealand & consumption growth: & & population: & \\
\hline \multirow[t]{6}{*}{1985 Q1-2010 Q4 } & 1970 Q1-2010 Q4 & (OECD) & $1970-2010$ & (OECD) \\
\hline & & & CPI: & \\
\hline & & & 1980 Q1 - 2012 Q4 & (19664..XZF...) \\
\hline & spot exchange rate: & & forward exchange rate: & \\
\hline & 1980 M1 - 1993 M12 & (NZDOLLR) & 1984 M12- 2012 M10 & (BBNZD3F) \\
\hline & 1994 M1 - 2012 M10 & (NZDOLLI) & & \\
\hline Norway & consumption growth: & & population: & \\
\hline \multirow[t]{6}{*}{1985 Q1-2010 Q4 } & 1970 Q1-2010 Q4 & (OECD) & $1970-2010$ & (OECD) \\
\hline & & & CPI: & \\
\hline & & & 1980 Q1 - 2012 Q4 & (14264..XZF...) \\
\hline & spot exchange rate: & & forward exchange rate: & \\
\hline & 1980 M1 -1993 M12 & (NORKRON) & 1980 M1- 1996 M12 & (NORKN3F) \\
\hline & 1994 M1 - 2012 M10 & (NORKRO\$) & 1997 M1- 2012 M10 & (USNOK3F) \\
\hline Poland & consumption growth: & & population: & \\
\hline \multirow[t]{6}{*}{1998 Q3-2010 Q4 } & 1995 Q2-2010 Q4 & (OECD) & 1970 - 2010 (break: 2011) & (OECD) \\
\hline & & & CPI: & \\
\hline & & & 1981 Q1 - 2012 Q4 & $(96464 . . X Z F \ldots)$ \\
\hline & spot exchange rate: & & forward exchange rate: & \\
\hline & 1989 M11 - 1995 M1 & (POLZLOT) & 1996 M8 - 2012 M10 & (TDPLN3F) \\
\hline & 1995 M1 - 2012 M10 & (POLZLO\$) & & \\
\hline Portugal & consumption growth: & & population: & \\
\hline \multirow[t]{6}{*}{1985 Q1-1998 Q4 } & 1970 Q1-1998 Q4 & (OECD) & 1970 - 2010 (break: 2011) & (OECD) \\
\hline & & & CPI: & \\
\hline & & & 1980 Q1 - 2012 Q4 & $(18264 . . X Z F \ldots)$ \\
\hline & spot exchange rate: & & forward exchange rate: & \\
\hline & 1980 M1 - 1993 M12 & (PORTESC) & 1980 M1- 1996 M12 & (PORTS3F) \\
\hline & 1994 M1 - 1998 M12 & (PORTES\$) & 1997 M1- 1998 M12 & (USPTE3F) \\
\hline
\end{tabular}




\begin{tabular}{|c|c|c|c|c|}
\hline Slovak Republic & consumption growth: & & population: & \\
\hline \multirow[t]{6}{*}{2002 Q1- 2008 Q4 } & 1993 Q2- 2008 Q4 & (OECD) & $1970-2010$ & (OECD) \\
\hline & & & CPI: & \\
\hline & & & 1994 Q1 - 2012 Q4 & (93664..XZF...) \\
\hline & spot exchange rate: & & forward exchange rate: & \\
\hline & 1991 M1 - 1997 M1 & (SLOVKOR) & 2002 M2 - 2008 M11 & (USSKK3F) \\
\hline & 1997 M2 - 2008 M11 & (SLOVKO\$) & & \\
\hline Slovenia & consumption growth: & & population: & \\
\hline \multirow[t]{6}{*}{2004 Q1-2006 Q4 } & 2000 Q1-2006 Q4* & (SJCNPER.D) & 1970 - 2010 (break: 2011) & (OECD) \\
\hline & & & CPI: & \\
\hline & & & 1993 Q1 - 2012 Q4 & (96164..XZF...) \\
\hline & spot exchange rate: & & forward exchange rate: & \\
\hline & 1992 M10 - 1997 M5 & (SLOVTOL) & 2004 M3 - 2006 M12 & (USSIT3F) \\
\hline & 1997 M6 - 2006 M12 & (SLOVTO\$) & & \\
\hline South Korea & consumption growth: & & population: & \\
\hline \multirow[t]{6}{*}{2002 Q1-2010 Q4 } & 1970 Q2-2010 Q4 & (OECD) & $1970-2010$ & (OECD) \\
\hline & & & CPI: & \\
\hline & & & 1980 Q1 - 2012 Q4 & (54264..XZF...) \\
\hline & spot exchange rate: & & forward exchange rate: & \\
\hline & 1980 M1 - 1993 M12 & (KORSWON) & 2002 M2 - 2012 M10 & (USKRW3F) \\
\hline & 1994 M1 - 2012 M10 & (KORSWO\$) & & \\
\hline Sweden & consumption growth: & & population: & \\
\hline \multirow[t]{6}{*}{1985 Q1-2010 Q4 } & 1970 Q1-2010 Q4 & (OECD) & 1970 - 2010 (break: 2011) & (SWI99Z..O) \\
\hline & & & CPI: & \\
\hline & & & 1980 Q1 - 2012 Q4 & (14464..XZF...) \\
\hline & spot exchange rate: & & forward exchange rate: & \\
\hline & 1991 M1 - 1997 M1 & (SLOVKOR) & 1980 M1- 1996 M12 & (SWEDK3F) \\
\hline & 1997 M2 - 2012 M10 & (SLOVKO\$) & 1997 M1-2012 M10 & (USSEK3F) \\
\hline Switzerland & consumption growth: & & population: & \\
\hline \multirow[t]{6}{*}{1985 Q1-2010 Q4 } & 1970 Q1-2010 Q4 & (OECD) & $1970-2010$ & (OECD) \\
\hline & & & CPI: & \\
\hline & & & 1980 Q1 - 2012 Q4 & (14664..XZF...) \\
\hline & spot exchange rate: & & forward exchange rate: & \\
\hline & 1980 M1 - 1993 M12 & (SWISSFR) & 1980 M1- 1996 M12 & (SWISF3F) \\
\hline & 1994 M1 - 2012 M10 & (SWISSF\$) & 1997 M1- 2012 M10 & (USCHF3F) \\
\hline Spain & consumption growth: & & population: & \\
\hline \multirow[t]{6}{*}{1985 Q1-2010 Q4 } & 1970 Q1 - 2010 Q4 & (OECD) & 1970 - 2010 (break: 2011) & (OECD) \\
\hline & & & CPI: & \\
\hline & & & 1980 Q1 - 2012 Q4 & (18464..XZF...) \\
\hline & spot exchange rate: & & forward exchange rate: & \\
\hline & 1980 M1 - 1993 M12 & SPANPES & 1980 M1 - 1996 M12 & SPANP3F \\
\hline & 1994 M1 - 1998 M12 & SPANPE\$ & 1997 M1 - 1998 M12 & USESP3F \\
\hline
\end{tabular}




\begin{tabular}{lllll}
\hline United Kingdom & consumption growth: & & population: & \\
1985 Q1-2010 Q4 & 1970 Q1-2010 Q4 & (OECD) & $1970-2010$ & CPI: \\
& & & 1989 Q1 - 2012 Q4 & (11264..XZF...) \\
& & & forward exchange rate: & \\
& spot exchange rate: & & 1980 M1- 1996 M12 & (USDOL3F) \\
& 1980 M1 - 2012 M10 & (UKDOLLR) & 1996 M12- 2012 M10 & (USGBP3F) \\
\hline United States & consumption growth: & & population: & \\
1985 Q1 -2010 Q4 & 1970 Q1 -2010 Q4 & (OECD) & $1970-2010$ (break: 2011) & (OECD) \\
& & & CPI: & \\
& & & 1980 Q1 - 2012 Q4 & (11164..XZF...) \\
\hline
\end{tabular}

Quarterly real consumption series are sourced from the OECD-database (http://stats.oecd.org/Index.aspxand) and from national sources accessed via Datastream. The OECD consumption data corresponds to time series of real private final consumption expenditure, of which the measure VOBARSA has been downloaded (VOBARSA: Millions of national currency, volume estimates, OECD reference year, annual levels, seasonally adjusted). For the quarterly consumption series accessed via Datastream, the DS Mnemonics are given in the table. Series denoted with an asterisk are not seasonally adjusted, such that we used the X13 ARIMA_SEATS seasonal adjustment software routine to correct for seasonal effects. Growth rates to the previous quarter are calculated by taking log differences of the level data. Note that for Belgium, there is a huge outlier in the consumption growth series in 1995 Q1. This value is replaced by the mean of the preceding and the subsequent quarters growth rate.

Annual population data is sourced from International Financial Statistics and accessed via Datastream. Again, DS Mnemonics are given in the table. Population estimates for the euro area are constructed by summing up the population figures of each country that was part of the EMU at a given point in time. Growth rates are calculated by taking log differences of the level data, and quarterly growth rates are given by one fourth of annual growth rates. Many population time series contain methodological breaks. These data points have been replaced by the mean of the preceding and following growth rate.

Data on quarterly changes of consumer price indexes (CPI) are sourced from IFS, the table reports the series codes.

Daily spot- and forward exchange rates are mainly sourced from Barclays Bank International (BBI), Reuters and WM/Reuters accessed via Datastream - see the DS mnemonics in the table. Where available, WM/Reuters exchange rates denoted in units of currency $k$ per one USD are used. End of month series are obtained by keeping the closing price (midpoint quote) of the last trading day of each month.

At a given point in time, a particular country's data is included into the analysis only if data for all time series is available. For each country, these time periods are given in the first row of the table. 
Table A.2: composition of consumption growth sorted portfolios

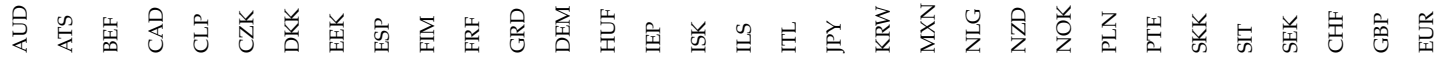

\begin{tabular}{|c|c|c|c|c|c|c|c|c|c|c|c|c|c|c|c|c|c|c|c|c|c|c|c|c|c|c|c|c|c|c|}
\hline 1990(1) & 3 & 6 & 6 & 2 & & & 1 & & 6 & & 3 & & 5 & & 5 & & 4 & 3 & & & 4 & 1 & 1 & & 5 & & 2 & 2 & 4 & \\
\hline 1990(2) & 3 & 5 & 4 & 1 & & & 2 & & 5 & & 3 & & 6 & & 3 & & 4 & 6 & & & 5 & 1 & 2 & & 6 & & 1 & 2 & 4 & \\
\hline 1990(3) & 3 & 5 & 5 & 1 & & & 2 & & 5 & & 4 & & 6 & & 2 & & 3 & 6 & & & 4 & 2 & 3 & & 6 & & 1 & 1 & 4 & \\
\hline 1990(4) & 2 & 5 & 4 & 1 & & & 1 & & 6 & & 4 & & 5 & & 2 & & 3 & 5 & & & 6 & 4 & 3 & & 6 & & 1 & 2 & 3 & \\
\hline 1991(1) & 2 & 4 & 4 & 1 & & & 3 & & 4 & & 2 & & 6 & & 3 & & 5 & 5 & & & 5 & 1 & 6 & & 6 & & 2 & 3 & 1 & \\
\hline 1991(2) & 2 & 5 & 6 & 1 & & & 3 & & 5 & & 3 & & 6 & & 4 & & 5 & 4 & & & 4 & 1 & 2 & & 6 & & 2 & 3 & 1 & \\
\hline 1991(3) & 2 & 5 & 6 & 1 & & & 5 & & 5 & & 2 & & 4 & & 4 & & 6 & 3 & & & 4 & 1 & 3 & & 6 & & 2 & 3 & 1 & \\
\hline 1991(4) & 2 & 4 & 6 & 1 & & & 3 & & 6 & & 2 & & 6 & & 4 & & 5 & 5 & & & 3 & 1 & 3 & & 5 & & 4 & 2 & 1 & \\
\hline 1992(1) & 3 & 4 & 5 & 3 & & & 5 & & 6 & & 2 & & 5 & & 4 & & 4 & 6 & & & 2 & 1 & 3 & & 6 & & 1 & 2 & 1 & \\
\hline 1992(2) & 4 & 4 & 4 & 2 & & & 5 & & 6 & & 2 & & 2 & & 5 & & 5 & 3 & & & 1 & 1 & 6 & & 6 & & 1 & 3 & 3 & \\
\hline 1992(3) & 3 & 4 & 3 & 2 & & & 5 & & 4 & & 3 & & 6 & & 6 & & 4 & 5 & & & 2 & 1 & 2 & & 6 & & 1 & 1 & 5 & \\
\hline 1992(4) & 4 & 4 & 2 & 3 & & & 5 & & 1 & & 4 & & 6 & & 5 & & 2 & 3 & & & 3 & 2 & 5 & & 6 & & 1 & 1 & 6 & \\
\hline 1993(1) & 5 & 4 & 3 & 5 & & & 2 & & 1 & & 3 & & 3 & & 6 & & 1 & 4 & & & 2 & 4 & 6 & & 5 & & 1 & 2 & 6 & \\
\hline 1993(2) & 5 & 3 & 3 & 5 & & & 2 & & 1 & & 4 & & 4 & & 6 & & 1 & 3 & & & 5 & 6 & 4 & & 2 & & 1 & 2 & 6 & \\
\hline 1993(3) & 4 & 4 & 3 & 4 & & & 3 & & 1 & & 2 & & 5 & & 6 & & 1 & 3 & & & 5 & 5 & 6 & & 2 & & 1 & 2 & 6 & \\
\hline 1993(4) & 5 & 3 & 4 & 4 & & & 4 & & 2 & & 3 & & 1 & & 6 & & 1 & 5 & & & 2 & 5 & 6 & & 2 & & 1 & 3 & 6 & \\
\hline 1994(1) & 4 & 2 & 3 & 3 & & & 6 & & 1 & & 1 & & 4 & & 5 & & 1 & 3 & & & 5 & 5 & 6 & & 2 & & 4 & 2 & 6 & \\
\hline 1994(2) & 4 & 3 & 4 & 3 & & & 6 & & 2 & & 1 & & 2 & & 6 & & 3 & 4 & & & 1 & 5 & 6 & & 5 & & 2 & 1 & 5 & \\
\hline 1994(3) & 5 & 2 & 3 & 3 & & & 6 & & 2 & & 3 & & 1 & & 6 & & 4 & 5 & & & 2 & 6 & 5 & & 4 & & 1 & 1 & 4 & \\
\hline 1994(4) & 5 & 2 & 3 & 4 & & & 6 & & 4 & & 1 & & 3 & & 6 & & 5 & 1 & & & 2 & 6 & 2 & & 5 & & 3 & 1 & 4 & \\
\hline 1995(1) & 6 & 3 & 2 & 3 & & & 5 & & 1 & & 4 & & 2 & & 6 & & 5 & 2 & & & 5 & 6 & 4 & & 4 & & 1 & 1 & 3 & \\
\hline 1995(2) & 6 & 2 & 1 & 2 & & & 2 & & 1 & & 5 & & 5 & & 5 & & 3 & 4 & & & 3 & 6 & 6 & & 4 & & 3 & 1 & 4 & \\
\hline 1995(3) & 5 & 3 & 1 & 4 & & & 2 & & 1 & & 3 & & 5 & & 6 & & 4 & 2 & & & 6 & 5 & 6 & & 3 & & 2 & 1 & 4 & \\
\hline 1995(4) & 5 & 3 & 4 & 3 & & & 4 & & 1 & & 2 & & 2 & & 6 & & 3 & 4 & & & 6 & 5 & 6 & & 2 & & 1 & 1 & 5 & \\
\hline 1996(1) & 3 & 1 & 2 & 3 & & & 4 & & 4 & & 3 & & 1 & & 6 & & 2 & 5 & & & 5 & 4 & 6 & & 5 & & 1 & 2 & 6 & \\
\hline 1996(2) & 4 & 2 & 4 & 4 & & & 3 & & 5 & & 1 & & 1 & & 6 & & 2 & 3 & & & 5 & 5 & 6 & & 3 & & 1 & 2 & 6 & \\
\hline 1996(3) & 3 & 1 & 3 & 2 & & & 3 & & 4 & & 4 & & 2 & & 6 & & 1 & 2 & & & 5 & 5 & 6 & & 5 & & 4 & 1 & 6 & \\
\hline 1996(4) & 2 & 1 & 3 & 4 & & 6 & 2 & & 3 & 5 & 1 & 1 & 1 & & 6 & & 2 & 3 & & 4 & 5 & 5 & 6 & & 5 & & 4 & 2 & 6 & \\
\hline 1997(1) & 2 & 1 & 3 & 5 & & 6 & 2 & & 4 & 5 & 1 & 4 & 2 & & 3 & & 1 & 6 & & 4 & 6 & 2 & 3 & & 5 & & 5 & 1 & 6 & \\
\hline 1997(2) & 3 & 1 & 2 & 6 & & 2 & 5 & & 3 & 5 & 1 & 3 & 1 & & 4 & & 5 & 1 & & 6 & 4 & 2 & 5 & & 4 & & 6 & 2 & 6 & \\
\hline 1997(3) & 5 & 2 & 2 & 6 & & 2 & 2 & & 5 & 5 & 1 & 3 & 1 & & 4 & & 6 & 1 & & 6 & 4 & 1 & 4 & & 5 & & 3 & 3 & 6 & \\
\hline 1997(4) & 5 & 2 & 2 & 5 & & 1 & 6 & & 6 & 4 & 2 & 2 & 1 & 4 & 6 & & 5 & 1 & & 6 & 3 & 1 & 3 & & 5 & & 3 & 3 & 4 & \\
\hline 1998(1) & 4 & 2 & 3 & 2 & & 1 & 3 & & 5 & 6 & 3 & 1 & 1 & 4 & 6 & & 6 & 1 & & 6 & 4 & 2 & 5 & & 5 & & 3 & 2 & 5 & \\
\hline 1998(2) & 4 & 2 & 3 & 3 & & 1 & 1 & & 6 & 5 & 4 & 2 & 1 & 5 & 6 & & 3 & 1 & & 6 & 5 & 2 & 4 & & 6 & & 3 & 2 & 5 & \\
\hline 1998(3) & 3 & 2 & 3 & 1 & & 1 & 4 & & 6 & 5 & 5 & 3 & 1 & 6 & 6 & & 3 & 1 & & 4 & 6 & 2 & 2 & & 5 & & 4 & 2 & 5 & \\
\hline 1998(4) & 4 & & & 2 & & 2 & 3 & & & & & 6 & & 6 & & & & 1 & & 1 & & 4 & 1 & & & & 5 & 3 & 5 & \\
\hline 1999(1) & 6 & & & 4 & & 4 & 2 & & & & & 3 & & 6 & & & & 1 & & 1 & & 3 & 6 & & & & 5 & 2 & 5 & 1 \\
\hline 1999(2) & 6 & & & 4 & & 4 & 1 & & & & & 3 & & 6 & & & & 3 & & 2 & & 5 & 1 & & & & 5 & 2 & 6 & 1 \\
\hline 1999(3) & 5 & & & 4 & & 2 & 1 & & & & & 3 & & 6 & & & & 1 & & 3 & & 6 & 4 & & & & 5 & 2 & 6 & 1 \\
\hline 1999(4) & 4 & & & 4 & & 2 & 1 & & & & & 1 & & 6 & & & & 1 & & 6 & & 3 & 5 & & & & 5 & 2 & 6 & 3 \\
\hline $2000(1)$ & 3 & & & 5 & & 1 & 1 & & & & & 4 & & 5 & & & & 1 & & 6 & & 2 & 3 & 2 & & & 6 & 2 & 6 & 4 \\
\hline $2000(2)$ & 3 & & & 4 & & 1 & 1 & & & & & 3 & & 5 & & & & 1 & & 6 & & 2 & 6 & 2 & & & 6 & 2 & 5 & 4 \\
\hline 2000(3) & 4 & & & 5 & & 3 & 1 & & & & & 1 & & 4 & & & & 1 & & 6 & & 2 & 5 & 2 & & & 6 & 2 & 6 & 3 \\
\hline $2000(4)$ & 4 & & & 4 & & 2 & 1 & & & & & & & 5 & & & & 1 & & 6 & & 1 & 3 & 6 & & & 5 & 2 & 6 & 3 \\
\hline 2001(1) & 4 & & & 5 & & 5 & 1 & & & & & & & 6 & & & & 1 & & 6 & & 2 & 2 & 3 & & & 3 & 4 & 6 & 1 \\
\hline 2001(2) & 5 & & & 2 & & 6 & 1 & & & & & & & 6 & & & & 4 & & 3 & & 3 & 2 & 5 & & & 1 & 4 & 6 & 1 \\
\hline 2001(3) & 3 & & & 2 & & 6 & 1 & & & & & & & 6 & & & & 4 & & 1 & & 5 & 4 & 5 & & & 2 & 3 & 6 & 1 \\
\hline $2001(4)$ & 3 & & & 3 & & 6 & 1 & & & & & & & 6 & & & & 4 & & 1 & & 5 & 5 & 4 & & & 2 & 2 & 6 & 1 \\
\hline 2002(1) & 3 & & & 3 & & 5 & 2 & & & & & & & 6 & & & & 2 & 6 & 1 & & 4 & 4 & 5 & 5 & & 2 & 1 & 6 & 1 \\
\hline 2002(2) & 3 & & & 4 & & 5 & 1 & & & & & & & 6 & & & & 2 & 6 & 2 & & 5 & 2 & 4 & 6 & & 3 & 1 & 5 & 1 \\
\hline 2002(3) & 5 & & & 5 & & 3 & 2 & & & & & & & 6 & & & & 2 & 6 & 1 & & 4 & 3 & 4 & 6 & & 2 & 1 & 5 & 1 \\
\hline $2002(4)$ & 4 & & & 3 & & 5 & 2 & & & & & & & 6 & & & & 2 & 6 & 1 & & 4 & 3 & 5 & 6 & & 5 & 1 & 2 & 1 \\
\hline 2003(1) & 4 & & & 4 & & 6 & 1 & & & & & & & 6 & & & & 1 & 2 & 3 & & 5 & 3 & 2 & 6 & & 5 & 1 & 5 & 2 \\
\hline 2003(2) & 4 & & & 3 & & 6 & 2 & & & & & & & 6 & & & & 2 & 1 & 1 & & 5 & 5 & 5 & 4 & & 3 & 1 & 6 & 2 \\
\hline 2003(3) & 3 & & & 4 & & 6 & 1 & & & & & & & 6 & & & & 1 & 1 & 3 & & 6 & 5 & 4 & 2 & & 5 & 2 & 5 & 2 \\
\hline 2003(4) & 5 & & & 3 & & 6 & 4 & & & & & & & 6 & & & & 2 & 1 & 3 & & 6 & 4 & 5 & 1 & & 2 & 2 & 5 & 1 \\
\hline 2004(1) & 5 & & & 2 & 6 & 3 & 3 & 6 & & & & & & 1 & 6 & 4 & & 2 & 1 & 2 & & 6 & 5 & 5 & 3 & 4 & 2 & 1 & 4 & 1 \\
\hline $2004(2)$ & 5 & & & 2 & 6 & 3 & 4 & 6 & & & & & & 3 & 6 & 2 & & 1 & 1 & 5 & & 4 & 6 & 5 & 4 & 3 & 2 & 1 & 2 & 1 \\
\hline 2004(3) & 5 & & & 2 & 6 & 3 & 5 & 6 & & & & & & 3 & 6 & 2 & & 2 & 1 & 5 & & 4 & 4 & 4 & 6 & 3 & 2 & 1 & 1 & 1 \\
\hline 2004(4) & 4 & & & 2 & 6 & 4 & 5 & 6 & & & & & & 1 & 6 & 5 & & 1 & 2 & 5 & & 3 & 4 & 3 & 6 & 3 & 2 & 1 & 1 & 2 \\
\hline
\end{tabular}




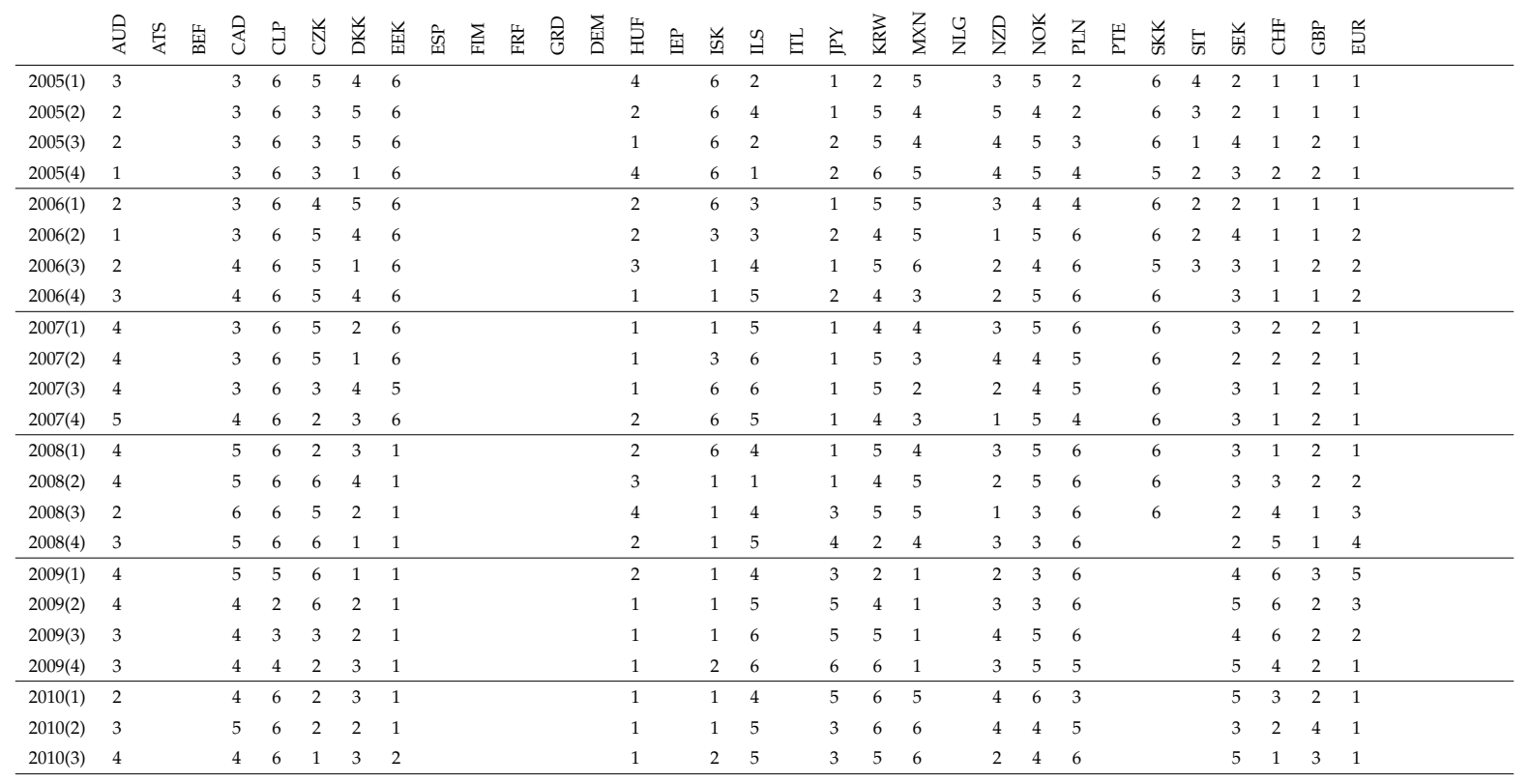

Australian dollar (AUD), Atusrian schilling (ATS), Belgian franc (BEF), Canadian dollar (CAD), Chilean peso (CLP), Czech koruna, Danish krone (DKK), Estonian kroon (EEK), Spanish peseta (ESP), Finnish markka (FIM), French franc (FRF), Greec drachma (GRD), German mark (DEM), Hungarian forinth (HUF), Irish pound (IEP), Icelandic krona, Israeli Shequel (ILS), Italian lira (ITL), Japanese yen (JPY), Korean won (KRW), Mexican peso (MXN), Dutch guilder (NLG), New Zealand dollar (NZD), Norwegian krone (NOK), Polisz zloty (PLN), Portugese escudo (PTE), Slovak koruna (SKK), Slowenian tolar (SIT), Swedish krone (SEK), Swiss franc (CHF), British pound (GBP), euro (EUR). 
Table A.3: forward discount sorted currency portfolios

\begin{tabular}{|c|c|c|c|c|c|c|c|}
\hline portfolio $j$ & low & 2 & 3 & 4 & 5 & high & $H M L_{F X}$ \\
\hline & \multicolumn{7}{|c|}{ excess return $r x^{j}$} \\
\hline $\begin{array}{l}\text { mean portfolio } \\
\text { return }\end{array}$ & 0.5843 & 1.2882 & 2.9673 & 3.3275 & 2.4090 & 4.2012 & 6.1482 \\
\hline $\begin{array}{l}\text { std portfolio } \\
\text { return }\end{array}$ & 19.3868 & 21.3215 & 19.7383 & 20.9398 & 18.7540 & 19.8020 & 20.3838 \\
\hline \multirow[t]{2}{*}{ Sharpe ratio } & 0.0301 & 0.0604 & 0.1503 & 0.1589 & 0.1285 & 0.2122 & 0.3016 \\
\hline & \multicolumn{7}{|c|}{ spot change $\Delta s^{k}$} \\
\hline mean & -1.0687 & -1.6682 & -1.1360 & -0.0059 & 0.6317 & 1.4256 & \\
\hline \multirow[t]{2}{*}{ std } & 18.2364 & 20.4498 & 22.2704 & 19.5472 & 21.8629 & 21.2398 & \\
\hline & \multicolumn{7}{|c|}{ consumption growth $\Delta c_{t-4, t}^{j}$} \\
\hline mean & 1.4659 & 1.7567 & 2.2213 & 2.3973 & 1.7044 & 1.6767 & \\
\hline \multirow[t]{2}{*}{ std } & 1.1905 & 1.7843 & 1.9682 & 1.7830 & 2.5061 & 3.7649 & \\
\hline & \multicolumn{7}{|c|}{ forward discount: $f^{j}-s^{j}$} \\
\hline mean & -0.0042 & -0.0002 & 0.0017 & 0.0038 & 0.0076 & 0.0174 & \\
\hline std & 0.0046 & 0.0048 & 0.0050 & 0.0049 & 0.0055 & 0.0074 & \\
\hline
\end{tabular}

This table presents descriptive statistics for the returns a US investor obtains from investing in different currency portfolios. At the beginning of each new quarter, currencies are sorted into six portfolios based on their forward discount against the US dollar observed at the end of the preceding quarter. The first portfolio always contains currencies of those countries with the lowest sixtile of forward discounts, and the last portfolio always contains currencies of countries with the highest sixtile of forward discounts. The last column shows descriptive statistics for the forward discount based carry trade portfolio $H M L_{F X}$ which is given by a short position in all currencies of the low interest rate portfolio and a long position in the currencies of the high interest rate portfolio. Portfolio excess returns are calculated as $r x_{t, t+1}^{j}=f_{t, t+1}^{j}-$ $s_{t}^{j}-\Delta s_{t+1}^{j}$, where $r x_{t, t+1}^{j}$ is the average quarterly return from borrowing in US dollars and investing in equal weights in all currencies of portfolio $j . f_{t, t+1}^{j}$ is the average of the log $3 \mathrm{M}$ forward exchange rate of the currencies in portfolio $j$ against the US dollar, and $\Delta s_{t, t+1}^{j}$ is the portfolio average of the log difference of the spot exchange rate between dates $t$ and $t+1 . f_{t}^{j}-s_{t}^{j}$ is the average forward discount (interest rate differential) of the currencies in portfolio $j$ against the US dollar. Exchange rates are in direct quotation, i.e. an increase in $s^{j}$ implies a depreciation of the currencies in portfolio $j$ against the US dollar. Except for the forward discount, all statistics are presented in percentages per annum. The data sample encompasses the OECD country set specified in the main text and in the appendix, and it spans the period from 1990(1) to 2010(4). The data is at quarterly frequency. 
Table A.4: exchange rate returns as test assets: time series regression

\begin{tabular}{lllcr}
\hline & $a^{j}$ & $\beta_{\overline{r x}}^{j}$ & $\beta_{H M L \_c}^{j}$ & $\bar{R}^{2}$ \\
\cline { 2 - 5 } low & -0.0024 & $0.9838^{* * *}$ & $-0.5163^{* * *}$ & \\
& $(0.0024)$ & $(0.0524)$ & $(0.0661)$ & 0.90 \\
2 & -0.0002 & $1.1008^{* * *}$ & -0.0638 & 0.88 \\
3 & $(0.0019)$ & $(0.0440)$ & $(0.0681)$ & \\
& 0.0035 & $0.9789^{* * *}$ & -0.0437 & 0.78 \\
4 & $(0.0028)$ & $(0.0721)$ & $(0.0706)$ & 0.78 \\
& 0.0033 & $1.0190^{* * *}$ & 0.0809 & \\
5 & $(0.0025)$ & $(0.0638)$ & $(0.0842)$ & 0.83 \\
& 0.0021 & $0.9181^{* * *}$ & $0.1148^{* *}$ & \\
\multirow{2}{*}{ high } & $(0.0018)$ & $(0.0460)$ & $(0.0662)$ & 0.94 \\
\hline
\end{tabular}

This table shows estimates and standard errors obtained from running the following time series regression for each currency portfolio $j$ separately:

$$
-\Delta s_{t, t+1}^{j}=a^{j}+\beta_{\overline{r x}}^{j} \cdot \overline{r x}_{t, t+1}+\beta_{H M L \_\Delta c}^{j} \cdot H M L \_\Delta c_{t, t+1}+\varepsilon_{t, t+1}^{j}
$$

Standard errors are corrected for serial correlation using the Newey and West (1987) estimator for the covariance matrix of the error terms $\varepsilon_{t, t+1}^{j}$. 
Table A.5: exchange rate returns as test assets: risk price and factor loadings

\begin{tabular}{lllll}
\hline & $\lambda_{\overline{r x}}$ & $\lambda_{H M L \_\Delta c}$ & $b_{\overline{r x}}$ & $b_{H M L \_c c}$ \\
\hline OLS estimate & 0.0017 & $0.0070^{* *}$ & 0.5117 & $6.3579^{*}$ \\
standard error & $(0.0049)$ & $(0.0042)$ & $(2.5301)$ & $(3.9992)$ \\
\cline { 2 - 5 } $\begin{array}{l}\text { pricing error test } \\
R^{2}\end{array}$ & & 0.8718 & & 0.8726 \\
\hline GLS estimate & 0.0017 & 0.72 & & 0.72 \\
standard error & $(0.0052)$ & $(0.0041)$ & $(2.3438)$ & $6.3356^{* *}$ \\
pricing error test & & 0.8557 & & 0.956 \\
\hline
\end{tabular}

This first two columns of this table report results from estimating the following cross-sectional regression:

$$
\boldsymbol{E}\left(-\Delta s^{j}\right)=\beta_{\overline{r x}}^{j} \cdot \lambda_{\overline{r x}}+\beta_{H M L \_\Delta c}^{j} \cdot \lambda_{H M L_{-} \Delta c}+\alpha^{j}
$$

$\beta_{\overline{T X}}^{j}$ and $\beta_{H M L \perp c}^{j}$ correspond to the estimates obtained from running time series regressions of portfolio returns on the risk factors as reported in Table 2 . Here, the factor $\beta$ s and the prices of risk $\lambda_{\overline{r x}}$ and $\lambda_{H M L} \Delta c$ have been estimated jointly using GMM. This approach yields standard errors which correct for the fact that the $\beta$ s are estimates. The third and the fourth column of this table report results from estimating the following cross-sectional regression:

$$
\boldsymbol{E}\left(-\Delta s^{j}\right)=\operatorname{cov}\left(\overline{r x}, \Delta s^{j}\right) \cdot b_{\overline{r x}}+\operatorname{cov}\left(H M L_{-} \Delta c, \Delta s^{j}\right) \cdot b_{H M L \_\Delta c}+\alpha^{j}
$$

where again, covariances and factor loadings $b$ have been estimated jointly using GMM. Furthermore, let $\bar{\mu}=$ $\frac{1}{J} \sum_{j=1}^{J} \mu^{j}=\mu^{\prime} \mathbf{1} / J$ where $\mathbf{1}$ is a $J \times 1$ vector of ones. Then $R^{2}$ measures are obtained using $R^{2}=1-\frac{\hat{\alpha}^{\prime} \hat{\alpha}}{(\mu-\bar{\mu} 1)^{\prime}(\mu-\bar{\mu} \mathbf{1})}$ where $\hat{\alpha}=\left[\begin{array}{llll}\alpha^{1}, & \alpha^{2}, & \ldots & \alpha^{J}\end{array}\right]^{\prime}$ is the vector of average portfolio $j$ pricing errors $\alpha^{j}$ given by $\alpha^{j}=\overline{r x}^{j}-$ $\operatorname{cov}\left(\hat{f}, r x^{j}\right)^{\prime} \hat{\boldsymbol{b}}=\overline{r x}^{j}-\hat{\boldsymbol{\beta}}^{j} \hat{\boldsymbol{\lambda}}$ where $\boldsymbol{\beta}^{j}=\left[\begin{array}{ll}\beta_{\overline{r x}}^{j} & \beta_{H M L-\Delta c}^{j}\end{array}\right]^{\prime}$ and $\lambda^{j}=\left[\begin{array}{ll}\lambda_{\overline{r x}}^{j} & \lambda_{H M L-\Delta c}^{j}\end{array}\right]^{\prime}$. Hats denote estimates. The pricing error test reports the $\mathrm{p}$-value for the null that the pricing errors are jointly zero. 
Table A.6: Currency portfolios sorted on $\beta_{H M L_{-} \Delta c, t}$

\begin{tabular}{|c|c|c|c|c|c|c|}
\hline portfolio $j$ & low & 2 & 3 & 4 & 5 & high \\
\hline & \multicolumn{6}{|c|}{ excess return $r x^{k}$} \\
\hline mean & 0.8836 & 1.7341 & -1.0063 & 1.6342 & 0.0509 & 3.8245 \\
\hline std & 20.2551 & 19.9704 & 22.4094 & 21.0777 & 18.7729 & 19.7072 \\
\hline \multirow[t]{2}{*}{ Sharpe ratio } & 0.0436 & 0.0868 & -0.0449 & 0.0775 & 0.0027 & 0.1941 \\
\hline & \multicolumn{6}{|c|}{ spot change $\Delta s^{k}$} \\
\hline mean & -2.1904 & -1.8687 & 0.6650 & -1.1809 & 1.2659 & -1.7230 \\
\hline \multirow[t]{2}{*}{ std } & 20.0189 & 19.5988 & 22.1728 & 20.6399 & 18.7120 & 18.9637 \\
\hline & \multicolumn{6}{|c|}{ consumption growth $\Delta c_{t-4, t}^{j}$} \\
\hline mean & 1.1374 & 1.7817 & 1.9361 & 2.0126 & 2.1484 & 2.1692 \\
\hline \multirow[t]{2}{*}{ std } & 1.8767 & 1.8011 & 1.7100 & 1.9052 & 1.5769 & 3.7958 \\
\hline & \multicolumn{6}{|c|}{ forward discount: $f^{j}-s^{j}$} \\
\hline mean & -0.0033 & -0.0003 & -0.0009 & 0.0011 & 0.0033 & 0.0053 \\
\hline std & 0.0045 & 0.0045 & 0.0053 & 0.0057 & 0.0039 & 0.0052 \\
\hline
\end{tabular}

This table presents descriptive statistics for the returns an US investor obtains by investing in different currency portfolios. Currencies are sorted into portfolios according to their $\beta_{t}$ with respect to the consumption carry trade factor $H M L_{-} \Delta c_{t}$. For each currency $k$ we estimate the following regression over rolling windows

$$
r x_{t, t+1}^{k}=a^{k}+\beta_{1}^{k} \cdot \overline{r x_{t, t+1}}+\beta_{2}^{k} \cdot H M L \_\Delta c_{t, t+1}+\varepsilon_{t, t+1}^{k}
$$

At time $t$, we run the regression using data for the quarters from $t-19$ to $t$ (20 quarters). The data sample is the OECD sample specified in section (). Due to the rolling window estimation, five years are lost, such that the data sample reaches from 1995(1) to 2010(4). The consumption carry trade factor $H M L \_\Delta c$ is constructed as described in the main text, based on six previous years consumption growth sorted currency portfolios. $\overline{r x}_{t, t+1}$ is the average return an investor obtains when he borrows in US dollars and invests in equal weights in all currencies available in the sample at a given point in time. Portfolio excess returns are calculated as $r x_{t, t+1}^{j}=f_{t, t+1}^{j}-s_{t}^{j}-\Delta s_{t+1}^{j}$, where $r x_{t, t+1}^{j}$ is the average quarterly return from borrowing in US dollars and investing in equal weights in all currencies of portfolio $j . f_{t, t+1}^{j}$ is the average of the $\log 3 \mathrm{M}$ forward exchange rate of the currencies in portfolio $j$ against the US dollar, and $\Delta s_{t, t+1}^{j}$ is the portfolio average of the $\log$ difference of the spot exchange rate between dates $t$ and $t+1 . f_{t}^{j}-s_{t}^{j}$ is the average forward discount of the currencies in portfolio $j$ against the US dollar. Exchange rates are in direct quotation, i.e. an increase in $s^{j}$ implies a depreciation of the currencies in portfolio $j$ against the US dollar. All statistics are presented in percentages per annum, only the statistics for the forward discount are quarterly values. 
Table A.7: time series regression with portfolio forward discount as additional pricing factor

\begin{tabular}{|c|c|c|c|c|c|}
\hline & $a^{j}$ & $\beta_{\overline{r x}}^{j}$ & $\beta_{H M L \_\Delta c}^{j}$ & $\beta_{\left(f^{j}-s^{j}\right)}^{j}$ & $\bar{R}^{2}$ \\
\hline \multirow[t]{4}{*}{ low } & 0.0015 & $0.9895^{* * *}$ & $-0.5490^{* * *}$ & & \\
\hline & $(0.0012)$ & $(0.0349)$ & $(0.0506)$ & & 0.94 \\
\hline & $0.0015^{*}$ & $0.9913^{* * *}$ & $-0.5593^{* * *}$ & $-0.3149^{* * *}$ & \\
\hline & $(0.0011)$ & $(0.0311)$ & $(0.0487)$ & $(0.1491)$ & 0.94 \\
\hline \multirow[t]{4}{*}{2} & $0.0032^{*}$ & $1.1018^{* * *}$ & -0.0638 & & \\
\hline & $(0.0020)$ & $(0.0491)$ & $(0.0633)$ & & 0.87 \\
\hline & $0.0032^{* *}$ & $1.1007^{* * *}$ & -0.0638 & $1.0081^{* * *}$ & \\
\hline & $(0.0019)$ & $(0.0440)$ & $(0.0681)$ & $(0.2932)$ & 0.88 \\
\hline \multirow[t]{4}{*}{3} & $0.0074^{* * *}$ & $0.9782^{* * *}$ & -0.0278 & & \\
\hline & $(0.0026)$ & $(0.0728)$ & $(0.0737)$ & & 0.80 \\
\hline & $0.0074^{* * *}$ & $0.9780^{* * *}$ & -0.0245 & -0.2036 & \\
\hline & $(0.0026)$ & $(0.0735)$ & $(0.0742)$ & $(0.4540)$ & 0.79 \\
\hline \multirow[t]{4}{*}{4} & $0.0083^{* * *}$ & $1.0123^{* * *}$ & 0.0773 & & \\
\hline & $(0.0029)$ & $(0.0660)$ & $(0.0939)$ & & 0.77 \\
\hline & $0.0083^{* * *}$ & $1.0182^{* * *}$ & 0.0805 & $0.8790^{* * *}$ & \\
\hline & $(0.0026)$ & $(0.0638)$ & $(0.0856)$ & $(0.4129)$ & 0.77 \\
\hline \multirow[t]{4}{*}{5} & $0.0060^{* * *}$ & $0.9378^{* * *}$ & $0.1195^{* *}$ & & \\
\hline & $(0.0017)$ & $(0.0428)$ & $(0.0648)$ & & 0.83 \\
\hline & $0.0060^{* * *}$ & $0.9267^{* * *}$ & $0.1168^{* *}$ & $0.5636^{* *}$ & \\
\hline & $(0.0017)$ & $(0.0444)$ & $(0.0652)$ & $(0.3092)$ & 0.83 \\
\hline \multirow[t]{4}{*}{ high } & $0.0105^{* * *}$ & $0.9895^{* * *}$ & $0.4510^{* * *}$ & & \\
\hline & $(0.0012)$ & $(0.0349)$ & $(0.0506)$ & & 0.95 \\
\hline & $0.0105^{* * *}$ & $0.9902^{* * *}$ & $0.4475^{* * *}$ & 0.2242 & \\
\hline & $(0.0013)$ & $(0.0340)$ & $(0.0479)$ & $(0.2195)$ & 0.95 \\
\hline
\end{tabular}

This table shows estimates and standard errors obtained from running the following time series regression for each currency portfolio $j$ separately:

$$
r x_{t, t+1}^{j}=a^{j}+\beta_{\overline{r x}}^{j} \cdot \overline{r x}_{t, t+1}+\beta_{H M L_{-} \Delta c}^{j} \cdot H M L_{-} \Delta c_{t, t+1}+\beta_{\left(f^{j}-s^{j}\right)}^{j} \cdot\left(f^{j}-s^{j}\right)+\varepsilon_{t, t+1}^{j}
$$

Standard errors are corrected for serial correlation using the Newey and West (1987) estimator for the covariance matrix of the error terms $\varepsilon_{t, t+1}^{j}$. 


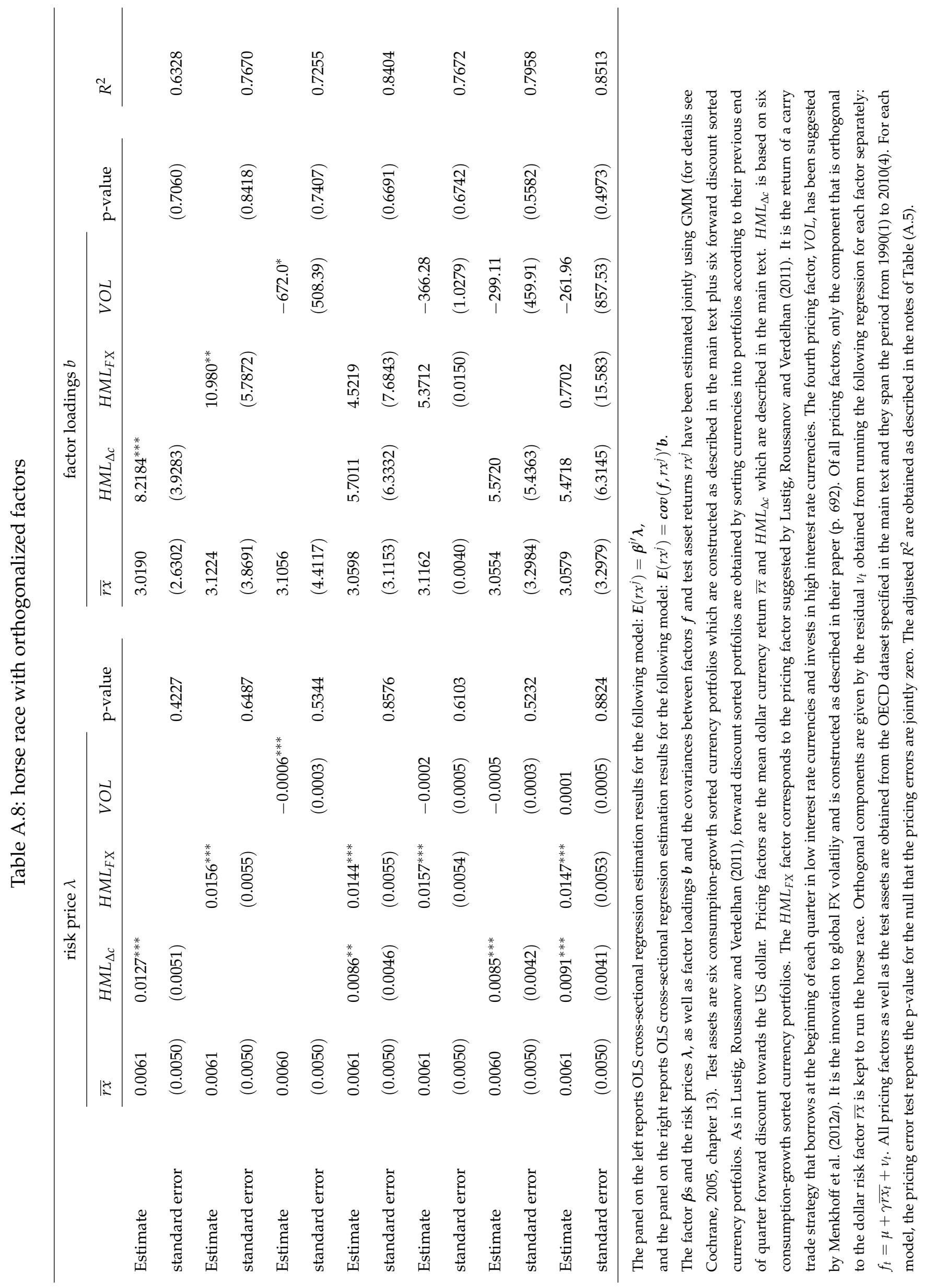


Table A.9: horse race - principal components of global risk factors

\begin{tabular}{|c|c|c|c|c|c|c|c|c|c|}
\hline & \multicolumn{7}{|c|}{ risk price $\lambda$} & \multirow[b]{2}{*}{$\mathrm{p}$-value } & \multirow[b]{2}{*}{$R^{2}$} \\
\hline & $\overline{r x}$ & $H M L_{\Delta c}$ & $H M L_{F X}$ & $V O L$ & $P C 1$ & $P C 2$ & PC3 & & \\
\hline Estimate & 0.0061 & & & & 0.3265 & 0.1958 & 0.1691 & & \\
\hline standard error & $(0.0050)$ & & & & $(0.2917)$ & $(0.1793)$ & $(0.2294)$ & 0.8824 & 0.8513 \\
\hline Estimate & 0.0061 & & & & $0.4764^{* * *}$ & & & & \\
\hline standard error & $(0.0050)$ & & & & $(0.1570)$ & & & 0.8238 & 0.8219 \\
\hline Estimate & 0.0061 & & & & & 0.1430 & & & \\
\hline standard error & $(0.0050)$ & & & & & $(0.1275)$ & & 0.0522 & 0.0851 \\
\hline Estimate & 0.0062 & & & & & & $0.2818^{* * *}$ & & \\
\hline standard error & $(0.0050)$ & & & & & & $(0.1211)$ & 0.0315 & 0.4424 \\
\hline Estimate & 0.0061 & $0.0088^{* * *}$ & & & $0.4762^{* * *}$ & & & & \\
\hline standard error & $(0.0050)$ & $(0.0044)$ & & & $(0.1567)$ & & & 0.8238 & 0.8219 \\
\hline Estimate & 0.0061 & & $0.0153^{* * *}$ & & $0.4858^{* * *}$ & & & & \\
\hline standard error & $(0.0050)$ & & $(0.0054)$ & & $(0.1711)$ & & & 0.7621 & 0.8228 \\
\hline Estimate & 0.0061 & & & -0.0001 & $0.3713^{*}$ & & & & \\
\hline standard error & $(0.0050)$ & & & $(0.0004)$ & $(0.2429)$ & & & 0.9112 & 0.8478 \\
\hline Estimate & 0.0061 & $0.0095^{* * *}$ & & & & & 0.1795 & & \\
\hline standard error & $(0.0050)$ & $(0.0048)$ & & & & & $(0.1096)$ & 0.9293 & 0.8512 \\
\hline Estimate & 0.0060 & & $0.0155^{* * *}$ & & & & -0.0460 & & \\
\hline standard error & $(0.0050)$ & & $(0.0053)$ & & & & $(0.1785)$ & 0.6929 & 0.8036 \\
\hline Estimate & 0.0060 & & & $-0.0006^{*}$ & & & -0.1242 & 0.4774 & 0.7257 \\
\hline standard error & $(0.0050)$ & & & $(0.0005)$ & & & $(0.2511)$ & & \\
\hline
\end{tabular}

The table reports OLS cross-sectional regression estimation results for the following model:

$$
E\left(r x^{j}\right)=\beta^{j \prime} \lambda
$$

The factor $\beta$ s and the risk prices $\lambda$ have been estimated jointly using GMM. Test assets are six consumption growth sorted currency portfolios which are constructed as described in the main text plus six forward discount sorted currency portfolios. As in Lustig, Roussanov and Verdelhan (2011), forward discount sorted portfolios are obtained by sorting currencies into portfolios according to their previous end of quarter forward discount towards the US dollar. Pricing factors are the mean dollar currency return $\overline{r x}$ and $H M L_{\Delta c}$ which are described in the main text. $H M L_{\Delta c}$ is based on six consumption growth sorted currency portfolios. The $H M L_{F X}$ factor corresponds to the pricing factor suggested by Lustig, Roussanov and Verdelhan (2011). It is the return of a carry trade strategy that borrows at the beginning of each quarter in low interest rate currencies and invests in high interest rate currencies. The fourth pricing factor, VOL, has been suggested by Menkhoff et al. 2012a). It is the innovation to global FX volatiliy and is constructed as described in their paper (p. 692). The factors denoted $P C 1, P C 2$ and $P C 3$ are the principal components of the three candidate slope factors $H M L_{\Delta c}, H M L_{F X}$ and $V O L$. All pricing factors as well as the test assets are obtained from the OECD data set specified in the main text. The data spans the period from 1990(1) to 2010(4). For each model, the pricing error test reports the p-value for the null that the pricing errors are jointly zero. The adjusted $R^{2}$ are obtained as described in the notes of Table A.5. 
Table A.10: principal components of pricing factors: descriptives

\begin{tabular}{|c|c|c|c|c|c|c|}
\hline & \multicolumn{3}{|c|}{ loadings } & \multicolumn{3}{|c|}{ correlations } \\
\hline & $P C 1$ & $P C 2$ & $P C 3$ & $P C 1$ & $P C 2$ & $P C 3$ \\
\hline \multirow[t]{2}{*}{$H M L_{\Delta c}$} & 0.4714 & 0.8539 & -0.2203 & 0.6289 & 0.7643 & -0.1427 \\
\hline & & & & $(0.0000)$ & $(0.0000)$ & $(0.1981)$ \\
\hline \multirow[t]{2}{*}{$H M L_{F X}$} & 0.6474 & -0.1655 & 0.7439 & 0.8636 & -0.1481 & 0.4819 \\
\hline & & & & $(0.0000)$ & $(0.1814)$ & $(0.0000)$ \\
\hline \multirow[t]{4}{*}{$V O L$} & -0.5988 & 0.4934 & 0.6309 & -0.7988 & 0.4416 & 0.4086 \\
\hline & & & & $(0.0000)$ & $(0.0000)$ & $(0.0001)$ \\
\hline & \multicolumn{3}{|c|}{ explained variance } & & & \\
\hline & $59 \%$ & $27 \%$ & $14 \%$ & & & \\
\hline
\end{tabular}

The panel on the left shows the principal component coefficients or loadings which are obtained from a principal components analysis of three candidate risk factors $H M L_{\Delta c}, H M L_{F X}$ and $V O L$. The last row of the lefthand panel shows how much of the total variability of the three risk factors each principal component accounts for. The panel on the right shows the correlation coefficients of the principal components with each candidate risk factor. p-values for the null that the correlations equal zero are reported in parentheses. The principal components analysis has been performed with standardized variables, i.e. it is based on correlations. 
Table A.11: currency portfolios sorted on previous year consumption growth: real returns

\begin{tabular}{lllllllll}
\hline portfolio $j$ & low & 2 & 3 & 4 & 5 & high & $\overline{r x}$ & $H M L_{\Delta c}$ \\
\hline \multicolumn{7}{c}{ excess return: $r x^{j}$} \\
mean & -2.0161 & -1.3121 & 0.3669 & 0.7271 & -0.1913 & 1.6008 & -0.1483 & 3.6169 \\
std & 19.2020 & 21.0662 & 19.9026 & 20.7902 & 18.5518 & 19.5521 & 17.9093 & 13.3143 \\
Sharpe ratio & -0.1050 & -0.0623 & 0.0184 & 0.0350 & -0.0103 & 0.0819 & -0.0083 & 0.2717 \\
\hline \multirow{7}{*}{ mean } & spot change: $\Delta s^{j}$ & & & & & & \\
std & 0.9662 & 0.0817 & -1.4008 & -1.3396 & -0.8545 & -1.6124 & & \\
\hline & 19.5364 & 21.1760 & 19.9418 & 20.9312 & 18.4037 & 19.8600 & & \\
mean & consumption growth: $\Delta c_{t-4, t}^{j}$ & & & & & \\
std & -1.2237 & 0.6728 & 1.5040 & 2.2225 & 3.0734 & 5.1521 & & \\
\hline & 3.2260 & 1.5270 & 1.3992 & 1.3506 & 1.3734 & 1.8136 & & \\
\hline mean & forward discount: $f^{j}-s^{j}$ & & & & & \\
\hline std & 0.0039 & 0.0034 & 0.0039 & 0.0050 & 0.0039 & 0.0065 & & \\
\hline
\end{tabular}

This table presents descriptive statistics for the returns an US investor obtains by investing in different currency portfolios. At the beginning of each quarter, currencies are sorted into six portfolios based on the associated countries' consumption growth rates over the preceding four quarters. The first portfolio always contains currencies of countries with the lowest sixtile of consumption growth rates, and the sixth portfolio always contains currencies of countries with the highest sixtile of consumption growth rates. The second last column presents the average return an US investor obtains when borrowing in US dollars and investing in equal weights into all currencies, this return is labelled $\overline{r x}_{t, t+1}$. The last column shows descriptive statistics for the consumption-based carry trade portfolio $H M L_{\Delta c}$ which is given by a short position in all currencies of the low consumption growth portfolio and a long position in the currencies of the high consumption growth portfolio. Portfolio excess returns are calculated as $r x_{t, t+1}^{j}=f_{t, t+1}^{j}-s_{t}^{j}-\Delta s_{t+1}^{j}$, where $r x_{t, t+1}^{j}$ is the average quarterly return from borrowing in US dollars and investing in equal weights in all currencies of portfolio $j . f_{t, t+1}^{j}$ is the average of the log $3 \mathrm{M}$ forward exchange rate of the currencies in portfolio $j$ against the US dollar, and $\Delta s_{t, t+1}^{j}$ is the portfolio average of the log difference of the spot exchange rate between dates $t$ and $t+1 . f_{t}^{j}-s_{t}^{j}$ is the average forward discount of the currencies in portfolio $j$ against the US dollar. Exchange rates are in direct quotation, i.e. an increase in $s^{j}$ implies a depreciation of the currencies in portfolio $j$ against the US dollar. Except for the forward discounts, all statistics are presented in percentages per annum. The data sample encompasses the OECD country set specified in the main text and in the appendix, and it spans the period from 1990(1) to 2010(4). The data is at quarterly frequency. 
Table A.12: real returns: time series regression

\begin{tabular}{lllcr}
\hline \multirow{2}{*}{ low } & $a^{j}$ & $\beta_{\overline{r x}}^{j}$ & $\beta_{H M L \_c}^{j}$ & $\bar{R}^{2}$ \\
\cline { 2 - 5 } & $-0.0050^{* * *}$ & $0.9852^{* * *}$ & $-0.5487^{* * *}$ & \\
& $(0.0012)$ & $(0.0345)$ & $(0.0499)$ & 0.94 \\
& $-0.0033^{*}$ & $1.0959^{* * *}$ & -0.0625 & 0.86 \\
3 & $(0.0020)$ & $(0.0494)$ & $(0.0638)$ & \\
& 0.0009 & $0.9973^{* * *}$ & -0.0296 & 0.80 \\
4 & $(0.0026)$ & $(0.0656)$ & $(0.0729)$ & 0.76 \\
& 0.0018 & $1.0125^{* * *}$ & 0.0774 & \\
5 & $(0.0029)$ & $(0.0661)$ & $(0.0937)$ & 0.83 \\
& -0.0005 & $0.9348^{* * *}$ & $0.1193^{* *}$ & \\
high & $(0.0017)$ & $(0.0411)$ & $(0.0652)$ & 0.94
\end{tabular}

This table shows estimates and standard errors obtained from running the following time series regression for each currency portfolio $j$ separately:

$$
r x_{t, t+1}^{j}=a^{j}+\beta_{\overline{r x}}^{j} \cdot \overline{r x}_{t, t+1}+\beta_{H M L \_\Delta c}^{j} \cdot H M L_{-} \Delta c_{t, t+1}+\varepsilon_{t, t+1}^{j}
$$

Standard errors are corrected for serial correlation using the Newey and West (1987) estimator for the covariance matrix of the error terms $\varepsilon_{t, t+1}^{j}$. 
Table A.13: real returns: risk price and factor loadings

\begin{tabular}{lllll}
\hline & $\lambda_{\overline{r x}}$ & $\lambda_{H M L_{-} \Delta c}$ & $b_{\overline{r x}}$ & $b_{H M L \_} \Delta c$ \\
\hline OLS estimate & -0.0004 & $0.0091^{* * *}$ & -0.5992 & $8.3851^{* * *}$ \\
standard error & $(0.0050)$ & $(0.0041)$ & $(2.4497)$ & $(3.9811)$ \\
\cline { 2 - 5 } pricing error test & & 0.7745 & & 0.7328 \\
$R^{2}$ & & 0.79 & 0.79 \\
\hline GLS estimate & -0.0004 & $0.0091^{* * *}$ & -0.3170 & $8.9710^{* * *}$ \\
standard error & $(0.0051)$ & $(0.0039)$ & $(2.3307)$ & $(3.5545)$ \\
pricing error test & & 0.7998 & 0.87 \\
\hline
\end{tabular}

This first two columns of this table report results from estimating the following cross-sectional regression:

$$
\boldsymbol{E}\left(r x^{j}\right)=\beta_{\overline{r x}}^{j} \cdot \lambda_{\overline{r x}}+\beta_{H M L \_\Delta c}^{j} \cdot \lambda_{H M L \_\Delta c}+\alpha^{j}
$$

$\beta_{\overline{r x}}^{j}$ and $\beta_{H M L \triangle A c}^{j}$ correspond to the estimates obtained from running time series regressions of portfolio returns on the risk factors as reported in Table 2 . Here, the factor $\beta \mathrm{s}$ and the prices of risk $\lambda_{\overline{r x}}$ and $\lambda_{H M L \_\Delta c}$ have been estimated jointly using GMM. This approach yields standard errors which correct for the fact that the $\beta$ s are estimates. The third and the fourth column of this table report results from estimating the following cross-sectional regression:

$$
\boldsymbol{E}\left(r x^{j}\right)=\operatorname{cov}\left(\overline{r x}, r x^{j}\right) \cdot b_{\overline{r x}}+\operatorname{cov}\left(H M L_{-} \Delta c, r x^{j}\right) \cdot b_{H M L \_\Delta c}+\alpha^{j}
$$

where again, covariances and factor loadings $b$ have been estimated jointly using GMM. The adjusted $R^{2}$ are obtained as described in the notes of Table A.5. The pricing error test reports the $\mathrm{p}$-value for the null that the pricing errors are jointly zero. 
Table A.14: consumption growth sorted currency portfolios: 1986(1)-2010(4)

\begin{tabular}{|c|c|c|c|c|c|c|c|c|}
\hline portfolio $j$ & low & 2 & 3 & 4 & 5 & high & $\overline{r x}$ & $H M L_{\Delta c}$ \\
\hline & \multicolumn{8}{|c|}{ excess return: $r x^{j}$} \\
\hline mean & 1.8466 & 1.7848 & 3.7710 & 3.9226 & 3.1721 & 4.8370 & 3.2133 & 2.9904 \\
\hline std & 19.3965 & 21.1163 & 19.4169 & 21.1808 & 19.7455 & 20.3649 & 18.4560 & 12.7884 \\
\hline \multirow[t]{2}{*}{ Sharpe ratio } & 0.0952 & 0.0845 & 0.1942 & 0.1852 & 0.1606 & 0.2375 & 0.1741 & 0.2338 \\
\hline & \multicolumn{8}{|c|}{ spot change: $\Delta s^{j}$} \\
\hline mean & -0.0349 & -0.4898 & -2.2074 & -1.9974 & -1.5689 & -2.0631 & & \\
\hline \multirow[t]{2}{*}{ std } & 19.5364 & 21.1760 & 19.9418 & 20.9312 & 18.4037 & 19.8600 & & \\
\hline & \multicolumn{8}{|c|}{ consumption growth: $\Delta c_{t-4, t}^{j}$} \\
\hline mean & -1.0922 & 0.8384 & 1.6596 & 2.3761 & 3.2583 & 5.3693 & & \\
\hline \multirow[t]{2}{*}{ std } & 3.0117 & 1.4674 & 1.3423 & 1.3022 & 1.3410 & 1.7542 & & \\
\hline & \multicolumn{8}{|c|}{ forward discount: $f^{j}-s^{j}$} \\
\hline mean & 0.0045 & 0.0032 & 0.0039 & 0.0048 & 0.0040 & 0.0069 & & \\
\hline std & 0.0076 & 0.0058 & 0.0057 & 0.0066 & 0.0059 & 0.0058 & & \\
\hline
\end{tabular}

This table presents descriptive statistics for the returns an US investor obtains by investing in different currency portfolios. At the beginning of each quarter anew, currencies are sorted into six portfolios based on the associated countries consumption growth rates over the past four quarters. The first portfolio always contains currencies of those countries with the lowest sixtile of consumption growth rates $\Delta c_{t-4, t}^{j}$ and the fourth portfolio always contains currencies of countries with the highest sixtile of consumption growth rates. The second last column presents the average return an US investor obtains when borrowing in US dollars and investing in equal weights in all currencies, this return is labelled $\overline{r x}_{t, t+1}$. The last column shows descriptive statistics for the consumption-based carry trade portfolio $H M L_{\Delta c}$ which is given by a short position in all currencies of the low consumption growth portfolio and a long position in the currencies of the high consumption growth portfolio. Portfolio excess returns are calculated as $r x_{t, t+1}^{j}=f_{t, t+1}^{j}-s_{t}^{j}-$ $\Delta s_{t+1}^{j}$, where $r x_{t, t+1}^{j}$ is the average quarterly return from borrowing in US dollars and investing in equal weights in all currencies of portfolio $j . f_{t, t+1}^{j}$ is the average of the log $3 \mathrm{M}$ forward exchange rate of the currencies in portfolio $j$ against the US dollar, and $\Delta s_{t, t+1}^{j}$ is the portfolio average of the log difference of the spot exchange rate between dates $t$ and $t+1 . f_{t}^{j}-s_{t}^{j}$ is the average forward discount of the currencies in portfolio $j$ against the US dollar. Exchange rates are in direct quotation, i.e. an increase in $s^{j}$ implies a depreciation of the currencies in portfolio $j$ against the US dollar. Except for the forward discounts, all statistics are presented in percentages per annum. The data sample encompasses the OECD country set specified in the main text and in the appendix, and it spans the period from 1986(1) to 2010(4). The data is at quarterly frequency. 
Table A.15: 1986(1)-2010(4): time series regression

\begin{tabular}{lllcr}
\hline \multirow{2}{*}{ low } & $a^{j}$ & $\beta_{\overline{r x}}^{j}$ & $\beta_{H M L \_c}^{j}$ & $\bar{R}^{2}$ \\
\cline { 2 - 5 } & $0.0046^{* * *}$ & $0.9936^{* * *}$ & $-0.5430^{* * *}$ & \\
& $(0.0011)$ & $(0.0304)$ & $(0.0478)$ & 0.95 \\
& $0.0045^{* * *}$ & $1.0711^{* * *}$ & -0.0751 & 0.87 \\
3 & $(0.0018)$ & $(0.0411)$ & $(0.0593)$ & \\
& $0.0094^{* * *}$ & $0.9550^{* * *}$ & -0.0482 & 0.81 \\
4 & $(0.0022)$ & $(0.0593)$ & $(0.0703)$ & 0.80 \\
& $0.0098^{* * *}$ & $1.0173^{* * *}$ & 0.0974 & \\
5 & $(0.0025)$ & $(0.0551)$ & $(0.0880)$ & 0.85 \\
& $0.0079^{* * *}$ & $0.9762^{* * *}$ & $0.1182^{* *}$ & \\
\multirow{2}{*}{ high } & $(0.0015)$ & $(0.0442)$ & $(0.0631)$ & 0.95 \\
\hline
\end{tabular}

This table shows estimates and standard errors obtained from running the following time series regression for each currency portfolio $j$ separately:

$$
r x_{t, t+1}^{j}=a^{j}+\beta_{\overline{r x}}^{j} \cdot \overline{r x}_{t, t+1}+\beta_{H M L_{-} \Delta c}^{j} \cdot H M L_{-} \Delta c_{t, t+1}+\varepsilon_{t, t+1}^{j}
$$

Standard errors are corrected for serial correlation using the Newey and West (1987) estimator for the covariance matrix of the error terms $\varepsilon_{t, t+1}^{j}$. 
Table A.16: 1986(1)-2010(4): risk price and factor loadings

\begin{tabular}{lllll}
\hline & $\lambda_{\overline{r x}}$ & $\lambda_{H M L_{-} \Delta c}$ & $b_{\overline{r x}}$ & $b_{H M L_{\triangle} \Delta c}$ \\
\hline OLS estimate & $0.0080^{*}$ & $0.0077^{* * *}$ & $3.2414^{*}$ & $7.0514^{* * *}$ \\
standard error & $(0.0048)$ & $(0.0036)$ & $(2.4880)$ & $(3.6400)$ \\
\cline { 2 - 5 } $\begin{array}{l}\text { pricing error test } \\
R^{2}\end{array}$ & & 0.3857 & & 0.3579 \\
\hline GLS estimate & & 0.57 & & 0.57 \\
standard error & $0.0080^{*}$ & $0.0076^{* * *}$ & 3.1356 & $8.0149^{* * *}$ \\
pricing error test & $(0.0048)$ & $(0.0034)$ & $(2.2696)$ & $(3.4641)$ \\
\hline
\end{tabular}

This first two columns of this table report results from estimating the following cross-sectional regression:

$$
\boldsymbol{E}\left(r x^{j}\right)=\beta_{\overline{r x}}^{j} \cdot \lambda_{\overline{r x}}+\beta_{H M L \_\Delta c}^{j} \cdot \lambda_{H M L_{-} \Delta c}+\alpha^{j}
$$

$\beta_{\overline{r x}}^{j}$ and $\beta_{H M L \triangle C}^{j}$ correspond to the estimates obtained from running time series regressions of portfolio returns on the risk factors as reported in Table 2 . Here, the factor $\beta$ s and the prices of risk $\lambda_{\overline{r x}}$ and $\lambda_{H M L} \Delta c$ have been estimated jointly using GMM. This approach yields standard errors which correct for the fact that the $\beta$ s are estimates. The third and the fourth column of this table report results from estimating the following cross-sectional regression:

$$
\boldsymbol{E}\left(r x^{j}\right)=\operatorname{cov}\left(\overline{r x}, r x^{j}\right) \cdot b_{\overline{r x}}+\boldsymbol{c o v}\left(H M L_{-} \Delta c, r x^{j}\right) \cdot b_{H M L \_\Delta c}+\alpha^{j}
$$

where again, covariances and factor loadings $b$ have been estimated jointly using GMM. The adjusted $R^{2}$ are obtained as described in the notes of Table A.5. The pricing error test reports the $\mathrm{p}$-value for the null that the pricing errors are jointly zero. 
Table A.17: consumption growth sorted currency portfolios 1990(1)-2006(4)

\begin{tabular}{|c|c|c|c|c|c|c|c|c|}
\hline portfolio $j$ & low & 2 & 3 & 4 & 5 & high & $\overline{r x}$ & $H M L_{\Delta c}$ \\
\hline & \multicolumn{8}{|c|}{ excess return: $r x^{j}$} \\
\hline mean & 0.3726 & 1.3450 & 2.3822 & 3.1900 & 2.5354 & 4.9113 & 2.4755 & 4.5387 \\
\hline std & 17.5474 & 19.3633 & 18.5433 & 20.3322 & 17.6150 & 18.6313 & 16.7415 & 13.8631 \\
\hline \multirow[t]{2}{*}{ Sharpe ratio } & 0.0212 & 0.0695 & 0.1285 & 0.1569 & 0.1439 & 0.2636 & 0.1479 & 0.3274 \\
\hline & \multicolumn{8}{|c|}{ spot change: $\Delta s^{j}$} \\
\hline mean & 0.9862 & 0.0862 & -0.6903 & -0.9881 & -0.7122 & -1.9432 & & \\
\hline \multirow[t]{2}{*}{ std } & 17.7157 & 19.1287 & 18.6801 & 20.2321 & 17.0541 & 18.6718 & & \\
\hline & \multicolumn{8}{|c|}{ consumption growth: $\Delta c_{t-4, t}^{j}$} \\
\hline mean & -0.4065 & 0.9724 & 1.7403 & 2.4087 & 3.2500 & 5.2381 & & \\
\hline \multirow[t]{2}{*}{ std } & 1.2789 & 0.9307 & 0.9183 & 0.9160 & 0.9879 & 1.6684 & & \\
\hline & \multicolumn{8}{|c|}{ forward discount: $f^{j}-s^{j}$} \\
\hline mean & 0.0034 & 0.0036 & 0.0042 & 0.0055 & 0.0046 & 0.0074 & & \\
\hline std & 0.0078 & 0.0061 & 0.0063 & 0.0069 & 0.0061 & 0.0058 & & \\
\hline
\end{tabular}

This table presents descriptive statistics for the returns an US investor obtains by investing in different currency portfolios. At the beginning of each quarter anew, currencies are sorted into six portfolios based on the associated countries consumption growth rates over the past four quarters. The first portfolio always contains currencies of those countries with the lowest sixtile of consumption growth rates $\Delta c_{t-4, t}^{j}$, and the fourth portfolio always contains currencies of countries with the highest sixtile of consumption growth rates. The second last column presents the average return an US investor obtains when borrowing in US dollars and investing in equal weights in all currencies, this return is labelled $\overline{r x}_{t, t+1}$. The last column shows descriptive statistics for the consumption-based carry trade portfolio $H M L_{\Delta c}$ which is given by a short position in all currencies of the low consumption growth portfolio and a long position in the currencies of the high consumption growth portfolio. Portfolio excess returns are calculated as $r x_{t, t+1}^{j}=f_{t, t+1}^{j}-s_{t}^{j}-$ $\Delta s_{t+1}^{j}$, where $r x_{t, t+1}^{j}$ is the average quarterly return from borrowing in US dollars and investing in equal weights in all currencies of portfolio $j . f_{t, t+1}^{j}$ is the average of the log $3 \mathrm{M}$ forward exchange rate of the currencies in portfolio $j$ against the US dollar, and $\Delta s_{t, t+1}^{j}$ is the portfolio average of the log difference of the spot exchange rate between dates $t$ and $t+1 . f_{t}^{j}-s_{t}^{j}$ is the average forward discount of the currencies in portfolio $j$ against the US dollar. Exchange rates are in direct quotation, i.e. an increase in $s^{j}$ implies a depreciation of the currencies in portfolio $j$ against the US dollar. Except for the forward discounts, all statistics are presented in percentages per annum. The data sample encompasses the OECD country set specified in the main text and in the appendix, and it spans the period from 1986(1) to 2006(4). The data is at quarterly frequency. 
Table A.18: 1990(1)-2006(4): time series regression

\begin{tabular}{lllcr}
\hline & $a^{j}$ & $\beta_{\overline{r x}}^{j}$ & $\beta_{H M L \_c}^{j}$ & $\bar{R}^{2}$ \\
\cline { 2 - 5 } low & 0.0009 & $0.9685^{* * *}$ & $-0.5401^{* * *}$ & \\
& $(0.0013)$ & $(0.0479)$ & $(0.0545)$ & 0.94 \\
& $0.0034^{*}$ & $1.1011^{* * *}$ & -0.0730 & 0.89 \\
3 & $(0.0021)$ & $(0.0646)$ & $(0.0703)$ & \\
& $0.0060^{* * *}$ & $0.9979^{* * *}$ & 0.0186 & 0.81 \\
4 & $(0.0027)$ & $(0.0783)$ & $(0.0690)$ & 0.76 \\
& $0.0080^{* * *}$ & $1.0613^{* * *}$ & $0.0135^{*}$ & \\
5 & $(0.0034)$ & $(0.0877)$ & $(0.0936)$ & 0.80 \\
& $0.0063^{* * *}$ & $0.9336^{* * *}$ & $0.1080^{* * *}$ & \\
\multirow{2}{*}{ high } & $(0.0019)$ & $(0.0523)$ & $(0.0719)$ & 0.95 \\
\hline
\end{tabular}

This table shows estimates and standard errors obtained from running the following time series regression for each currency portfolio $j$ separately:

$$
r x_{t, t+1}^{j}=a^{j}+\beta_{\overline{r x}}^{j} \cdot \overline{r x}_{t, t+1}+\beta_{H M L_{-} \Delta c}^{j} \cdot H M L_{-} \Delta c_{t, t+1}+\varepsilon_{t, t+1}^{j}
$$

Standard errors are corrected for serial correlation using the Newey and West (1987) estimator for the covariance matrix of the error terms $\varepsilon_{t, t+1}^{j}$. 
Table A.19: 1990(1)-2006(4): risk price and factor loadings

\begin{tabular}{lllll}
\hline & $\lambda_{\overline{r x}}$ & $\lambda_{H M L \_\Delta c}$ & $b_{\overline{r x}}$ & $b_{H M L \_c}$ \\
\hline OLS estimate & 0.0061 & $0.0114^{* * *}$ & 2.6016 & $9.2740^{* * *}$ \\
standard error & $(0.0055)$ & $(0.0045)$ & $(3.2415)$ & $(4.4789)$ \\
\cline { 2 - 5 } pricing error test & & 0.8397 & & 0.8403 \\
$R^{2}$ & & 0.85 & 0.85 \\
\hline GLS estimate & 0.0061 & $0.0114^{* * *}$ & 1.8484 & $10.5861^{* * *}$ \\
standard error & $(0.0052)$ & $(0.0044)$ & 2.7314 & 4.0196 \\
pricing error test & & 0.7945 & & 0.9324 \\
\hline
\end{tabular}

This first two columns of this table report results from estimating the following cross-sectional regression:

$$
\boldsymbol{E}\left(r x^{j}\right)=\beta_{\overline{r x}}^{j} \cdot \lambda_{\overline{r x}}+\beta_{H M L \_\Delta c}^{j} \cdot \lambda_{H M L \_\Delta c}+\alpha^{j}
$$

$\beta_{\overline{r x}}^{j}$ and $\beta_{H M L \_c}^{j}$ correspond to the estimates obtained from running time series regressions of portfolio returns on the risk factors as reported in Table 2 . Here, the factor $\beta \mathrm{s}$ and the prices of risk $\lambda_{\overline{r x}}$ and $\lambda_{H M L \_\Delta c}$ have been estimated jointly using GMM. This approach yields standard errors which correct for the fact that the $\beta$ s are estimates. The third and the fourth column of this table report results from estimating the following cross-sectional regression:

$$
\boldsymbol{E}\left(r x^{j}\right)=\operatorname{cov}\left(\overline{r x}, r x^{j}\right) \cdot b_{\overline{r x}}+\operatorname{cov}\left(H M L_{-} \Delta c, r x^{j}\right) \cdot b_{H M L \_\Delta c}+\alpha^{j}
$$

where again, covariances and factor loadings $b$ have been estimated jointly using GMM. The adjusted $R^{2}$ are obtained as described in the notes of Table A.5. The pricing error test reports the p-value for the null that the pricing errors are jointly zero. 
Table A.20: consumption growth sorted currency portfolios: most traded currencies

\begin{tabular}{|c|c|c|c|c|c|}
\hline portfolio $j$ & low & 2 & high & $\overline{r x}$ & $H M L_{\Delta c}$ \\
\hline & \multicolumn{5}{|c|}{ excess return $r x^{k}$} \\
\hline mean & -0.3964 & 3.1168 & 3.2181 & 1.8305 & 3.6145 \\
\hline std & 18.5585 & 16.6764 & 12.9744 & 14.1092 & 14.4390 \\
\hline \multirow[t]{2}{*}{ Sharpe ratio } & -0.0214 & 0.1869 & 0.2480 & 0.1297 & 0.2503 \\
\hline & \multicolumn{5}{|c|}{ spot change $\Delta s^{k}$} \\
\hline mean & 0.9960 & -1.9466 & -1.5590 & & \\
\hline \multirow[t]{2}{*}{ std } & 18.6030 & 16.6930 & 12.9892 & & \\
\hline & \multicolumn{5}{|c|}{ consumption growth $\Delta c_{t-4, t}^{j}$} \\
\hline mean & -0.2722 & 1.6549 & 3.7053 & & \\
\hline \multirow[t]{2}{*}{ std } & 1.7463 & 1.3131 & 1.4160 & & \\
\hline & \multicolumn{5}{|c|}{ forward discount: $f^{j}-s^{j}$} \\
\hline mean & 0.5996 & 1.1702 & 1.6591 & & \\
\hline std & 2.6043 & 2.2219 & 1.8853 & & \\
\hline
\end{tabular}

This table presents descriptive statistics for the returns a US investor obtains from investing in different currency portfolios. At the beginning of each quarter, currencies are sorted into three portfolios based on the associated countries' consumption growth rates over the preceding four quarters. The first portfolio always contains currencies of countries with the lowest third of consumption growth rates, and the third portfolio always contains currencies of countries with the highest third of consumption growth rates. The second last column presents the average return a US investor obtains when borrowing in US dollars and investing in equal weights into all currencies, this return is labelled $\overline{r x}_{t, t+1}$. The last column shows descriptive statistics for the consumption-based carry trade portfolio $H M L_{\Delta c}$ which is given by a short position in all currencies of the low consumption growth portfolio and a long position in the currencies of the high consumption growth portfolio. Portfolio excess returns are calculated as $r x_{t, t+1}^{j}=f_{t, t+1}^{j}-s_{t}^{j}-\Delta s_{t+1}^{j}$, where $r x_{t, t+1}^{j}$ is the average quarterly return from borrowing in US dollars and investing in equal weights in all currencies of portfolio $j . f_{t, t+1}^{j}$ is the average of the log $3 \mathrm{M}$ forward exchange rate of the currencies in portfolio $j$ against the US dollar, and $\Delta s_{t, t+1}^{j}$ is the portfolio average of the log difference of the spot exchange rate between dates $t$ and $t+1 . f_{t}^{j}-s_{t}^{j}$ is the average forward discount of the currencies in portfolio $j$ against the US dollar. Exchange rates are in direct quotation, i.e. an increase in $s^{j}$ implies a depreciation of the currencies in portfolio $j$ against the US dollar. Except for the forward discounts, all statistics are presented in percentages per annum. The data sample encompasses the most traded currencies, which are the Australian dollar (AUD), Canadian dollar (CAD), Swiss franc (CHF), Euro (EUR), British pound (GBP), Hong-Kong dollar (HKD), Japanese yen (JPY), Mexican peso (MXN), Norwegian krone (NOK), New Zealand dollar (NZD), Swedish krone (SEK), and the US dollar (USD). The data spans the period from 1990(1) to 2010(4), and it is at quarterly frequency. 
Table A.21: most traded currencies: time series regression

\begin{tabular}{lllcr}
\hline \multirow{2}{*}{ low } & $a^{j}$ & $\beta_{\overline{r x}}^{j}$ & $\beta_{H M L \_c}^{j}$ & $\bar{R}^{2}$ \\
\cline { 2 - 5 } & -0.0010 & $0.9608^{* * *}$ & $-0.5530^{* * *}$ & \\
\multirow{2}{*}{2} & $(0.0010)$ & $(0.0353)$ & $(0.0252)$ & 0.96 \\
& $0.0078^{* * *}$ & $1.0793^{* * *}$ & $0.1326^{* * *}$ & 0.76 \\
\multirow{2}{*}{ high } & $(0.0024)$ & $(0.0791)$ & $(0.0584)$ & \\
& $0.0080^{* * *}$ & $0.9608^{* * *}$ & $0.4470^{* * *}$ & 0.93 \\
\hline
\end{tabular}

This table shows estimates and standard errors obtained from running the following time series regression for each currency portfolio $j$ separately:

$$
r x_{t, t+1}^{j}=a^{j}+\beta_{\overline{r x}}^{j} \cdot \overline{r x_{t, t+1}}+\beta_{H M L-\Delta c}^{j} \cdot H M L_{-} \Delta c_{t, t+1}+\varepsilon_{t, t+1}^{j}
$$

Standard errors are corrected for serial correlation using the Newey and West (1987) estimator for the covariance matrix of the error terms $\varepsilon_{t, t+1}^{j}$.

Table A.22: most traded currencies: risk price and factor loadings

\begin{tabular}{lllll}
\hline & $\lambda_{\overline{r x}}$ & $\lambda_{H M L \_d c}$ & $b_{\overline{r x}}$ & $b_{H M L \_d c}$ \\
\hline OLS estimate & 0.0049 & $0.0095^{* * *}$ & $8.2459^{* * *}$ & $10.5549^{* * *}$ \\
standard error & $(0.0041)$ & $(0.0046)$ & $(3.0426)$ & $(4.1045)$ \\
\cline { 2 - 5 } $\begin{array}{l}\text { pricing error test } \\
R^{2}\end{array}$ & & 0.6107 & 0.6070 \\
\hline GLS estimate & 0.0049 & $0.0093^{* * *}$ & $7.8086^{* * *}$ & 0.95 \\
standard error & $(0.0042)$ & $(0.0042)$ & $(2.9260)$ & $10.0363^{* * *}$ \\
pricing error test & & 0.6244 & & 0.61 \\
\hline
\end{tabular}

This first two columns of this table report results from estimating the following cross-sectional regression:

$$
\boldsymbol{E}\left(r x^{j}\right)=\beta_{\overline{r x}}^{j} \cdot \lambda_{\overline{r x}}+\beta_{H M L \_\Delta c}^{j} \cdot \lambda_{H M L \_\Delta c}+\alpha^{j}
$$

$\beta_{\overline{r x}}^{j}$ and $\beta_{H M L \_\Delta c}^{j}$ correspond to the estimates obtained from running time series regressions of portfolio returns on the risk factors as reported in Table 2. Here, the factor $\beta \mathrm{s}$ and the prices of risk $\lambda_{\overline{r x}}$ and $\lambda_{H M L \_} \Delta c$ have been estimated jointly using GMM. This approach yields standard errors which correct for the fact that the $\beta$ s are estimates. The third and the fourth column of this table report results from estimating the following cross-sectional regression:

$$
\boldsymbol{E}\left(r x^{j}\right)=\operatorname{cov}\left(\overline{r x}, r x^{j}\right) \cdot b_{\overline{r x}}+\boldsymbol{c o v}\left(H M L_{-} \Delta c, r x^{j}\right) \cdot b_{H M L_{-} \Delta c}+\alpha^{j}
$$

where again, covariances and factor loadings $b$ have been estimated jointly using GMM. The adjusted $R^{2}$ are obtained as described in the notes of Table A.5. The pricing error test reports the p-value for the null that the pricing errors are jointly zero. 
Table A.23: consumption growth sorted currency portfolios: Swiss investor

\begin{tabular}{lllllllll}
\hline portfolio $j$ & low & 2 & 3 & 4 & 5 & high & $\overline{r x}$ & $H M L_{\Delta c}$ \\
\hline \multicolumn{7}{c}{ excess return $r x^{k}$} \\
mean & 0.0075 & 0.7027 & 1.0788 & 1.8565 & 2.3418 & 3.3646 & 1.5072 & 3.3571 \\
std & 16.0050 & 15.8244 & 17.4435 & 18.1535 & 18.5258 & 17.0860 & 14.6774 & 13.4332 \\
Sharpe ratio & 0.0005 & 0.0444 & 0.0618 & 0.1023 & 0.1264 & 0.1969 & 0.1027 & 0.2499 \\
\hline \multirow{7}{*}{ mean } & spot change $\Delta s^{k}$ & & & & & & \\
std & 0.8233 & 0.1350 & -0.5079 & -0.6777 & -1.7245 & -1.7797 & & \\
\hline & 18.5302 & 19.0534 & 19.2490 & 20.7448 & 17.2338 & 20.0173 & & \\
mean & consumption growth $\Delta c_{t-4, t}^{j}$ & & & & & \\
std & -1.1481 & 0.7615 & 1.5869 & 2.2794 & 3.1153 & 5.1478 & & \\
\hline & 3.2586 & 1.5828 & 1.4706 & 1.3921 & 1.4151 & 1.8354 & & \\
\hline mean & forward discount: $f^{j}-s^{j}$ & & & & & \\
std & 0.0078 & 0.0078 & 0.0071 & 0.0086 & 0.0072 & 0.0097 & & \\
\hline
\end{tabular}

This table presents descriptive statistics for the returns a Swiss investor obtains by investing in different currency portfolios. At the beginning of each quarter anew, currencies are sorted into six portfolios based on the associated countries consumption growth rates over the past four quarters. The first portfolio always contains currencies of those countries with the lowest sixtile of consumption growth rates $\Delta c_{t-4, t}^{j}$ and the last portfolio always contains currencies of countries with the highest sixtile of consumption growth rates. The second last column presents the average return a Swiss investor obtains when borrowing in Swiss francs and investing in equal weights in all currencies, this return is labelled $\bar{r} \bar{x}_{t, t+1}$. The last column shows descriptive statistics for the consumption-based carry trade portfolio $H M L_{-} \Delta c$ which is given by a short position in all currencies of the low consumption growth portfolio and a long position in the currencies of the high consumption growth portfolio. Portfolio excess returns are calculated as $r x_{t, t+1}^{j}=f_{t, t+1}^{j}-$ $s_{t}^{j}-\Delta s_{t+1}^{j}$, where $r x_{t, t+1}^{j}$ is the average quarterly return from borrowing in Swiss francs and investing in equal weights in all currencies of portfolio $j . f_{t, t+1}^{j}$ is the average of the log $3 \mathrm{M}$ forward exchange rate of the currencies in portfolio $j$ against the Swiss franc dollar, and $\Delta s_{t, t+1}^{j}$ is the portfolio average of the log difference of the spot exchange rate between dates $t$ and $t+1 . f_{t}^{j}-s_{t}^{j}$ is the average forward discount (interest rate differential) of the currencies in portfolio $j$ against the Swiss franc. Exchange rates are in direct quotation, i.e. an increase in $s^{j}$ implies a depreciation of the currencies in portfolio $j$ against the Swiss franc. Except for the forward discounts, all statistics are presented in percentages per annum. The data sample encompasses the OECD country set specified in the main text and in the appendix, and it spans the period from 1990(1) to 2010(4). The data is at quarterly frequency. 
Table A.24: Swiss investor: time series regression

\begin{tabular}{llllr}
\hline \multirow{2}{*}{ low } & $a^{j}$ & $\beta_{\overline{r x}}^{j}$ & $\beta_{H M L \_c}^{j}$ & $\bar{R}^{2}$ \\
\cline { 2 - 5 } & 0.0000 & $0.9921^{* * *}$ & $-0.5522^{* * *}$ & \\
& $(0.0011)$ & $(0.0445)$ & $(0.0420)$ & 0.92 \\
& 0.0018 & $0.8845^{* * *}$ & -0.0791 & 0.65 \\
3 & $(0.0020)$ & $(0.0709)$ & $(0.1017)$ & \\
& 0.0027 & $0.9890^{* * *}$ & -0.0952 & 0.67 \\
4 & $(0.0028)$ & $(0.1337)$ & $(0.1108)$ & 0.70 \\
& $0.0046^{*}$ & $1.0210^{* * *}$ & $0.1380^{* *}$ & \\
5 & $(0.0029)$ & $(0.0915)$ & $(0.0740)$ & 0.83 \\
& $0.0059^{* * *}$ & $1.1221^{* * *}$ & $0.1616^{* * *}$ & \\
\multirow{2}{*}{ high } & $(0.0015)$ & $(0.0695)$ & $(0.0488)$ & 0.93 \\
\hline
\end{tabular}

This table shows estimates and standard errors obtained from running the following time series regression for each currency portfolio $j$ separately:

$$
r x_{t, t+1}^{j}=a^{j}+\beta_{\overline{r x}}^{j} \cdot \overline{r x_{t, t+1}}+\beta_{H M L \_\Delta c}^{j} \cdot H M L \_\Delta c_{t, t+1}+\varepsilon_{t, t+1}^{j}
$$

Standard errors are corrected for serial correlation using the Newey and West (1987) estimator for the covariance matrix of the error terms $\varepsilon_{t, t+1}^{j}$. 
Table A.25: Swiss investor: risk price and factor loadings

\begin{tabular}{lllll}
\hline & $\lambda_{\overline{r x}}$ & $\lambda_{H M L_{-} d c}$ & $b_{\overline{r x}}$ & $b_{H M L_{-} d c}$ \\
\hline OLS estimate & 0.0039 & $0.0084^{* * *}$ & 2.0012 & $7.2039^{* *}$ \\
standard error & $(0.0037)$ & $(0.0041)$ & $(3.4592)$ & $(4.0787)$ \\
\cline { 2 - 5 } $\begin{array}{l}\text { pricing error test } \\
R^{2}\end{array}$ & & 0.9470 & & 0.9373 \\
\hline GLS estimate & 0.0039 & 0.94 & & 0.94 \\
standard error & $(0.0038)$ & $(0.0040)$ & $(3.1325)$ & $8.3359^{* * *}$ \\
pricing error test & & 0.97 & & 0.95 \\
\hline
\end{tabular}

This first two columns of this table report results from estimating the following cross-sectional regression:

$$
\boldsymbol{E}\left(r x^{j}\right)=\beta_{\overline{r x}}^{j} \cdot \lambda_{\overline{r x}}+\beta_{H M L \_\Delta c}^{j} \cdot \lambda_{H M L \_\Delta c}+\alpha^{j}
$$

$\beta_{\overline{r x}}^{j}$ and $\beta_{H M L \_c}^{j}$ correspond to the estimates obtained from running time series regressions of portfolio returns on the risk factors as reported in Table 2 . Here, the factor $\beta \mathrm{s}$ and the prices of risk $\lambda_{\overline{r x}}$ and $\lambda_{H M L \_\Delta c}$ have been estimated jointly using GMM. This approach yields standard errors which correct for the fact that the $\beta$ s are estimates. The third and the fourth column of this table report results from estimating the following cross-sectional regression:

$$
\boldsymbol{E}\left(r x^{j}\right)=\operatorname{cov}\left(\overline{r x}, r x^{j}\right) \cdot b_{\overline{r x}}+\operatorname{cov}\left(H M L_{-} \Delta c, r x^{j}\right) \cdot b_{H M L \_\Delta c}+\alpha^{j}
$$

where again, covariances and factor loadings $b$ have been estimated jointly using GMM. The adjusted $R^{2}$ are obtained as described in the notes of Table A.5. The pricing error test reports the p-value for the null that the pricing errors are jointly zero. 